\title{
Produtividade de Criadouros em Área Urbana de \\ Coexistência de Aedes aegypti e Aedes albopictus, São \\ Sebastião, Litoral Norte de Estado de São Paulo, Brasil
}

Marylene de Brito Arduino

Tese de doutorado apresentada ao Programa de Pós-Graduação em Saúde Pública para obtenção do título de Doutor em Saúde Pública

Área de concentração: Epidemiologia

Orientadora: Prof ${ }^{\mathrm{a}} \mathrm{Dr}^{\mathrm{a}}$ Iná Kakitani

São Paulo

2006 


\section{$47503 / 2006$ doc}

Autorizo, exclusivamente para fins acadêmicos e científicos, a reprodução total ou parcial desta tese, por processos fotocopiadores.

Assinatura:

Data: 


\section{HOMENAGEM}

Estas linhas têm a pretensão de fazer homenagem a ilustre pessoa do Professor Dr. Oswaldo Paulo Forattini. Considero esta, uma tarefa difícil e ao mesmo tempo fácil, pois seu reconhecido dom em escrever e a riqueza de conhecimentos que possui traz implícito a necessidade de um texto que corresponda a tal posição. Por outro lado, a facilidade está em fazer referência a sua grande obra e contribuição ao conhecimento científico, sua dedicação e respeito pela ciência que sempre inspiraram a busca pelo conhecimento e pela investigação. As ricas oportunidades de ouvi-lo discorrer sobre determinado assunto tinham o poder de despertar em mim a vontade de investigar, estudar e crescer, não somente como profissional mas também como pessoa. Sou grata por toda sua contribuição para a ciência, para a Saúde Pública no país e, principalmente, para o despertar de muitos profissionais nesta área. São muitas as palavras que poderiam compor a homenagem que faria a devida honra, eu poderia ainda fazer uso de alguma frase de efeito dita por alguma célebre personalidade da história, contudo, acredito que não seriam suficientes para expressar os sentimentos que na realidade cultivo. Sendo assim, prefiro dizer que o lapso de tempo em que tive o privilégio de estar sentada ao banco de sua sala de aula me fez descobrir no mestre, um grande amigo. Obrigado Professor Forattini. 
Dedico este trabalho a Luiz Fernando e Luiz Guilherme, os maiores homens que conheci. Pois devo a eles os mais singelos, profundos e verdadeiros aprendizados de minha vida, como mulher e como mãe. 


\section{AGRADECIMENTOS}

A Deus, fonte de todo o conhecimento e sabedoria que me guiou e permitiu chegar aqui. Pois, todas as coisas foram feitas por Ele e sem Ele, nada do que foi feito se fez.

Ao Professor Dr. Oswaldo Paulo Forattini pela amizade e orientação nos primeiros anos deste estudo que com grande sabedoria sempre me estimulou a busca de novos conhecimentos.

À Professora $\mathrm{Dr}^{\mathrm{a}}$ Iná Kakitani que tem me acompanhado desde o mestrado coorientando os trabalhos de campo, sobretudo pelo apoio, carinho e dedicação com que me acolheu e orientou na conclusão deste trabalho.

À Professora Dr ${ }^{\mathrm{a}}$ Gisela Yuka Shimizu do Departamento de Ecologia do Instituto de Biociências da Universidade de São Paulo pela leitura e sugestões no trabalho.

À Professora Dr ${ }^{\mathrm{a}}$ Eunice A. B. Galatti do Departamento de Epidemiologia da Faculdade de Saúde Pública da Universidade de São Paulo pela valiosa contribuição do texto.

Ao Professor Dr. Delsio Natal pelas discussões e sugestões no trabalho.

Ao Prof ${ }^{\circ}$ Dr. Aristides de Almeida Rocha pelo carinho e disposição em orientar quais os parâmetros físicos e químicos a serem medidos.

À Dra Gisela R. A. M. Marques e Ligia L. N. Serpa colegas de trabalho no Laboratório de Culicídeos da Superintendência de Controle de Endemias de Taubaté pelo companheirismo e apoio em minha ausência e na leitura e discussões dos resultados. 
À $\mathrm{Dr}^{\mathrm{a}}$ Helene Mariko Ueno pela qual tenho profunda admiração, sempre pronta a emprestar sua contribuição na leitura e importantes sugestões no manuscrito.

À $\mathrm{Dr}^{\mathrm{a}}$ Dalva M.V. Wanderley pela contribuição na elaboração do projeto e discussão da tese.

À $\mathrm{Dr}^{\mathrm{a}}$ Mara de Brito Filadelfo minha irmã e amiga com a qual posso contar sempre para a revisão do texto.

Ao biólogo Aristides Fernandes do Laboratório de Culicidologia do Departamento de Epidemiologia da Faculdade de Saúde Pública da Universidade de São Paulo pelo treinamento de pessoal e identificação de parte do material.

Ao colega Luiz Milton Bonafé do Laboratório de Culicídeos da Superintendência de Controle de Endemias de Taubaté e às bolsistas Sarah Elizabeth Eugênio e Mara Danielli Marcelão da Fundação de Desenvolvimento e Administração (FUNDAP) pela contribuição na identificação do material.

Aos colegas: Laércio Molinari, Afonso José Gonzaga, Ailton José Barbosa, Valdecir Magina Ribeiro, Marcio Rodrigues, José Luiz Espíndola, Benedito Bento Filho e Antonio Waldomiro de Oliveira pela dedicação e seriedade na execução das coletas em campo, fundamentais para o bom desenvolvimento e resultado de todas as demais fases da pesquisa.

À colega e bolsista da Fundação de Desenvolvimento e Administração (FUNDAP) Aline Thiemi Kita pelo coleguismo e colaboração nas atividades de supervisão de campo, leitura do material e digitação dos dados.

Aos demais colegas do Laboratório de Culicídeos da Superintendência de Controle de Endemias de Taubaté pelo apoio nas atividades de rotina. 
Aos colegas Francisco Carlos dos Santos e Maria Helena de Campos Fonseca do setor de Caraguatatuba, Regional 3 da SUCEN pelo apoio no período das coletas de campo.

Ao engenheiro Alberto Jesus de Oliveira do Serviço Regional de Taubaté, da Superintendência de Controle de Endemias pelas discussões sobre a atividade de Avaliação do Programa de Controle.

À Superintendência de Controle de Endemias (SUCEN) pelo apoio logístico e de laboratório imprescindíveis à execução do presente estudo.

À Fundação de Amparo a Pesquisa do Estado de São Paulo - FAPESP no apoio para aquisição de equipamentos de campo, de laboratório e alojamento ao pessoal de campo, sem os quais não seria possível a realização do trabalho.

À Prefeitura Municipal de São Sebastião pelo apoio no fornecimento de informações técnicas e no levantamento de dados.

À Prof ${ }^{a}$ Maria do Carmo Doria Pereira do Laboratório de Qualidade de Água do Departamento de Saúde Ambiental da Faculdade de Saúde Pública /USP pela aferição do equipamento e sugestões na mensuração dos parâmetros físicos e químicos.

Aos professores Elisabete de Santis Braga e Luiz Vianna Nonnato do Laboratório de Instrumentação Oceanográfica do Instituto Oceanográfico/USP pela aferição do equipamento e sugestões.

A todos os que contribuíram de forma direta ou indireta para a execução e realização deste estudo. 


\section{RESUMO}

Arduino MB. Produtividade de criadouros em área urbana de coexistência de Aedes aegypti e Aedes albopictus, São Sebastião, Litoral Norte do Estado de São Paulo, Brasil. São Paulo, 2006 [Tese de doutorado - Faculdade de Saúde Pública da Universidade de São Paulo].

Objetivos: Avaliar: produtividade, emergência de fêmeas, variáveis físicas e químicas da água dos criadouros e a relação entre os Índices Entomológicos e a Emergência de fêmeas em criadouros. Material e Métodos: Foram coletadas todas as pupas e amostras de larvas de quarto estadio de recipientes nos imóveis inspecionados. Foi mensurado: oxigênio dissolvido, $\mathrm{pH}$, temperatura, condutividade elétrica, volume e salinidade da água do criadouro. Foram estimados a produtividade, Índices, Indicadores de Densidade e a emergência de fêmeas. Resultados: Aedes aegypti foi a mais frequiente $(44,1 \%)$. As categorias de recipientes mais importantes em frequiência e produção foram: plástico e metal. Mais de 55\% dos recipientes eram removíveis. As duas espécies foram tolerantes a amplo gradiente dos parâmetros físicos e químicos. Os índices de rotina foram pouco associados com os Indicadores e a Emergência de fêmeas. Discussão e Conclusões: $A e$. aegypti apresentou predominância. As duas espécies coexistiam em criadouros e no ambiente urbano. A produtividade das duas espécies não pareceu ser afetada pela variação de valores dos parâmetros físicos e químicos. Os Indicadores de Densidade e a Emergência de Fêmeas podem ser utilizados em rotina para aprimorar as informações da avaliação e subsidiar o controle direcionado de criadouros.

Descritores: Aedes aegypti, Aedes albopictus, produtividade, parâmetros físicos e químicos, controle de vetores, coexistência. 


\section{SUMMARY}

Arduino MB. Produtividade de criadouros em área de coexistência de Aedes aegypti e Aedes albopictus, São Sebastião, Litoral Norte do Estado de São Paulo, Brasil. [Productivity of containers in urban area of coexistence of Aedes aegypti and Aedes albopictus in São Sebastião, coastal area of São Paulo State, Brazil]. São Paulo (BR); 2006 [Tese de doutorado - Faculdade de Saúde Pública da Universidade de São Paulo].

Objective: To evaluate: the productivity, the emergency of females, the physical and chemical variables in containers, the association among the Indexes and the Emergency of females. Material and Methods: All of the pupae and samples of fourth instar larval were collected all the containers in inspected premises. It was checked: dissolved oxygen, $\mathrm{pH}$, temperature, electric conductivity, volume and salinity of the water of the containers. It was it was done the productivity, Indexes and the emergency of females. Results: Aedes aegypti was more frequent species $(44,1 \%)$. The categories of more important containers were: plastic, metal. More than $55 \%$ of the containers were susceptible to removal. The two species was tolerant to wide gradient of the physical and chemical parameters. The indexes used in routine were little associated with the Indicators and the Emergency of females. Discussion and Conclusions: Ae. aegypti presented predominance. The two species coexisted in containers and in the urban area. The productivity of the two species didn't seem to be affected by the variation of values of the physical and chemical parameters. The Density Indicators and the Emergency of Females can be used in routine, to improve the information of the evaluation and to subsidize the addressed control of containers.

Descriptors: Aedes aegypti, Aedes albopictus, productivity, physical and chemical parameters, control of vectors, coexistence. 


\section{ÍNDICE}

1 INTRODUÇÃO

2 OBJETIVOS

3 MATERIAL E MÉTODOS 9

3.1 Caracterização da Região 9

3.2 Localidade de Estudo 9

3.3 Método de Coleta 12

3.3.1 Avaliação de densidade larvária (ADL) 12

3.3.2 Adequações da ADL para o projeto 13

$\begin{array}{ll}\text { 3.3.3 Identificação do Material } & 14\end{array}$

3.3.4 Classificação dos recipientes 15

$\begin{array}{ll}\text { 3.3.5 Classificação dos imóveis } & 18\end{array}$

3.4 Índices Entomológicos $\quad 19$

3.5 Tratamento dos dados $\quad 21$

4 RESULTADOS 23

4.1 Composição da fauna de culicídeos encontrada nos criadouros 23

4.2 Descrição dos imóveis e recipientes positivos 26

4.2.1 Imóveis 26

$\begin{array}{llr}\text { 4.2.2 } & \text { Recipientes } & 28\end{array}$

4.3 Abundância e produtividade de larvas e pupas de Aedes aegypti e Aedes albopictus em recipientes fixos e removíveis segundo a categoria

4.3.1 Recipientes contendo Aedes aegypti 32

4.3.2 Recipientes contendo Aedes albopictus 37

4.3.3 Recipientes contendo ambas as espécies $\quad 42$

4.4 Emergência de fêmeas 45

4.4.1 Emergência mensal de fêmeas 45

4.4.2 Emergência de fêmeas segundo a categoria do recipiente 46

4.5 Variáveis físicas e químicas e a associação com abundância e a 
produtividade de imaturos

4.5.1 Descrição dos valores dos parâmetros físicos e químicos da água dos criadouros

4.5.2 Temperatura ambiente e Índices pluviométricos

4.5.3 Associação entre a produção média de imaturos e os parâmetros físicos e químicos da água do criadouro

4.5.4 Associação entre a produção média de imaturos a temperatura ambiente e os índices pluviométricos

4.6 Associação entre Índices entomológicos utilizados na rotina, Indicadores de densidade de larvas e pupas em imóveis e recipientes e Emergência de fêmeas

5 DISCUSSÃO

5.1 Composição da fauna de culicídeos encontrada nos criadouros

66

5.2 Imóveis e recipientes positivos

5.3 Abundância e produção em relação a categoria do recipiente $\mathbf{7 6}$

5.4 Emergência de fêmeas

5.5 Associação entre as variáveis físicas e químicas e a frequiência e produção

5.6 Associação entre Índices entomológicos utilizados na rotina, Indicadores de densidade de larvas e pupas em imóveis e recipientes e Emergência de fêmeas

6 CONCLUSÕES

7 COMENTÁRIOS FINAIS

8 REFERÊNCIAS

ANEXO

Tabela 30 - Distribuição do $\mathrm{N}^{\circ}$ e \% de recipientes positivos para larvas e A 1 pupas de Ae. aegypti

Tabela 31 - Distribuição do $\mathrm{N}^{\circ}$ e $\%$ de recipientes positivos para larvas e A 2 pupas de Ae. albopictus

Tabela 32 - Distribuição do $\mathrm{N}^{\circ}$ e \% de recipientes, larvas e pupas de Aedes 
aegypti e Ae. albopictus em recipientes contendo as duas espécies

Tabela 33 - Relação entre os sexos de pupas de Ae. aegypti e Ae. albopictus

Figuras 17 e 18 - Produção média de imaturos de Ae. aegypti e Ae. albopictus por categoria de recipiente

Tabela 34 - Distribuição mensal dos valores de Índice de Recipiente, Predial e de Breteau, de Ae. aegypti, Ae. albopictus e as duas espécies em coexistência

Tabela 35 - Distribuição mensal dos valore de Indicadores de Densidade de larvas e pupas por recipientes e imóveis, de Ae. aegypti, Ae. albopictus e das duas espécies em coexistência

Tabela 36 - Distribuição do \% de recipientes, Média de larvas e pupas por categoria segundo o tamanho do recipiente positivo para Ae. aegypti

Tabela 37 - Distribuição do \% de recipientes, Média de larvas e pupas por categoria segundo o tamanho do recipiente positivo para Ae. albopictus

Tabela 38 - Coeficiente de Incidência de casos autóctones na região do litoral norte do Estado de São Paulo por município - Período de 2001 a 2004

Figura 19 - Imagem obtida do Satélite LANDSAT 7 em 2004, evidenciando a área urbana e mata de São Sebastião, São Paulo

Figuras 20 e 21 - Aspectos da área central do município de São Sebastião, São Paulo

Figuras 22 e 23 - Fotos da área do porto e área urbana do município de São Sebastião, São Paulo

Figuras 24 a 26 - Fotos de equipamentos e simulação da técnica de varredura para inspeção de grandes recipientes 


\section{INTRODUÇÃO}

Dentro do contexto atual das doenças infecciosas reemergentes, aquelas causadas por vírus estão entre as mais importantes, pois muitas vezes resultam em grandes epidemias que afligem a humanidade, de especial interesse, são as doenças que envolvem a participação de vetores. Estas possuem dinâmica de transmissão mais complexa, pois sofrem a influência de fatores ecológicos, tornando mais difícil sua compreensão e a busca de soluções para o problema. Os mosquitos da família Culicidae são responsáveis pela disseminação de muitos vírus e dentre os quais destacam-se os vetores dos vírus da dengue, Aedes aegypti (Linnaeus, 1762) e Aedes albopictus (Skuse, 1894) (FORATTINI 2002).

Ae. aegypti tem mostrado eficiência na transmissão dos quatro sorotipos de dengue, com participação em quase todas as epidemias registradas no mundo (WHO 2005). Esta espécie teve a competência confirmada para transmissão de vários outros arbovírus, inclusive o da febre amarela, sendo que este último ocorre atualmente em ciclo enzoóticos nas Américas. Com a reinfestação das áreas urbanas por esta espécie, concebe-se a possibilidade de ocorrência de transmissão da febre amarela, fora do ambiente silvestre, nos países de ocorrência da doença. É espécie originária do Continente Africano, e hoje, alcança extensa distribuição nos cinco continentes (FORATTINI 2002).

No Brasil, a distribuição atual desta espécie alcança todos os Estados da Federação (SOUZA-SANTOS e CARVALHO 2000). Em São Paulo, após sua reintrodução em 1985, teve rápida e ampla dispersão, atualmente está presente em quase toda área do Estado ${ }^{1}$. Tem sido referida como espécie altamente domiciliada, convivendo em ambientes substancialmente modificados, criando-se quase que exclusivamente em recipientes artificiais e alimentam-se, principalmente, de sangue humano (FORATTINI 2002).

Ae. albopictus é outra espécie apontada como capaz de transmitir os vírus da dengue ao homem. Sua participação foi confirmada no continente de origem,

\footnotetext{
${ }^{1}$ Secretaria de Estado da Saúde de São Paulo/Superintendência de Controle de Endemias - Arquivos.
} 
a Ásia (JUMALI e col. 1979), nas Ilhas Seychelles, situadas ao norte de Madagascar no Oceano Índico (METSELAAR e col. 1980) e mais recentemente na China (ALMEIDA e col. 2005). No Continente Americano ainda não houve registro de seu envolvimento na transmissão dos vírus da dengue, em que pese o encontro de machos naturalmente infectados durante um surto de dengue na cidade de Reynosa, no México (IBANEZ-BERNAL e col. 1997) e o isolamento de vírus em larvas no Estado de Minas Gerais, no Brasil (SERUFO e col.1993). Sua importância epidemiológica também reside no fato de apresentar competência para 22 vírus (ESTRADA-FRANCO e CRAIG JR 1995). Após várias tentativas de invasão nas Américas, a população dessa espécie foi encontrada estabelecida, em 1985, no Texas, Estados Unidos (MOORE 1999). No ano seguinte, sua presença foi registrada no Brasil, no Estado do Rio de Janeiro (FORATTINI 1986) e, em seqüência, no Estado de São Paulo (BRITO e col. 1986). Atualmente, apenas 7 Estados não registraram infestação por esta espécie (SANTOS, 2003).

As duas espécies estão amplamente distribuídas no Estado de São Paulo. Dos 645 municípios paulistas, 496 encontravam-se infestados por Ae. aegypti e 542 por Ae. albopictus em 2003. Salienta-se, ainda, a coexistência das duas espécies em $80 \%$ dos municípios infestados. Na região leste do Estado de São Paulo, o Ae.aegypti está presente nos quatro municípios do litoral norte: São Sebastião, Ilhabela, Caraguatatuba e Ubatuba; no Vale do Paraíba registra-se a infestação dos municípios de Potim, Aparecida e Cruzeiro. Enquanto que Ae. albopictus está presente em todos os municípios do Litoral Norte e Vale do Paraíba, excetuando-se Campos do Jordão ${ }^{2}$.

A dengue é uma doença infecciosa com distribuição nos trópicos e subtrópicos, abrangendo quase todos os continentes, com exceção do Europeu. A doença é endêmica nas Américas, no mediterrâneo oriental, na Ásia, no Pacífico ocidental e nas áreas tropicais da África. Este quadro tem-se agravado com a forma hemorrágica da doença; são 50 milhões de infecções ao ano, com 500.000 casos hospitalizados e 21.000 óbitos em média, $90 \%$ dos quais em crianças. Antes de 1970, no mundo, apenas 9 países registravam febre de hemorrágica de dengue, número este

\footnotetext{
${ }^{2}$ Secretaria de Estado da Saúde de São Paulo/Superintendência de Controle de Endemias - Arquivos.
} 
que aumentou mais de quatro vezes e continua subindo. Os vírus da dengue são transmitidos atualmente em quase 100 países tropicais, com 2,5 bilhões de pessoas expostas ao risco. A pandemia de dengue dos séculos 20 e 21 se estabeleceu diretamente em razão do estilo de vida atual: a explosão de população, urbanização e transporte rápido de grande número de pessoas. Devido ao montante com despesas em programas nacionais e dificuldades de combate ao mosquito, a vacina de dengue seria a ideal solução para o controle deste problema de saúde global, entretanto, ela ainda não existe (WHO 2005; PAHO 2005).

No Continente Americano, a distribuição da endemia estende-se desde o México, ao norte, até a Argentina, ao sul (FORATTINI 2002).

Em nosso país a incidência foi alta entre os anos de 2001 a 2003, e as regiões mais afetadas foram a Sudeste e Nordeste. Do total de casos confirmados, os maiores percentuais foram registrados nos Estados do Rio de Janeiro, Bahia, Ceará, Pernambuco e São Paulo (MS/FNS 2003). Embora, neste dois últimos anos houvesse redução do registro de casos de dengue clássico, a incidência da forma hemorrágica preocupa as autoridades (MS/FNS 2005).

Após a reinfestação do Estado de São Paulo pelo Ae.aegypti em meados dos anos 80, epidemias anuais são registradas desde o 1990 em várias regiões. A região da Baixada Santista apresentou epidemia de grande magnitude, com mais de 29.000 casos em 2002. No litoral norte, o município de São Sebastião registrou a primeira epidemia em 2001, com 445 casos, sendo que em 2002 somaram-se 1.300 casos. Com a circulação dos sorotipos 1,2 e 3 na região, são esperadas epidemias com maior agravamento nos próximos anos, pois, já foram registrada a ocorrência de casos de dengue da forma hemorrágica em alguns municípios do litoral sul do Estado (SESSP/CVE).

Atualmente os esforços direcionados ao controle dos vetores de dengue são baseados na redução da densidade populacional das populações de mosquitos a níveis que impeçam a transmissão dos vírus (SESSP/SUCEN, 2002).

Dentre as atividades do Programa de Controle de Vetores, destaca-se a Avaliação de Densidades Larvária. Esta consiste na avaliação dos níveis de infestação de uma determinada área geográfica, num determinado momento. Essa 
avaliação é realizada geralmente numa amostra dos imóveis da área. Com esta amostragem são estimados índices de infestação, os quais auxiliam na avaliação no que se refere ao risco de transmissão. Entre os índices existentes, três são estimados no programa do Estado de São Paulo: Índice Predial, Índice de Recipientes e o Índice de Breteau. Além dos índices, as avaliações permitem identificar a freqüência e os tipos de recipientes positivos na área, auxiliando no direcionamento do controle de criadouros (SES/SUCEN, 2002).

Os índices, são estimativas de freqüência com base na população larval, ou seja, a contagens de recipientes contendo larvas de Ae. aegypti (SES/SUCEN,1997). Eles foram criados para monitorar o progresso do controle do vetor e para determinar se os níveis de profilaxia tinham sido alcançados na transmissão da febre amarela em 1923 (CONNOR e MONROE 1923).

A Organização Mundial de Saúde, em 1972, elaborou o Índice de Densidade, cálculo que considera a relação dos três índices, que resultou em tabela que fornece parâmetro para indicação do risco de transmissão (SESSP/SUCEN 1997). Contudo, é importante lembrar que o limiar crítico de risco para dengue nunca foi estabelecido e a associação dos resultados da densidade larval com a de adulto é difícil de ser avaliada por vários fatores, podendo ser destacados pelo menos três: 1) a fase larval geralmente é distante da fase adulta e pode haver várias implicações bioecológicas neste intervalo não considerado, como por exemplo, a mortalidade de larvas; 2) os índices geralmente não são associados com o número de casos de dengue; 3) os índices não levam em conta a produtividade dos tipos de criadouro, ou seja, o quanto os diferentes recipientes contribuem para a população adulta local (TUN-LIN e col. 1995; FOCKS e col. 2000).

Pesquisadores e profissionais de Saúde Pública buscam alternativas rápidas e eficientes para monitorar as densidades das populações desses vetores, diminuindo os esforços operacionais e a aplicação de inseticidas. Vários estudos envolvendo as diversas fases do ciclo de vida dos mosquitos foram realizados, mas até o momento, nunca conseguiram chegar a um consenso (SERVICE 1992).

Discutindo a importância da ecologia no controle da dengue, SERVICE (1992) sugere que provavelmente não exista método eficiente e realizável 
de medida de densidade da população de adulto e, mesmo se houvesse, não seria universalmente aplicado, isto porque, diferentes populações geográficas podem diferir em sua competência vetorial, taxas de sobrevivência, capacidade de ocupação de hábitats entre muitos outros aspectos. Argumenta ainda, que os levantamentos de ovos são mais sensíveis que os de larvas, mas sua limitação está em não poder localizar os sítios de criação e na dificuldade de identificação da espécie nesta fase, o que para o controle dos locais de criação seriam informações imprescindíveis.

Hoje, vários estudos exploram outros aspectos bioecológicos, como a produtividade de criadouros, visando buscar critérios que possam ser aplicados no sentido de aprimorar as avaliações, ou seja, a contribuição dos criadouros para a densidade populacional de adultos. FOCKS e col. (1981) propuseram o cálculo de Emergência, utilizando o número de pupas coletadas nos recipientes para estimar a população de fêmeas adultas. Outros autores discutem a produtividade de criadouros, sugerindo "imóveis chaves" e "recipientes chaves", ou seja, seriam imóveis e recipientes com características que estariam permitindo produção maior de adultos em relação aos demais no local (TUN-LIN e col. 1995).

FOCKS e col. (2000) propuseram estimar o limiar de risco da localidade por meio de simulação computacional. O cálculo usaria dados de contagem de pupas, soroprevalência de anticorpos do vírus da dengue, temperatura ambiente local, entre outros dados. Este limiar indicaria o número de mosquitos por pessoa que seria necessário para ocorrer a transmissão local.

É consenso que diversos tipos de criadouros podem assumir papéis diferenciados de acordo com a cultura local para a produção maior ou menor de indivíduos da população adulta (BARRERA e col. 1993; MACORIS e col. 1997; CHADEE e RAHAMN 2000; FORATTINI e BRITO 2004). Como exemplo, em estudo conduzido em Santos, no litoral sul do Estado de São Paulo, caixa d'água, calha e ralo de escoamento de chuvas em edificações foram apontados, como os criadouros mais produtivos para Ae.aegypti (PEREIRA 2001). Identificar a importância dos microhabitats e sua contribuição para a produtividade de adultos nas diversas regiões, é ainda informação necessária para orientação do controle dos criadouros. 
Cabe ressaltar que muitos fatores podem exercer influência no ambiente e contribuir para o sucesso de uma espécie na exploração de criadouros, assim como na capacidade em manter-se neles. WASHBURN (1995) sugere que a falta de alimentação primária em recipientes artificiais pode limitar o nível trófico e reduzir a probabilidade de serem estabelecidas populações de predadores, conseqüentemente favorecendo o sucesso de outras, que seriam potenciais presas. A dinâmica das populações de mosquitos que utilizam recipientes pode sofrer várias influências do meio, as quais muitas vezes, contribui fortemente para a distribuição das espécies no hábitat.

É conhecida a preferência de Ae. aegypti por criadouros contendo água relativamente limpa, embora tenha sido encontrado em água poluída (CLEMENTS 1992). Há registro da presença da espécie em criadouros de natureza vegetal, como ocos de árvores e bromélias, na literatura (CHADEE e col. 1998; FORATTINI e MARQUES 2000), estes podem variar amplamente nas características físicas e na composição química do seu conteúdo líquido. Considerando que esses tipos de microhabitats, particularmente as bromélias nativas, estão presentes em ambientes urbanos da região do litoral norte do Estado de São Paulo. Aliado ao fato de que estes vegetais têm sido comumente utilizados para fins paisagísticos, não é difícil a exploração dos mesmos por esta espécie. Alguns autores sugerem que na escassez de outros criadouros, em razão de atividades de controle, os ecótopos naturais poderiam albergar populações de Ae aegypti, permitindo a reposição da população no ambiente urbano, pois, na maioria das vezes, não são alvos do controle (CHADEE e col. 1998).

Vale ressaltar que o criadouro de natureza vegetal e o artificial apresentam características físicas e químicas muito diferente e, portanto, são ecologicamente distintos. Sendo assim, seria de se supor que espécies bem adaptadas a criadouro artificial necessitassem de esforço adaptativo para ocupar o criadouro natural.

Além de todas as considerações feitas se acrescenta o fato da coexistência das duas espécies na região do litoral norte. Sabe-se que as interações 
ecológicas advindas desta situação podem resultar na mudança da produtividade de indivíduos para a população adulta.

Portanto, estudos em campo para estimar a produtividade dos criadouros utilizados por essas duas espécies, com e sem situação de coexistência, levando em conta os vários microhabitats presentes e seus aspectos físicos e químicos, são necessários para levantar informações adicionais, que possam contribuir para o aprimoramento das avaliações da densidade populacional e incremento das ações de controle desses vetores. 


\section{OBJETIVOS}

\section{1 - Geral}

Estimar a produtividade em campo de Ae. aegypti e Ae. albopictus com e sem situação de coexistência.

\section{2 - Específicos}

1 - Apresentar a composição da fauna de culicídeos encontrada nos criadouros;

2 - Descrever os tipos de imóveis e os criadouros positivos;

3 - Avaliar a abundância e produtividade de larvas e pupas de Ae. aegypti e Ae. albopictus em relação a categoria do recipiente;

4 - Estimar a emergência de fêmeas;

5 - Analisar a abundância e produtividade larvas e pupas de Ae. aegypti e Ae. albopictus em relação as variáveis físicas e químicas;

6 - Analisar a associação entre os Índices utilizados em rotina, Indicadores de Densidade de larvas e pupas em imóveis e recipientes e a Emergência de fêmeas. 


\section{MATERIAL E MÉTODOS}

\section{1 - Caracterização da Região}

O litoral norte paulista compreende ambientes de planícies costeiras e extensa área de cobertura vegetal preservada a qual é parte integrante da reserva da Mata Atlântica. Os núcleos urbanos, em grande parte, têm características peculiares, com ocupação do solo para fins de implantação de moradias com pouco planejamento, favorecendo a formação de núcleos residenciais secundários muito próximo das matas, permitindo assim a existência de manchas residuais de mata entre as moradias. A população é crescente e a especulação imobiliária flagrante em razão da exploração turística (INPE 1992).

A região destaca-se como importante pólo turístico do Estado de São Paulo, abrigando, em épocas de verão, população flutuante três vezes maior que a existente. São quatro os municípios que fazem parte da região: São Sebastião, Caraguatatuba, Ubatuba e Ilhabela.

O clima é quente e úmido, com médias anuais de temperatura que não são inferiores a $18^{\circ} \mathrm{C}$ nos meses mais frios e acima $30^{\circ} \mathrm{C}$ nos meses mais quentes ${ }^{3}$.

\section{2 - Localidade de Estudo}

São Sebastião, localiza-se no litoral norte do Estado de São Paulo, a $10 \mathrm{~m}$ do nível do mar, $23^{\circ} 21^{\prime} 00^{\prime \prime}$ de latitude sul e $45^{\circ} 21^{\prime} 00^{\prime \prime}$ longitude oeste, a $220 \mathrm{~km}$ da capital paulista ${ }^{3}$ (Figura 1).

A superfície territorial do município totaliza $479 \mathrm{~km}^{2}$, destes aproximadamente 27.000 hectares fazem parte do Parque Estadual da Serra do Mar, coberta por mata preservada (SEMASP/IF). Concentrado numa estreita faixa de terra

\footnotetext{
${ }^{3}$ Secretaria de Estado da Agricultura de São Paulo - Instituto Agronômico de Campinas - Arquivos.
} 
entre a serra e o mar, o ambiente urbano de São Sebastião possui cerca de $100 \mathrm{~km}$ distribuídos em mais de 30 praias. A população urbana é de 57.452 habitantes, sendo que, durante o período de verão, chega a ser cinco vezes maior; comprometendo a infra-estrutura existente no município (IBGE 2003).

Privilegiado pelas excelentes condições do mar que permitiram a localização de um porto com calado de até 50 metros (Anexo 13, Figura 22), o município é uma peça importante na economia petroleira, pois tem instalado em seu núcleo urbano o Terminal Almirante Barroso/TEBAR da Petrobrás, responsável pela movimentação de mais de $60 \%$ do petróleo no Centro-Oeste e Sudeste brasileiro ${ }^{4}$.

Por sua localização e por seu patrimônio histórico, São Sebastião é uma das mais atraentes áreas turísticas do litoral norte paulista. $\mathrm{O}$ ecoturismo tem hoje importância estratégica, pois este, representa para o município forma de uso considerado racional, econômico e produtivo das riquezas naturais ali encontradas.

\footnotetext{
${ }^{4}$ Secretaria de Estado de Economia e Planejamento de São Paulo-Arquivos.
} 


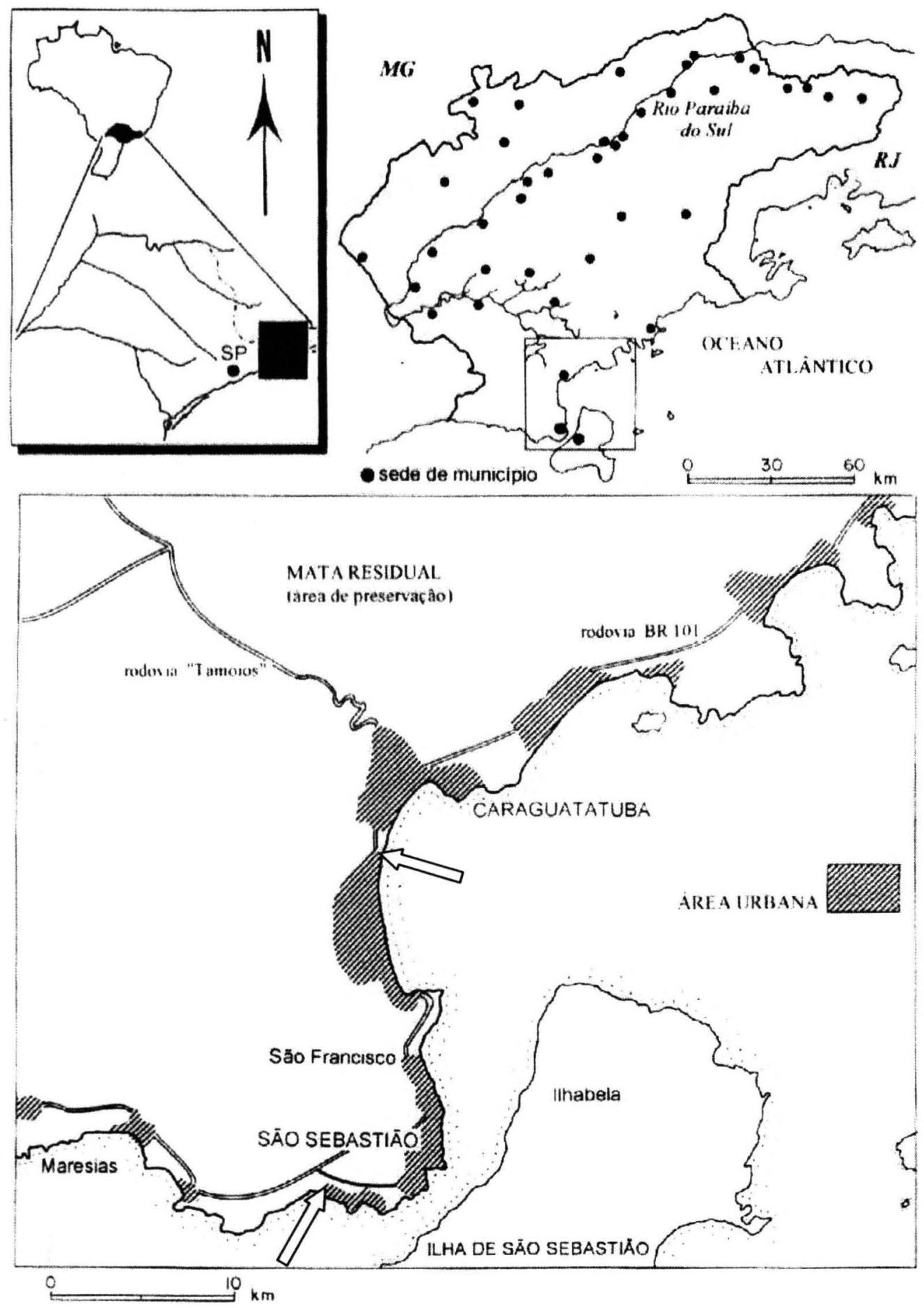

As setas indicam os limites da área de estudos.

Figura 1 - Representação esquemática da localização do município e delimitação, entre setas, da área trabalhada no município de São Sebastião, São Paulo, Brasil. 


\subsection{Método de Coleta}

As coletas foram realizadas durante de uma das atividades de rotina do Programa de Vigilância e Controle dos Vetores de Dengue da Secretaria de Estado da Saúde de São Paulo, Superintendência de Controle de Endemias (SUCEN), a Avaliação de Densidade Larvária (ADL), realizada sistematicamente em São Sebastião. Foram feitas algumas adequações para que este estudo pudesse ser desenvolvido.

\subsection{1 - Avaliação de Densidade Larvária (ADL)}

As avaliações de densidades larvárias permitem estimar o Índices de Recipientes, o Índice Predial e o Índice de Breteau tendo como um dos objetivos avaliar o impacto das atividades de controle sobre a população de vetores e dar parâmetro para a indicação de risco de transmissão (SESSP/SUCEN, 1997).

Sua mensuração é feita em uma amostragem probabilística das edificações existentes no perímetro urbano, da qual ficam excluídos os Pontos estratégicos, locais considerados como mais favoráveis à infestação, os quais são submetidos a pesquisas sistemáticas. O plano amostral utilizado no Programa de Controle de Vetores do Estado de São Paulo foi adaptado por ALVES (1995) e está preconizado no Manual de Vigilância Entomológica de Ae. aegypti da Superintendência de Controle de Endemias da Secretaria de Estado da Saúde de São Paulo (SES/SUCEN,2002).

A amostra mínima em municípios com mais de 20 mil habitantes e área com mais de 4800 edificações, é de no mínimo 400 edificações. Para seu cálculo devem ser consideradas as taxas de recusa e de imóveis fechados. No caso de São Sebastião, estas taxas correspondem em média a $42 \%$.

No sorteio, o quarteirão é considerado como unidade amostral. Para tanto foram ajustados os tamanhos dos mesmos, com média de 35 edificações, ou seja, quarteirões grandes são desmembrados, enquanto que os pequenos são 
agrupados. Favelas são demarcadas em grupamentos de 30 a 35 casas, representando um quarteirão. Depois é realizado o sorteio do número de quarteirões da área que resultará no total de edificações estabelecido na amostra.

Os quarteirões sorteados são assinalados em mapa da área, para que a equipe possa fazer o roteiro de trabalho. É feita a inspeção de $100 \%$ dos imóveis, excetuando-se terrenos, praças, parques e pontos estratégicos de inspeção periódica. A seqüência de inspeção no quarteirão é feita a partir da esquina ao norte, de onde partem dois operadores em direções opostas, com a finalidade de cobrir o quarteirão, conforme esquema abaixo.

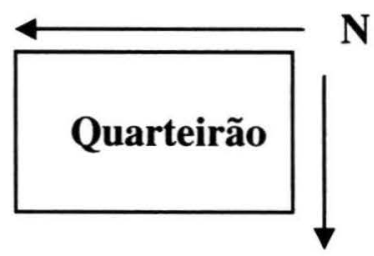

A inspeção das edificações obedece a uma metodologia:

- Em prédios de condomínios, a área coletiva, o sub-solo, a cobertura e cada apartamento do primeiro andar e térreo são considerados como unidades de edificação.

- Casas e sobrados, inspeciona-se fora e depois dentro do imóvel, começando do primeiro andar, quando houver.

- São recolhidas amostras de larvas de todos os recipientes com presença de culicídeos e acondicionadas em álcool 70\%, para posterior identificação.

Foi realizado piloto no período de novembro de 2001 a março de 2002, para dimensionamento da capacidade operacional de campo e laboratório, assim como a aferição de toda a metodologia.

\subsection{2 - Adequações da ADL para o projeto}

Para este estudo foram coletadas $100 \%$ das pupas e amostra das larvas de $4^{\circ}$ estádio $\left(\mathrm{L}_{4}\right)$ dos culicídeos encontradas em todos os recipientes pesquisados durante as atividades da ADL. 
Em parte do universo de recipientes com presença de imaturos, foram mensurados os seguintes parâmetros físicos e químicos da água do criadouro: volume, oxigênio dissolvido (OD), $\mathrm{pH}$, salinidade, condutividade elétrica e temperatura da água através de equipamento multiparâmetro portátil Sension 156 (C) Hach company, 2001 USA) (Anexo 14, Figura 24). Para esta amostra, tentou-se medir a água de no mínimo 30 recipientes, ao acaso, para cada avaliação mensal.

$\mathrm{O}$ aparelho foi aferido pelo Laboratório de Qualidade de Água do Departamento de Saúde Ambiental da Faculdade de Saúde Pública /USP e pelo Laboratório de Instrumentação Oceanográfica do Instituto Oceanográfico/USP.

A equipe foi composta por 4 duplas, sendo que 2 duplas percorreram um mesmo quarteirão, portanto, dois quarteirões foram examinados concomitantemente. As duplas foram compostas de um operador, que inspecionava os recipiente, e um técnico de campo, que fez as mensurações e registros.

$\mathrm{O}$ contato entre as equipes dos dois quarteirões foi feito por meio de rádio "walk-talk", para notificar a localização e término de cada quarteirão, facilitando o trabalho e racionalizando o tempo.

Para coleta da água das bromélias, dos ralos e ocos de árvores, foi utilizado tubo flexível conectado a uma bomba de sucção manual. O processo que permite a retirada do máximo volume líquido do recipiente (Anexo 14, Figura 25).

Para a coleta de imaturos em grandes criadouros, foi utilizada a técnica de varredura (KUBOTA e col. 2003) (Anexo 14, Figura 26).

\subsection{3 - Identificação do Material}

Todo as larvas e pupas foram encaminhadas ao Laboratório de Culicídeos de Taubaté, da Superintendência de Controle de Endemias para identificação específica. O Laboratório de Culicidologia da Faculdade de Saúde Pública da Universidade de São Paulo, forneceu suporte para esta identificação. 


\subsection{4 - Classificação dos recipientes}

A classificação dos recipientes é aspecto importante a ser considerado na avaliação da produtividade. Neste estudo optou-se por adotar quatro classificações:

\section{A - Segundo o tipo:}

A classificação base nos dados levantados no piloto procurou detalhar ao máximo o tipo do recipiente encontrado no ambiente urbano:

- Pote, frasco e garrafas de plástico;

- Balde de plástico;

- Caixa plástica;

- Galão plástico

- Vaso e prato de planta;

- Lona e piscina plástica;

- Pneu;

- Garrafas, potes e copos de vidro;

- Latas;

- Peças de metal;

- Peças de louça;

- Peças de Carro;

- Peças de plástico;

- Peças de vidro;

- Bebedouro;

- Embalagens plásticas;

- Planta aquática;

- Caixa leite longa-vida;

- Canoa de madeira; 
- Outros removíveis.

- Caixa d'água e reservatório de água;

- Tanque, tambor e barril de metal;

- Barco, caiaque e peça de barco;

- Peças de fibra;

- Calha;

- Vaso sanitário;

- Ralos;

- Canaletas de escoamento de água;

- Caixa de areia e cimento;

- Fonte e cascata;

- Casa de máquina;

- Bandeja de geladeira;

- Lajes, calçadas e pisos;

- Piscinas fixas;

- Caixas de descarga;

- Outros não removíveis.

- Bromélia;

- Oco de árvore;

- Bambu;

- Casca de coco, caules e axilas de folhas;

- Outros de natureza vegetal.

\section{B - Segundo a categoria:}

Para facilitar a avaliação da produtividade, buscou-se reduzir o número de recipientes, agrupando-os em categorias. Foram levadas em conta algumas características em relação ao uso ou ao tipo de material. Alguns tipos foram mantidos em categoria isolada devido às características e importância já reconhecidas.

- Caixa d'água; 
- Cimento;

- Fibra;

- Louça e cerâmica;

- Ralo;

- Natural;

- Metal;

- Plástico;

- Planta aquática;

- Pneu;

- Vaso ou prato de planta;

- Vidro;

- Outros.

\section{C - Segundo a situação no ambiente}

Os recipientes também podem pertencer a duas classes distintas, que vão interferir diretamente na produtividade, aqueles que não podiam ser retirados do ambiente foram considerados Fixos e os que, de alguma forma, poderiam ser removidos foram aqui chamados Removíveis.

Fixos: caixa d'água, cimento, fibra, louça, natural e ralo.

Removíveis: metal, plástico, planta aquática, pneu, vaso/prato de planta, vidro e outros

\section{D - Segundo o volume}

O volume da água do criadouro foi aferido apenas naqueles que tiveram medição dos parâmetros físicos e químicos. Em razão da variação nos valores do volume, os criadouros foram classificados em tamanhos. Já que as espécies não foram comparadas, decidiu-se adotar número diferente para cada 
espécie, devido o número de recipientes na amostra para cada intervalo. Em criadouros com a presença de ambas as espécies, a amostra não foi suficiente para realizar esta classificação.

\begin{tabular}{|ll|}
\hline \multicolumn{1}{|c|}{ Aedes aegypti } & \multicolumn{1}{c|}{ Aedes albopictus } \\
\hline Pequeno $=$ até $500 \mathrm{ml}$ & Pequeno $=$ até $500 \mathrm{ml}$ \\
Intermediário $=$ de 501 a $2.000 \mathrm{ml}$ & Médio $=501$ a $5.000 \mathrm{ml}$ \\
Médio $=2.001$ a $10.000 \mathrm{ml}$ & Grande $=$ acima de $5.000 \mathrm{ml}$ \\
Grande $=$ acima de $10.000 \mathrm{ml}$ & \\
\hline
\end{tabular}

\subsection{5 - Classificação dos imóveis}

A classificação dos imóveis obedeceu àquela adotada no programa de controle, ou seja, geralmente são classificados segundo tipo de atividade exercida no imóvel.

- Borracharia, depósito pneus e recauchutadora;

- Ferro velho, oficina de desmanche;

- Posto de gasolina, troca de óleo e lava rápido;

- Oficina mecânica e funilaria;

- Depósito de material de construção;

- Garagem de ônibus, carro e transportadora;

- Estação ferroviária e rodoviária;

- Porto e aeroporto;

- Armazém, silo e entreposto;

- Depósito de container;

- Construção e canteiro de obra;

- Cemitério;

- Casa térrea e sobrado;

-Apartamento; 
- Ponto comercial e escritório;

- Indústria;

- Escolas e creches;

- Hospital, asilo e clínicas;

- Quartel, prisão e delegacia;

- Hotel, pousada e pensão;

- Área verde urbana;

- Clube, centro esportivo e estádio;

- Prédio público;

- Outros

\section{4 - Índices Entomológicos}

Foram calculados os três Índices Entomológicos comumente utilizados nas rotinas dos programas de controle do Estado de São Paulo: o Índice de Recipiente, o Índice Predial e o Índice de Breteau. Calculou-se também os Indicadores de Densidades e a produção de fêmeas por meio do cálculo de Emergência, baseado no modelo proposto por FOCKS e col. (1981) :

\section{- Índices utilizados no Programa de Controle:}

Índice de Recipientes - IR

$\underline{\mathrm{N}^{0} \text { de recipientes positivos }} \quad \mathrm{X} 100$

$\mathrm{N}^{\mathrm{o}}$ de recipientes pesquisados

Índice Predial - IP

$\underline{\mathrm{N}^{0} \text { de imóveis positivos }} \quad \mathrm{X} 100$

$\mathrm{N}^{0}$ de imóveis trabalhados 
Índice de Breteau - IB

$\underline{\mathrm{N}^{\mathrm{o}} \text { de recipientes positivos }} \quad \mathrm{X} 100$

$\mathrm{N}^{\mathrm{o}}$ de imóveis trabalhados

- Índices de Densidades:

Índice de Densidade de Larvas por Recipiente - DLR

$\begin{array}{cc}\mathrm{N}^{\mathrm{o}} \text { Larvas } & \mathrm{X} 100 \\ \mathrm{~N}^{\mathrm{o}} \text { de recipientes pesquisados } & \end{array}$

Índice de Densidade de Pupas por Recipiente - DPR

$\begin{array}{cc}\mathrm{N}^{\mathrm{o}} \text { Pupas } & \mathrm{X} 100 \\ \mathrm{~N}^{\mathrm{o}} \text { de recipientes pesquisados } & \end{array}$

Índice de Densidade de Larvas por Imóveis - DLI

$\frac{\mathrm{N}^{\circ} \text { Larvas }}{\mathrm{N}^{\mathrm{o}} \text { de imóveis trabalhados }} \times 100$

Índice de Densidade de Pupas por Imóveis - DPI

$\begin{array}{cc}\mathrm{N}^{\mathrm{o}} \text { Pupas } & \mathrm{X} 100 \\ \mathrm{~N}^{\mathrm{o}} \text { de imóveis trabalhados } & \end{array}$

\section{- Produção de fêmeas}

Emergência de fêmeas por mês - EM

$$
E M=\left[\frac{N \cdot(0,5)}{(2 . q)} \times 100\right] \times 30
$$

Onde: $\mathrm{N}$ = número de pupas coletadas para determinada espécie; 
0,5 = relação dos sexos;

2 = número médio do período pupal;

$\mathrm{q}$ = número de imóveis trabalhados;

30 = número de dias do mês.

Emergência de fêmeas por categoria de recipiente - ER

$$
\mathrm{ER}=\underline{\mathrm{N}} \cdot(0,5)
$$

Onde: $\mathrm{N}=$ número de pupas da espécie por categoria de criadouro;

$0,5=$ relação dos sexos;

2 = número médio do período pupal;

$\mathrm{n}=$ número de recipientes pesquisados por categoria.

Os dados do clima foram considerados aqueles fornecidos pela estação de coleta do município de Ubatuba, do Instituto Agronômico da Secretaria de Estado da Agricultura de São Paulo. Foram utilizadas as médias dos quinze dias anteriores à coleta.

As coletas foram realizadas mensalmente de outubro/2002 a abril/2003 e de outubro/2003 a abril/2004.

\section{5 - Tratamento dos dados}

As análises foram feitas nos softwares Statistica 5.0 e StatsDirect 2.4.5 com valor de $\alpha=0,05$.

Os dados foram tratados separadamente para os recipientes contendo Ae. aegypti e Ae. albopictus e em recipientes onde as duas espécies coexistiam. 
Foi realizada estatística descritiva para apresentar a caracterização dos imóveis e recipientes.

A produtividade foi analisada por meio de testes estatísticos como segue:

- para avaliar a produção média de larvas e pupas de Ae. aegypti e Ae. albopictus em relação aos valores dos parâmetros físicos e químicos da água do criadouro e aos dados do clima foi utilizado o Teste de Correlação de Spearman;

- para avaliar a produção média de larvas e pupas de Ae. aegypti e Ae. albopictus entre as categorias de recipiente foi aplicado o Teste de Kruskal-Wallis e o de Dwas-Steel-Chritchlow-Flingner para as posteriores comparações múltiplas;

- para comparar a Emergência de fêmeas entre Ae. aegypti e Ae. albopictus o Teste de Mann-Whitney. A Emergência de fêmeas por tipo de recipiente foi comparada aplicando-se o Teste de Kruskal-Wallis e o de Dwas-Steel-Chritchlow-Flingner para as posteriores comparações múltiplas;

- para comparar a variação dos parâmetros físicos e químicos da água dos criadouros nos intervalos de volume, foi utilizado o teste Kruskal-Wallis.

- para comparar os Índices de Densidade e os Índices Entomológicos tradicionais, assim como estes dois em relação a Emergência mensal de fêmeas, foram feitos Testes de Correlação de Spearman. 


\section{4 - RESULTADOS}

\section{1 - Composição da fauna de culicídeos encontrada nos criadouros}

Foram identificados 11 gêneros e 30 espécies do total de 27.135 exemplares coletados nos criadouros.

Ae. aegypti foi a mais freqüente $(44,1 \%)$ no total de espécies e na maior parte dos criadouros. Em seguida as espécies que apresentaram maiores percentuais foram: Ae. albopictus (17,5\%), Limatus durhami (11,1\%), Culex quinquefasciatus (7,0\%), Ochlerotatus fluviatilis $(5,6 \%)$ e Wyeomyia edwardsi $(3,5 \%)$.

A categoria "natural" foi composta por $80 \%$ de bromélias que estavam localizadas no peridomicílio. Chamou atenção pela riqueza encontrada, com total de 22 espécies, além de alguns exemplares de predadores do gênero Toxorhynchites sp. A presença de Ae. aegypti e Ae. albopictus também foi acentuada neste tipo de criadouro, com 783 e 998 indivíduos, respectivamente.

Ae. aegypti, Ae. albopictus e Cx. quinquefasciatus foram encontradas em todas as categorias de criadouro, Li. durhami só não estava presente na categoria "ralo".

Ainda que pouco freqüentes, duas espécies do gênero Anopheles foram encontradas em criadouros artificiais. A espécie Ochlerotatus scapularis também foi registrada em diversos criadouros artificiais (Tabela 1). 
Tabela 1 - Distribuição do ${ }^{\circ}$ de imaturos por espécie ou gênero, segundo a categoria de recipiente no período de 10/2002 a 04/2003 e 10/2003 a 04/2004 em São Sebastião, São Paulo, Brasil.

\begin{tabular}{|c|c|c|c|c|c|c|c|c|c|c|c|c|c|c|}
\hline Recipiente & $\begin{array}{r}\text { Caixa } \\
\text { D'água } \\
\end{array}$ & Cimento & Fibra & Louça & Metal & Plástico & $\begin{array}{l}\text { Planta } \\
\text { Aquát. }\end{array}$ & Pneu & Ralo & $\begin{array}{l}\text { Vaso } \\
\text { Prato }\end{array}$ & Natural & Outros & Total & $\%$ \\
\hline Ae. aegypti & 589 & 471 & 1381 & 394 & 2506 & 3028 & 256 & 317 & 695 & 1256 & 783 & 279 & 11955 & 44,1 \\
\hline Ae. albopictus & 214 & 81 & 83 & 182 & 739 & 1462 & 36 & 227 & 37 & 470 & 998 & 228 & 4757 & 17,5 \\
\hline Li. durhami & 8 & 18 & 8 & 127 & 652 & 1465 & 5 & 114 & 0 & 73 & 143 & 408 & 3021 & 11,1 \\
\hline Cx. quinquefasciatus & 23 & 630 & 2 & 75 & 200 & 172 & 100 & 32 & 478 & 73 & 95 & 18 & 1898 & 7,0 \\
\hline Oc. fluviatilis & 1104 & 29 & 33 & 14 & 124 & 180 & 0 & 0 & 8 & 13 & 11 & 0 & 1516 & 5,6 \\
\hline Wy. edwardsi & 0 & 0 & 0 & 1 & 0 & 1 & 0 & 0 & 0 & 0 & 956 & 0 & 958 & 3,5 \\
\hline Cx. gairus & 0 & 0 & 0 & 1 & 2 & 5 & 0 & 0 & 0 & 0 & 448 & 0 & 456 & 1,7 \\
\hline Oc. scapularis & 2 & 70 & 0 & 0 & 6 & 8 & 0 & 0 & 13 & 3 & 268 & 6 & 376 & 1,4 \\
\hline Wy. bourrouli & 1 & 0 & 0 & 0 & 0 & 3 & 0 & 0 & 0 & 0 & 302 & 1 & 307 & 1,1 \\
\hline Cx. pleuristatus & 0 & 0 & 0 & 0 & 0 & 0 & 0 & 2 & 1 & 0 & 286 & 6 & 295 & 1,1 \\
\hline Cx. davisi & 0 & 0 & 0 & 0 & 0 & 0 & 0 & 5 & 0 & 0 & 186 & 1 & 192 & 0,7 \\
\hline Cx. albipes & 0 & 0 & 0 & 0 & 0 & 0 & 0 & 0 & 0 & 0 & 124 & 0 & 124 & 0,5 \\
\hline${ }^{*} P s$. cingulata & 17 & 56 & 0 & 0 & 0 & 0 & 0 & 0 & 0 & 0 & 13 & 0 & 86 & 0,3 \\
\hline Cx. corniger & 0 & 23 & 14 & 0 & 10 & 8 & 0 & 0 & 6 & 0 & 22 & 0 & 83 & 0,3 \\
\hline Cx. nigripalpus & 25 & 27 & 0 & 0 & 0 & 0 & 0 & 0 & 4 & 0 & 0 & 0 & 56 & 0,2 \\
\hline Cx. lanei & 0 & 0 & 0 & 30 & 0 & 0 & 0 & 0 & 0 & 0 & 18 & 0 & 48 & 0,2 \\
\hline Cx. dolosus & 0 & 0 & 0 & 0 & 2 & 31 & 0 & 0 & 0 & 1 & 13 & 0 & 47 & 0,2 \\
\hline Cx. reducens & 0 & 0 & 0 & 0 & 0 & 0 & 0 & 0 & 0 & 0 & 40 & 0 & 40 & 0,1 \\
\hline Oc. terrens & 0 & 0 & 0 & 0 & 0 & 0 & 0 & 0 & 0 & 39 & 0 & 0 & 39 & 0,1 \\
\hline Wy. theobaldi & 0 & 0 & 0 & 0 & 0 & 0 & 0 & 0 & 0 & 0 & 15 & 0 & 15 & 0,1 \\
\hline${ }^{*}$ Ur. lowii & 0 & 4 & 0 & 0 & 0 & 9 & 0 & 0 & 0 & 0 & 0 & 0 & 13 & 0,0 \\
\hline Cx. neglectus & 0 & 0 & 0 & 0 & 1 & 0 & 0 & 0 & 0 & 0 & 11 & 0 & 12 & 0,0 \\
\hline An. evansae & 3 & 0 & 0 & 0 & 0 & 8 & 0 & 0 & 0 & 0 & 0 & 0 & 11 & 0,0 \\
\hline Wy. mystes/finlaya & 0 & 0 & 0 & 0 & 0 & 0 & 0 & 0 & 0 & 0 & 10 & 0 & 10 & 0,0 \\
\hline An. argyritarsis & 3 & 0 & 0 & 0 & 0 & 4 & 0 & 0 & 0 & 0 & 0 & 0 & 7 & 0,0 \\
\hline Cx. worontzoni & 0 & 0 & 0 & 0 & 0 & 0 & 0 & 0 & 0 & 0 & 2 & 0 & 2 & 0,0 \\
\hline "Ps. ferox & 0 & 0 & 0 & 0 & 0 & 0 & 0 & 0 & 0 & 0 & 2 & 0 & 2 & 0,0 \\
\hline Sub total 1 & 1989 & 1409 & 1521 & 829 & 4242 & 6384 & 397 & 697 & 1242 & 1928 & 4746 & 947 & 26326 & 97,0 \\
\hline
\end{tabular}


Continuação da Tabela 1.

\begin{tabular}{|c|c|c|c|c|c|c|c|c|c|c|c|c|c|c|}
\hline Gênero\ Recipiente & $\begin{array}{r}\text { Caixa } \\
\text { D'água } \\
\end{array}$ & Cimento & Fibra & Louça & Metal & Plástico & $\begin{array}{l}\text { Planta } \\
\text { Aquát. }\end{array}$ & Pneu & Ralo & $\begin{array}{l}\text { Vaso } \\
\text { Prato } \\
\end{array}$ & Natural & Outros & Total & $\%$ \\
\hline$C x$. gr. imitator & 0 & 0 & 0 & 0 & 1 & 26 & 0 & 0 & 0 & 0 & 230 & 0 & 257 & 0,9 \\
\hline Aedes sp & 15 & 0 & 0 & 3 & 0 & 9 & 4 & 0 & 5 & 0 & 122 & 0 & 158 & 0,6 \\
\hline$C x$. gr. coronator & 8 & 2 & 9 & 0 & 22 & 41 & 0 & 3 & 0 & 0 & 26 & 0 & 111 & 0,4 \\
\hline$C x$. próx. mollis & 0 & 0 & 0 & 0 & 20 & 0 & 0 & 0 & 0 & 0 & 37 & 19 & 76 & 0,3 \\
\hline Cx. próx. declarator & 2 & 18 & 0 & 1 & 8 & 11 & 0 & 0 & 0 & 14 & 16 & 0 & 70 & 0,3 \\
\hline$C x .(C u x.) \mathrm{sp}$ & 2 & 4 & 0 & 0 & 2 & 0 & 0 & 0 & 0 & 0 & 85 & 0 & 93 & 0,3 \\
\hline Anopheles sp & 0 & 0 & 0 & 0 & 1 & 17 & 0 & 0 & 0 & 1 & 0 & 0 & 19 & 0,1 \\
\hline$C x$. gr.pilosus & 0 & 0 & 0 & 0 & 0 & 0 & 0 & 0 & 0 & 0 & 2 & 0 & 2 & 0,0 \\
\hline Limatus sp & 0 & 0 & 0 & 0 & 10 & 0 & 0 & 0 & 0 & 0 & 0 & 0 & 10 & 0,0 \\
\hline Toxorhynchites sp & 0 & 0 & 0 & 0 & 0 & 2 & 0 & 0 & 0 & 1 & 10 & 0 & 13 & 0,0 \\
\hline Sub total 2 & 27 & 24 & 9 & 4 & 64 & 106 & 4 & 3 & 5 & 16 & 528 & 19 & 809 & 3,0 \\
\hline Total & 2016 & 1433 & 1530 & 828 & 4306 & 6490 & 401 & 700 & 1247 & 1944 & 5274 & 966 & 27135 & 100,0 \\
\hline
\end{tabular}




\section{2 - Descrição dos imóveis e recipientes positivos}

Os resultados e análises que serão apresentados a seguir destacarão apenas Ae. aegypti e Ae. albopictus.

\subsection{1 - Imóveis}

Foram pesquisados 5.566 imóveis no período, sendo que em 803 $(14,4 \%)$ foi registrada a presença de imaturos de culicídeos.

Do total de imóveis com presença de culicídeos em $42,1 \%$ registrouse a presença de Ae. aegypti, em 18,7\% Ae. albopictus, 17,8\% em situação de coexistência das duas espécies e em $21,4 \%$ com outras espécies.

O tipo "casa", que são as residências térreas e assobradadas, abrigou $85,1 \%$ do total de culicídeos encontrados. Nesta categoria de imóvel, também foram registrados os maiores percentuais de Ae. aegypti (77,5\%), Ae. albopictus $(95,3 \%) \mathrm{e}$ quando estas estavam em situação de coexistência $(89,5 \%)$ do total de exemplares coletados.

Dos 18 tipos, apenas seis foram responsáveis por 93\% dos imóveis positivos para Ae. aegypti, casa, outros, apartamento, hotel/pousada, garagem e hospitais/unidades de saúde e clínicas.

A categoria "outros", onde foram incluídas as marinas, garagens de barcos, foi o segundo tipo de imóvel com maior freqüência de Ae. aegypti.

Quatro tipos foram responsáveis por $98 \%$ dos imóveis positivos para Ae. albopictus, casa, comércio, construção e hotel/pousada.

Do total de imóveis com culicídeos, em 59,9\% e 36,5\% foi registrada a presença de Ae. aegypti e Ae. albopictus respectivamente (Tabela 2). 
Tabela 2 - Distribuição do $\mathrm{n}^{\circ} \mathrm{e} \%$ de Imóveis com presença de culicídeos, Ae. aegypti, Ae. albopictus, com as duas espécies e outras espécies de culicídeos, no período de 10/2002 a 04/2003 e 10/2003 e 04/2004, em São Sebastião, SP, Brasil

\begin{tabular}{|c|c|c|c|c|c|c|c|c|c|c|}
\hline Tipo de Imóvel & $\begin{array}{c}\text { Imóveis } \\
\text { c/culicídeos }\end{array}$ & $\begin{array}{c}\% \\
\text { Total } \\
\end{array}$ & $\begin{array}{l}\text { Só Ae. } \\
\text { aegypti }\end{array}$ & $\begin{array}{l}\% \text { Ae. } \\
\text { aegypti }\end{array}$ & $\begin{array}{c}\text { Só Ae. } \\
\text { albopictus }\end{array}$ & $\begin{array}{c}\% \text { Ae. } \\
\text { albopictus }\end{array}$ & $\begin{array}{l}\mathrm{C} / \text { Ambas } \\
\text { espécies }\end{array}$ & $\begin{array}{c}\% \\
\text { Amb } \\
\end{array}$ & $\begin{array}{l}\text { c/outras } \\
\text { espécies }\end{array}$ & $\begin{array}{c}\% \\
\text { outras } \\
\end{array}$ \\
\hline Casa & 683 & 85,1 & 262 & 77,5 & 143 & 95,3 & 128 & 89,5 & 150 & 87,2 \\
\hline Outros ${ }^{\star}$ & 28 & 3,5 & 18 & 5,3 & 1 & 0,7 & 4 & 2,8 & 5 & 2,9 \\
\hline Comércio & 22 & 2,7 & 17 & 5,0 & 2 & 1,3 & 1 & 0,7 & 2 & 1,2 \\
\hline Apartamento & 14 & 1,7 & 13 & 3,8 & 0 & 0,0 & 1 & 0,7 & 0 & 0,0 \\
\hline Hotel/Pousada & 10 & 1,2 & 6 & 1,8 & 1 & 0,7 & 2 & 1,4 & 1 & 0,6 \\
\hline Garagem & 7 & 0,9 & 1 & 0,3 & 0 & 0,0 & 3 & 2,1 & 3 & 1,7 \\
\hline Construção & 7 & 0,9 & 1 & 0,3 & 2 & 1,3 & 1 & 0,7 & 3 & 1,7 \\
\hline Oficina & 5 & 0,6 & 3 & 0,9 & 1 & 0,7 & 1 & 0,7 & 0 & 0,0 \\
\hline Escola/Creche & 5 & 0,6 & 3 & 0,9 & 0 & 0,0 & 0 & 0,0 & 2 & 1,2 \\
\hline Posto Combustível & 4 & 0,5 & 1 & 0,3 & 0 & 0,0 & 0 & 0,0 & 3 & 1,7 \\
\hline Hospital/Unidade Saúde & 4 & 0,5 & 4 & 1,2 & 0 & 0,0 & 0 & 0,0 & 0 & 0,0 \\
\hline Quartel & 4 & 0,5 & 3 & 0,9 & 0 & 0,0 & 0 & 0,0 & 1 & 0,6 \\
\hline Loja de Construção & 3 & 0,4 & 2 & 0,6 & 0 & 0,0 & 1 & 0,7 & 0 & 0,0 \\
\hline Ferro Velho/Desmanche & 2 & 0,2 & 2 & 0,6 & 0 & 0,0 & 0 & 0,0 & 0 & 0,0 \\
\hline Depósito de Containers & 2 & 0,2 & 1 & 0,3 & 0 & 0,0 & 0 & 0,0 & 1 & 0,6 \\
\hline Borracharia & 1 & 0,1 & 0 & 0,0 & 0 & 0,0 & 0 & 0,0 & 1 & 0,6 \\
\hline Indústria & 1 & 0,1 & 1 & 0,3 & 0 & 0,0 & 0 & 0,0 & 0 & 0,0 \\
\hline Clube & 1 & 0,1 & 0 & 0,0 & 0 & 0,0 & 1 & 0,7 & 0 & 0,0 \\
\hline TOTAL & 803 & 100,0 & 338 & 100,0 & 150 & 100,0 & 143 & 100,0 & 172 & 100,0 \\
\hline$\%$ & - & - & 42,1 & - & 18,7 & - & 17,8 & - & 21,4 & \\
\hline$\%$ Total da espécie & - & - & 59,9 & - & 36,5 & - & - & - & - & \\
\hline
\end{tabular}

*Inclusive as marinas $(n=6)$ - Responsáveis por grande número de recipientes positivos 


\subsection{2 - Recipientes}

No período do estudo foi registrada a presença de 26.914 recipientes no ambiente. Deste total, 59\% estavam com água e, portanto, foram alvos de inspeção. Em 1.642 recipientes havia larvas e ou pupas de culicídeos (Tabela 3).

Tabela 3- Distribuição mensal do $\mathrm{n}^{\circ} \mathrm{e} \%$ de recipientes existentes, pesquisados e com presença de culicídeos no período de 10/2002 a 04/2003 e 10/2003 e 04/2004, em S.Sebastião, SP, Brasil.

\begin{tabular}{lccccr}
\hline & \multicolumn{5}{c}{ Recipientes } \\
\cline { 2 - 6 } \multicolumn{1}{c}{ Mês } & Existentes & Pesquisados & $\%$ & Com culicídeos & \multicolumn{1}{c}{$\%$} \\
\hline Outubro & 2845 & 1461 & 51,4 & 31 & 2,1 \\
Novembro & 1585 & 1111 & 70,1 & 103 & 9,3 \\
Dezembro & 1745 & 1124 & 64,4 & 125 & 11,1 \\
Janeiro & 1306 & 442 & 33,8 & 163 & 36,9 \\
Fevereiro & 1777 & 1024 & 57,6 & 128 & 12,5 \\
Março & 1964 & 1391 & 70,8 & 130 & 9,3 \\
Abril & 1817 & 972 & 53,5 & 141 & 14,5 \\
Outubro & 1689 & 812 & 48,1 & 56 & 6,9 \\
Novembro & 2226 & 1259 & 56,6 & 98 & 7,8 \\
Dezembro & 2093 & 1401 & 66,9 & 128 & 9,1 \\
Janeiro & 2518 & 1099 & 43,6 & 123 & 11,2 \\
Fevereiro & 2129 & 1436 & 67,4 & 103 & 7,2 \\
Março & 1583 & 1181 & 74,6 & 157 & 13,3 \\
Abril & 1637 & 1151 & 70,3 & 156 & 13,6 \\
\hline \multicolumn{1}{c}{ Total } & 26914 & 15864 & 58,9 & 1642 & 10,4 \\
\hline
\end{tabular}

Na Figura 2, observamos que a proporção de recipientes com as duas espécies estudadas foi em média $70 \%$ do total de recipientes com culicídeos ao longo dos meses, evidenciando a densidade delas em relação aos demais culicídeos. 


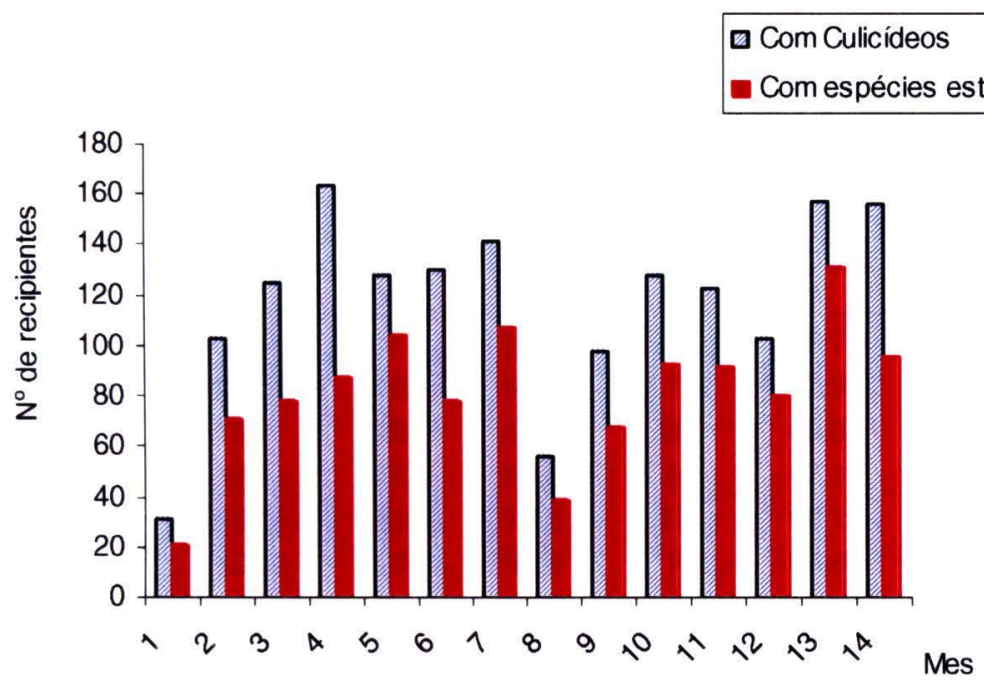

Figura 2 - Distribuição mensal do $\mathrm{n}^{\circ}$ de recipientes com culicídeos e a proporção com as espécies estudadas.

Nas tabelas 4 e 5 observa-se que as Ae. aegypti e Ae. albopictus foram encontradas isoladamente em $70,3 \%$ e $41,1 \%$ dos recipientes; as duas espécies em coexistência em $15,2 \%$ e $23 \%$, estavam com outras espécies de culicídeos em $14,5 \%$ e $35,9 \%$ e presentes em $48,6 \%$ e $32,1 \%$ do total de recipientes positivos para culicídeos respectivamente.

$\mathrm{Na}$ figura 3, nota-se a tendência de queda do número de recipientes com Ae. albopictus isoladamente, aumento dos positivos para Ae. aegypti e valores baixos, no entanto constantes ao longo do período do estudo, para os recipientes com ambas as espécies. 
Tabela 4 - Distribuição mensal do $\mathrm{n}^{0}$ de recipientes com presença de Ae. aegypti, coexistindo com Ae. albopictus e com outros culicídeos, no período de 10/2002 a 04/2003 e 10/2003 e 04/2004, em São Sebastião, SP, Brasil.

\begin{tabular}{|c|c|c|c|c|c|c|c|c|c|}
\hline \multirow[t]{2}{*}{ Mês } & \multirow{2}{*}{$\begin{array}{c}\begin{array}{c}\text { Total } \\
\text { culicídeos }\end{array} \\
\mathrm{N}^{\circ} \\
\end{array}$} & \multicolumn{2}{|c|}{$\begin{array}{c}\text { Ae. } \\
\text { aegypti }\end{array}$} & \multicolumn{2}{|c|}{$\begin{array}{c}\text { ambas } \\
\text { espécies }\end{array}$} & \multicolumn{2}{|c|}{$\begin{array}{l}\text { Ae. aeg. } \\
\text { c/ outros }\end{array}$} & \multicolumn{2}{|c|}{$\begin{array}{c}\text { Total } \\
\text { Ae. aegypti }\end{array}$} \\
\hline & & $\mathrm{N}^{\circ}$ & $\%$ & $\mathrm{~N}^{\circ}$ & $\%$ & $\mathrm{~N}^{\circ}$ & $\%$ & $\mathrm{~N}^{\circ}$ & $\%$ \\
\hline Outubro & 31 & 9 & 50,0 & 3 & 16,7 & 6 & 33,3 & 18 & 100,0 \\
\hline Novembro & 103 & 25 & 64,1 & 7 & 17,9 & 7 & 17,9 & 39 & 100,0 \\
\hline Dezembro & 125 & 28 & 56,0 & 20 & 40,0 & 2 & 4,0 & 50 & 100,0 \\
\hline Janeiro & 163 & 24 & 68,6 & 6 & 17,1 & 5 & 14,3 & 35 & 100,0 \\
\hline Fevereiro & 128 & 53 & 73,6 & 13 & 18,1 & 6 & 8,3 & 72 & 100,0 \\
\hline Março & 130 & 29 & 64,4 & 7 & 15,6 & 9 & 20,0 & 45 & 100,0 \\
\hline Abril & 141 & 54 & 77,1 & 11 & 15,7 & 5 & 7,1 & 70 & 100,0 \\
\hline Outubro & 56 & 16 & 57,1 & 3 & 10,7 & 9 & 32,1 & 28 & 100,0 \\
\hline Novembro & 98 & 41 & 75,9 & 10 & 18,5 & 3 & 5,6 & 54 & 100,0 \\
\hline Dezembro & 128 & 45 & 72,6 & 9 & 14,5 & 8 & 12,9 & 62 & 100,0 \\
\hline Janeiro & 123 & 48 & 71,6 & 10 & 14,9 & 9 & 13,4 & 67 & 100,0 \\
\hline Fevereiro & 103 & 47 & 75,8 & 6 & 9,7 & 9 & 14,5 & 62 & 100,0 \\
\hline Março & 157 & 89 & 79,5 & 7 & 6,3 & 16 & 14,3 & 112 & 100,0 \\
\hline Abril & 156 & 53 & 63,1 & 9 & 10,7 & 22 & 26,2 & 84 & 100,0 \\
\hline Total & 1642 & 561 & & 121 & & 116 & & 798 & \\
\hline $\begin{array}{c}\% \text { total da } \\
\text { espécie }\end{array}$ & & 70,3 & & 15,2 & & 14,5 & & & \\
\hline
\end{tabular}

Tabela 5 - Distribuição mensal do $\mathrm{n}^{\circ}$ de recipientes com presença de Ae. albopictus, coexistindo com Ae. aegypti e com outros culicídeos, no período de 10/2002 a 04/2003 e 10/2003 e 04/2004, em São Sebastião, SP, Brasil.

\begin{tabular}{|c|c|c|c|c|c|c|c|c|c|}
\hline \multirow[t]{2}{*}{ Mês } & \multirow{2}{*}{$\begin{array}{c}\begin{array}{c}\text { Tt com } \\
\text { culicídeos }\end{array} \\
N^{\circ}\end{array}$} & \multicolumn{2}{|c|}{$\begin{array}{c}\text { Ae. } \\
\text { albopictus }\end{array}$} & \multicolumn{2}{|c|}{$\begin{array}{c}\text { ambas } \\
\text { espécies }\end{array}$} & \multicolumn{2}{|c|}{$\begin{array}{l}\text { Ae. alb. } \\
\text { c/ outros }\end{array}$} & \multicolumn{2}{|c|}{$\begin{array}{c}\text { Total } \\
\text { Ae. albopictus }\end{array}$} \\
\hline & & $\mathrm{N}^{\circ}$ & $\%$ & $\mathrm{~N}^{\circ}$ & $\%$ & $\mathrm{~N}^{\circ}$ & $\%$ & $\mathrm{~N}^{\circ}$ & $\%$ \\
\hline Outubro & 31 & 4 & 50,0 & 3 & 37,5 & 1 & 12,5 & 8 & 100,0 \\
\hline Novembro & 103 & 19 & 45,2 & 7 & 16,7 & 16 & 38,1 & 42 & 100,0 \\
\hline Dezembro & 125 & 20 & 40,0 & 20 & 40,0 & 10 & 20,0 & 50 & 100,0 \\
\hline Janeiro & 163 & 30 & 43,5 & 6 & 8,7 & 33 & 47,8 & 69 & 100,0 \\
\hline Fevereiro & 128 & 21 & 42,9 & 13 & 26,5 & 15 & 30,6 & 49 & 100,0 \\
\hline Março & 130 & 25 & 58,1 & 7 & 16,3 & 11 & 25,6 & 43 & 100,0 \\
\hline Abril & 141 & 17 & 30,9 & 11 & 20,0 & 27 & 49,1 & 55 & 100,0 \\
\hline Outubro & 56 & 5 & 38,5 & 3 & 23,1 & 5 & 38,5 & 13 & 100,0 \\
\hline Novembro & 98 & 14 & 48,3 & 10 & 34,5 & 5 & 17,2 & 29 & 100,0 \\
\hline Dezembro & 128 & 16 & 37,2 & 9 & 20,9 & 18 & 41,9 & 43 & 100,0 \\
\hline Janeiro & 123 & 12 & 31,6 & 10 & 26,3 & 16 & 42,1 & 38 & 100,0 \\
\hline Fevereiro & 103 & 12 & 41,4 & 6 & 20,7 & 11 & 37,9 & 29 & 100,0 \\
\hline Março & 157 & 16 & 47,1 & 7 & 20,6 & 11 & 32,4 & 34 & 100,0 \\
\hline Abril & 156 & 6 & 24,0 & 9 & 36,0 & 10 & 40,0 & 25 & 100,0 \\
\hline Total & 1642 & 217 & & 121 & & 189 & & 527 & \\
\hline $\begin{array}{c}\text { \% total da } \\
\text { espécie }\end{array}$ & & 41,1 & & 23,0 & & 35,9 & & & \\
\hline
\end{tabular}




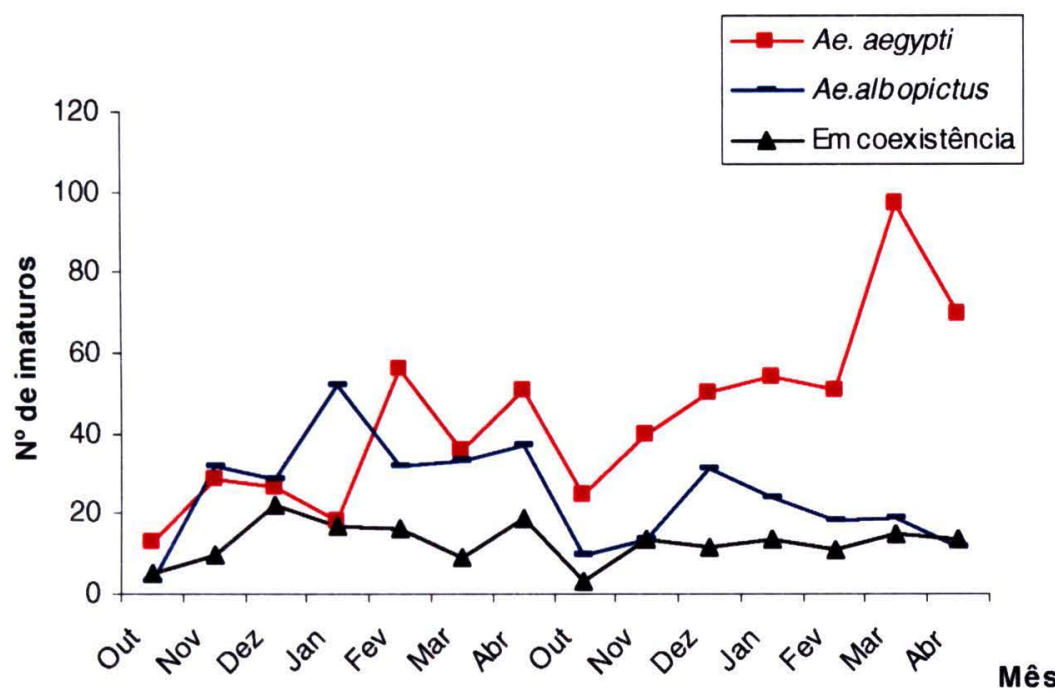

Figura 3 - Distribuição mensal do número de recipientes positivos para Ae. aegypti, Ae. albopictus e em situação de coexistência no período de 10/2002 a 04/2003 e 10/2003 e 04/2004, em São Sebastião, SP, Brasil. 
4.3 - Abundância e produtividade de larvas e pupas de Ae. aegypti e Ae. albopictus em recipientes fixos e removíveis segundo a categoria

\subsection{1 - Recipientes contendo Ae. aegypti}

A tabela 6 apresenta a análise descritiva da freqüência de larvas e pupas por categoria.

Os maiores percentuais de positividade foram nas categorias: plástico $(23,8 \%)$, metais $(12,9 \%)$, vaso/prato de planta $(11 \%)$ e a natural $(13,8 \%)$. A categoria "natural", em sua grande maioria, foi composta por bromélias fixas.

O percentual de exemplares em relação ao total coletado também foi maior nos recipientes removíveis; o plástico e o metal foram os que mais se destacaram tanto para larvas $(26,3 \%$ e $18,1 \%)$ quanto para pupas $(21,5$ e $32,9 \%)$. A fibra, que foi considerada como recipiente fixo e onde os barcos foram em maior número, passa a ter maiores percentuais para larvas $(11,3 \%)$ e pupas $(12,6 \%)$. E o natural apresentou menores percentuais para larvas e pupas.

Quando consideramos a média de exemplares na categoria, a fibra tem sua importância acentuada (17lv/rec. e 4,6 pp/rec.), o metal e o plástico continuam sendo mais representativos para larvas. Enquanto para pupas, o metal e a fibra permanecem com percentual mais alto, a categoria cimento $(5,7 \mathrm{pp} / \mathrm{rec}$.) aparece com maior média que plástico .

Do total de recipientes positivos, 55,6\% foram aqueles classificados como removíveis.

A figura 4 ilustra um crescimento do número de imaturos ao longo dos meses pesquisados; nota-se que há um pico no final do período, para a maior parte das categorias. 
Tabela 6 - Distribuição do $\mathrm{n}^{\circ}$, \% e média de larvas e pupas de Ae. aegypti em recipientes fixos e removíveis segundo categoria, no período de 10/2002 a 04/2003 e 10/2003 e 04/2004, em São Sebastião, SP, Brasil.

\begin{tabular}{|c|c|c|c|c|c|c|c|c|c|}
\hline \multirow[b]{2}{*}{ CATEGORIA } & \multicolumn{2}{|c|}{ Recipiente } & \multicolumn{3}{|c|}{ Larvas } & \multicolumn{3}{|c|}{ Pupas } & \multirow{2}{*}{$\begin{array}{c}\text { Total } \\
\text { Imaturos }\end{array}$} \\
\hline & $\mathrm{N}^{\circ}$ & $\%$ & $\mathrm{~N}^{\circ}$ & $\%$ & $\begin{array}{c}\text { Méd } \\
\text { Lv/Rec }\end{array}$ & $\mathrm{N}^{\circ}$ & $\%$ & $\begin{array}{c}\text { Méd } \\
\text { Pp/Rec }\end{array}$ & \\
\hline \multicolumn{10}{|l|}{ Fixos } \\
\hline Cx. d'água & 52 & 6,5 & 527 & 5,5 & 10,1 & 62 & 2,7 & 1,2 & 589 \\
\hline Cimento & 29 & 3,6 & 305 & 3,2 & 10,5 & 166 & 7,1 & 5,7 & 471 \\
\hline Fibra & 64 & 8,0 & 1089 & 11,3 & 17,0 & 292 & 12,6 & 4,6 & 1381 \\
\hline Louça/cerâmica & 48 & 6,0 & 353 & 3,7 & 7,4 & 41 & 1,8 & 0,9 & 394 \\
\hline Ralo & 51 & 6,4 & 547 & 5,7 & 10,7 & 148 & 6,4 & 2,9 & 695 \\
\hline Natural & 110 & 13,8 & 691 & 7,2 & 6,3 & 92 & 4,0 & 0,8 & 783 \\
\hline Subtotal 1 & 354 & 44,4 & 3512 & 36,5 & 9,9 & 801 & 34,5 & 2,3 & 4313 \\
\hline \multicolumn{10}{|l|}{ Removíveis } \\
\hline Metal & 103 & 12,9 & 1742 & 18,1 & 16,9 & 764 & 32,9 & 7,4 & 2506 \\
\hline Plástico & 190 & 23,8 & 2529 & 26,3 & 13,3 & 499 & 21,5 & 2,6 & 3028 \\
\hline Planta aquática & 20 & 2,5 & 228 & 2,4 & 11,4 & 23 & 1,0 & 1,2 & 251 \\
\hline Pneu & 25 & 3,1 & 272 & 2,8 & 10,9 & 45 & 1,9 & 1,8 & 317 \\
\hline Vaso/prato planta & 88 & 11,0 & 1108 & 11,5 & 12,6 & 148 & 6,4 & 1,7 & 1256 \\
\hline Vidro & 16 & 2,0 & 194 & 2,0 & 12,1 & 20 & 0,9 & 1,3 & 214 \\
\hline Outros & 02 & 0,3 & 47 & 0,5 & 23,5 & 23 & 1,0 & 11,5 & 70 \\
\hline Subtotal 2 & 444 & 55,6 & 6120 & 63,5 & 13,8 & 1522 & 65,5 & 3,4 & 7642 \\
\hline Total & 798 & 100 & 9632 & 100 & 12,1 & 2323 & 100 & 2,9 & 11955 \\
\hline
\end{tabular}


Figura 4 - Distribuição mensal do $\mathrm{n}^{\circ}$ de imaturos de Ae. aegypti por recipiente segundo categoria, em São Sebastião, São Paulo no período de 10/2002 a 04/2003 e de $10 / 2003$ a $04 / 2004$.
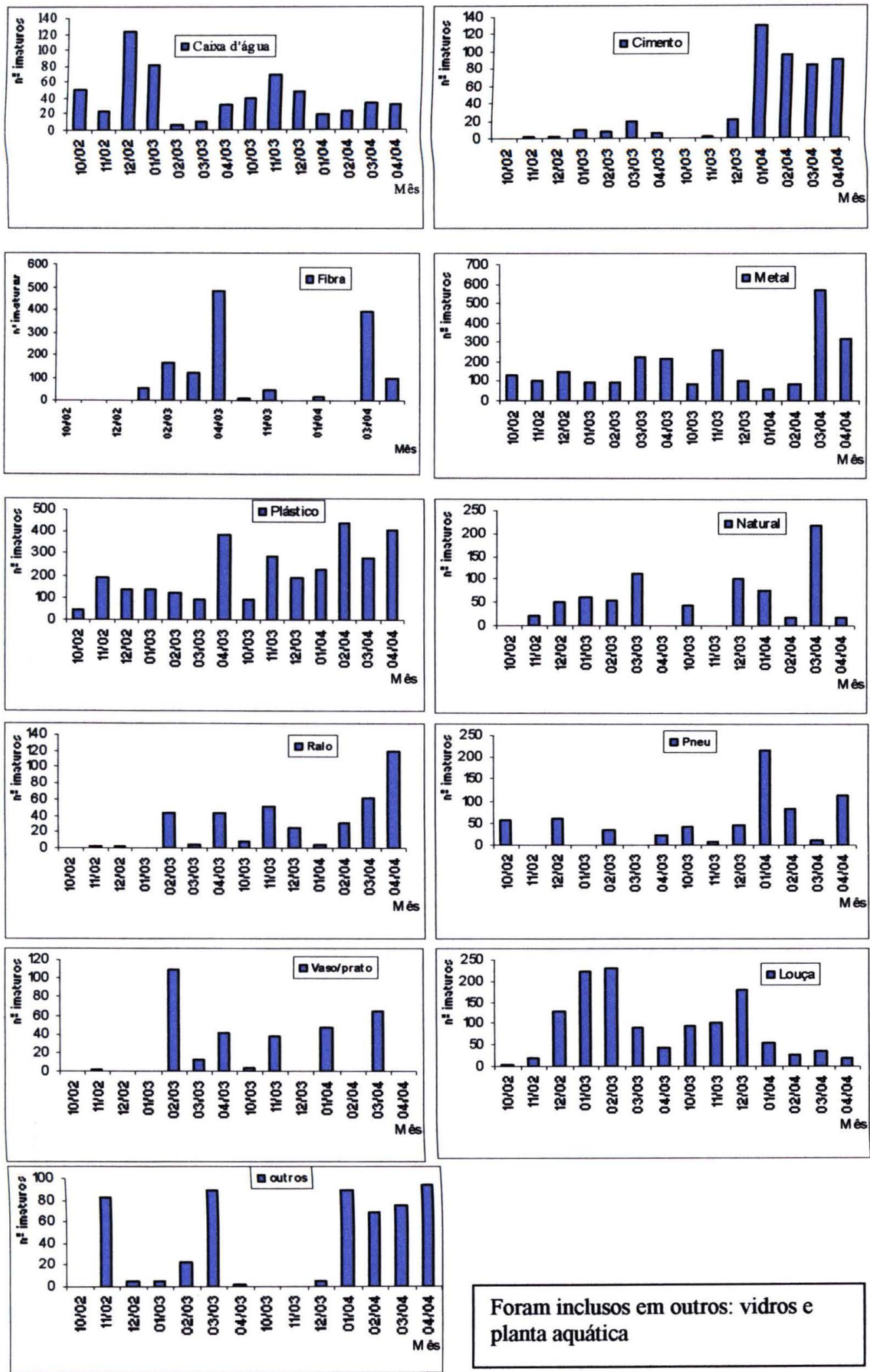

Foram inclusos em outros: vidros e planta aquática 
A tabela 7 apresenta as diferenças na produção média de larvas de Aedes aegypti entre os recipientes segundo categoria $(\mathrm{n}=798 ; \mathrm{H}=83,42 ; \mathrm{gl}=12$ e $\mathrm{p}<0,0001)$. Observa-se na Figura 5 os recipientes que em média produziram mais larvas: metal e plástico.

Para a produção média de pupas de Aedes aegypti também houve diferença com significância estatística entre os recipientes $(\mathrm{n}=301 ; \mathrm{H}=48,84 ; \mathrm{gl}=$ 12 e $\mathrm{p}<0,000$ ) destaca-se também os da categoria metal e plástico (Tabela 8 e Figura 6).

Tabela 7 - Comparação entre a produção média de larvas de Aedes aegypti segundo a categoria do recipiente, em São Sebastião, São Paulo, Brasil, no período de 10/2002 a $04 / 2003$ e de $10 / 2003$ a 042004.

\begin{tabular}{|c|c|}
\hline Kruskal - Wallis $-\mathrm{H}=83,42$ & $p<0,0001(n=798)$ \\
\hline \multicolumn{2}{|c|}{ Comparações entre grupos: Teste de Dwass - Steel - Chritchlow - Flingner $(\alpha<0,05)$} \\
\hline Metal X Caixa d'água & $p=0,011$ \\
\hline Metal X Cimento & $p=0,002$ \\
\hline Metal X Louça & $p=0,004$ \\
\hline Metal X Planta & $p=0,001$ \\
\hline Metal X Ralo & $p=0,040$ \\
\hline Metal X Pneu & $p=0,003$ \\
\hline Metal X Vidro & $p=0,001$ \\
\hline Metal X Outros & $p=0,000$ \\
\hline Plástico X Caixa d'água & $p=0,002$ \\
\hline Plástico X Cimento & $p=0,002$ \\
\hline Plástico X Louça & $p=0,002$ \\
\hline Plástico X Natural & $p=0,017$ \\
\hline Plástico X Planta & $p=0,001$ \\
\hline Plástico X Ralo & $p=0,007$ \\
\hline Plástico X Pneu & $p=0,001$ \\
\hline Plástico X Vidro & $p=0,001$ \\
\hline Plástico X Outros & $p=0,000$ \\
\hline
\end{tabular}

* Apenas os resultados com significância estatística. 


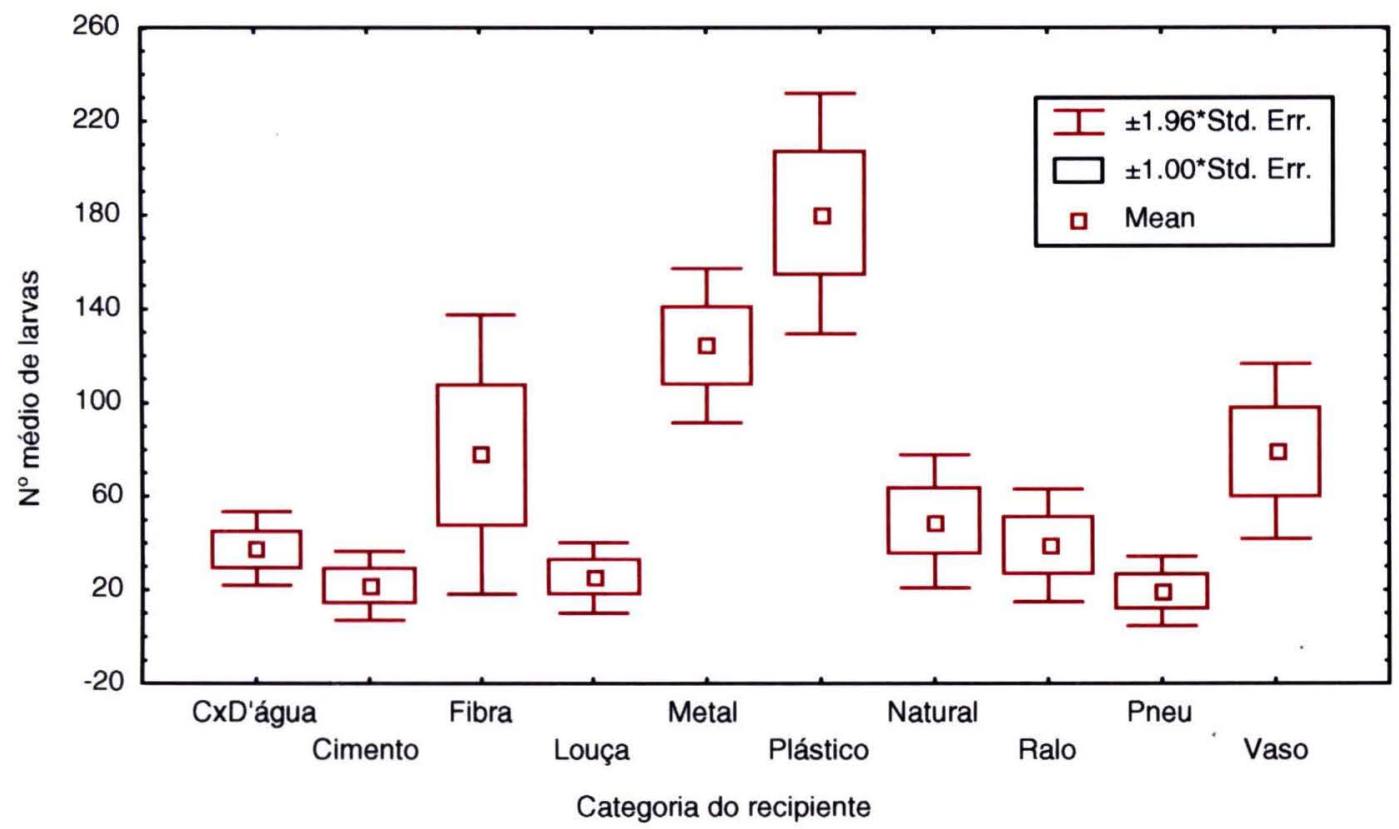

Figura 5 - Produção de larvas de Aedes aegypti segundo categoria do recipiente em São Sebastião, São Paulo, Brasil, no período de 10/2002 a 04/2003 e de 10/2003 a $04 / 2004$.

Tabela 8 - Comparação entre a produção média de pupas de Aedes aegypti segundo categoria do recipiente, em São Sebastião, São Paulo, Brasil, no período de 10/2002 a $04 / 2003$ e de $10 / 2003$ a 04/2004.

Kruskal - Wallis $-\mathrm{H}=48,84 \quad \mathrm{p}<0,0001(n=301)$

Comparações entre grupos: Teste de Dwass - Steel - Chritchlow - Flingner $(\alpha<0,05)$

Metal X Louça

Metal X Planta

Metal X Pneu

Metal X Vidro

Metal X Outros

Plástico X Louça

Plástico X Planta

Plástico X Pneu

Plástico X Vidro

Plástico X Outros

$$
p=0,018
$$$$
p=0,007
$$$$
p=0,013
$$$$
p=0,007
$$$$
p=0,002
$$$$
p=0,023
$$$$
p=0,006
$$$$
p=0,014
$$$$
p=0,005
$$

$p=0,001$

* Apenas os resultados com significância estatística. 


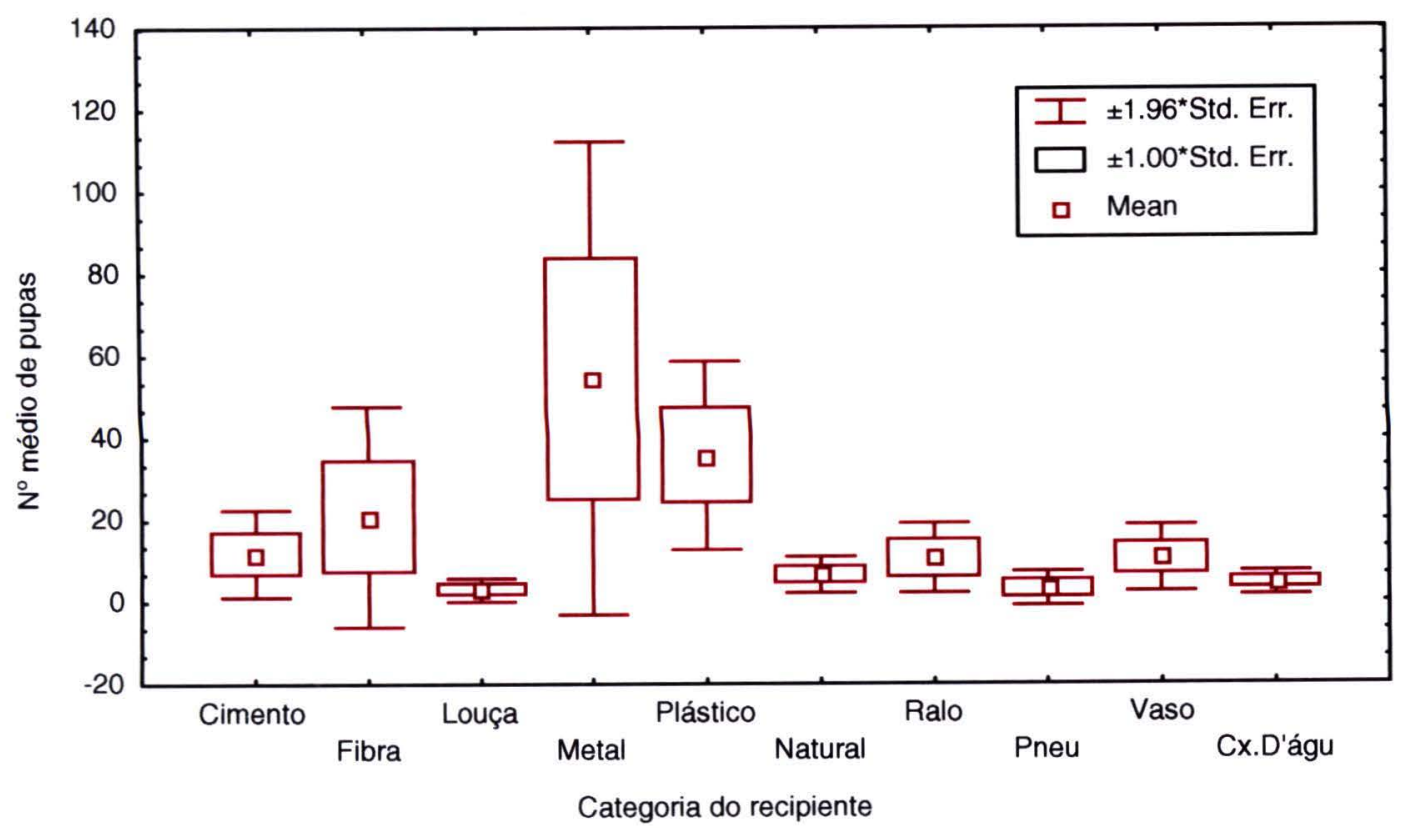

Figura 6 - Produção de pupas de Aedes aegypti segundo categoria do recipiente em São Sebastião, São Paulo, Brasil, no período de 10/2002 a 04/2003 e de 10/2003 a 04/2004.

\subsection{2 - Recipientes contendo Ae. albopictus}

No que se refere à espécie Ae. albopictus (Tabela 9), a positividade de recipientes foi maior nas categorias natural $(30,7 \%)$, plástico $(25,4 \%)$ e metal $(12,1 \%)$. Os recipientes com maiores percentuais de larvas e pupas em relação ao total coletado foram: plástico $(30,1 \%$ e $34,9 \%)$, natural $(21,3$ e $19,9 \%)$ e metal (17,3 e $11 \%)$. Quando observamos as médias de larvas por recipiente, a maior média foi observada em metais (10,7 lv/rec.), e os pneus (10,6 lv/rec.) passam a ter maior representatividade; o plástico perde importância em relação $(8,9 \mathrm{lv} / \mathrm{rec}$.) a caixa d' água $(9,2 \mathrm{lv} / \mathrm{rec}$.). As pupas têm nas categorias fibra $(5,6 \mathrm{pp} / \mathrm{rec}$.) e pneus $(3,6$ $\mathrm{pp} / \mathrm{rec}$.) maiores médias que os plásticos e metais. Do total de recipientes positivos a grande maioria $(56,5 \%)$ também foi classificada como "removíveis". A distribuição do número de recipientes positivos por categoria, diferentemente de Ae. aegypti, apresentou tendência de decréscimo no número de recipientes, embora apresente pico 
em pelo menos um mês no final do período, para maior parte das categorias (Figura $6)$.

Tabela 9 - Distribuição do no, \% e média de larvas e pupas de Ae. albopictus em recipientes fixos e removíveis segundo categoria, no período de 10/2002 a 04/2003 e 10/2003 e 04/2004, em São Sebastião, SP, Brasil.

\begin{tabular}{|c|c|c|c|c|c|c|c|c|c|}
\hline \multirow[b]{2}{*}{$\begin{array}{c}\text { CATEGORIA } \\
\text { Fixos } \\
\end{array}$} & \multicolumn{2}{|c|}{ Recipientes } & \multicolumn{3}{|c|}{ Larvas } & \multicolumn{3}{|c|}{ Pupas } & \multirow{2}{*}{$\begin{array}{l}\text { Total } \\
\text { Imaturos }\end{array}$} \\
\hline & $\mathrm{N}^{\circ}$ & $\%$ & $\mathrm{~N}^{\circ}$ & $\%$ & $\begin{array}{c}\text { Méd } \\
\text { Lv/Rec }\end{array}$ & $\mathrm{N}^{\circ}$ & $\%$ & $\begin{array}{c}\text { Méd } \\
\text { Pp/Rec }\end{array}$ & \\
\hline Caixa d'água & 22 & 4,2 & 202 & 5,1 & 9,2 & 12 & 1,6 & 0,5 & 214 \\
\hline Cimento & 9 & 1,7 & 65 & 1,6 & 7,2 & 16 & 2,1 & 1,8 & 81 \\
\hline Fibra & 7 & 1,3 & 44 & 1,1 & 6,3 & 39 & 5,1 & 5,6 & 83 \\
\hline Louça & 21 & 4,0 & 160 & 4,0 & 7,6 & 22 & 2,9 & 1,0 & 182 \\
\hline Natural & 162 & 30,7 & 845 & 21,3 & 5,2 & 152 & 19,9 & 0,9 & 997 \\
\hline Ralo & 8 & 1,5 & 25 & 0,6 & 3,1 & 12 & 1,6 & 1,5 & 37 \\
\hline Sub-Total 1 & 229 & 43,5 & 1341 & 33,8 & 5,9 & 253 & 33,1 & 1,1 & 1594 \\
\hline \multicolumn{10}{|l|}{ Removíveis } \\
\hline Metal & 64 & 12,1 & 686 & 17,3 & 10,7 & 84 & 11,0 & 1,3 & 770 \\
\hline Plástico & 134 & 25,4 & 1195 & 30,1 & 8,9 & 267 & 34,9 & 2,0 & 1462 \\
\hline Pneu & 16 & 3,0 & 170 & 4,3 & 10,6 & 57 & 7,5 & 3,6 & 227 \\
\hline Vaso/prato planta & 54 & 10,2 & 383 & 9,6 & 7,1 & 86 & 11,3 & 1,6 & 469 \\
\hline Outros & 30 & 5,7 & 196 & 4,9 & 6,5 & 17 & 2,2 & 0,6 & 213 \\
\hline Sub-Total 2 & 298 & 56,5 & 2630 & 66,2 & 8,8 & 511 & 66,9 & 1,7 & 3141 \\
\hline Total & 527 & 100 & 3971 & 100 & 7,5 & 764 & 100 & 1,4 & 4735 \\
\hline
\end{tabular}


Figura 7 - Número de exemplares de Ae. albopictus por recipiente segundo categoria e mês em São Sebastião, São Paulo no período de 10/2002 a 04/2003 e de 10/2003 a $04 / 2004$.
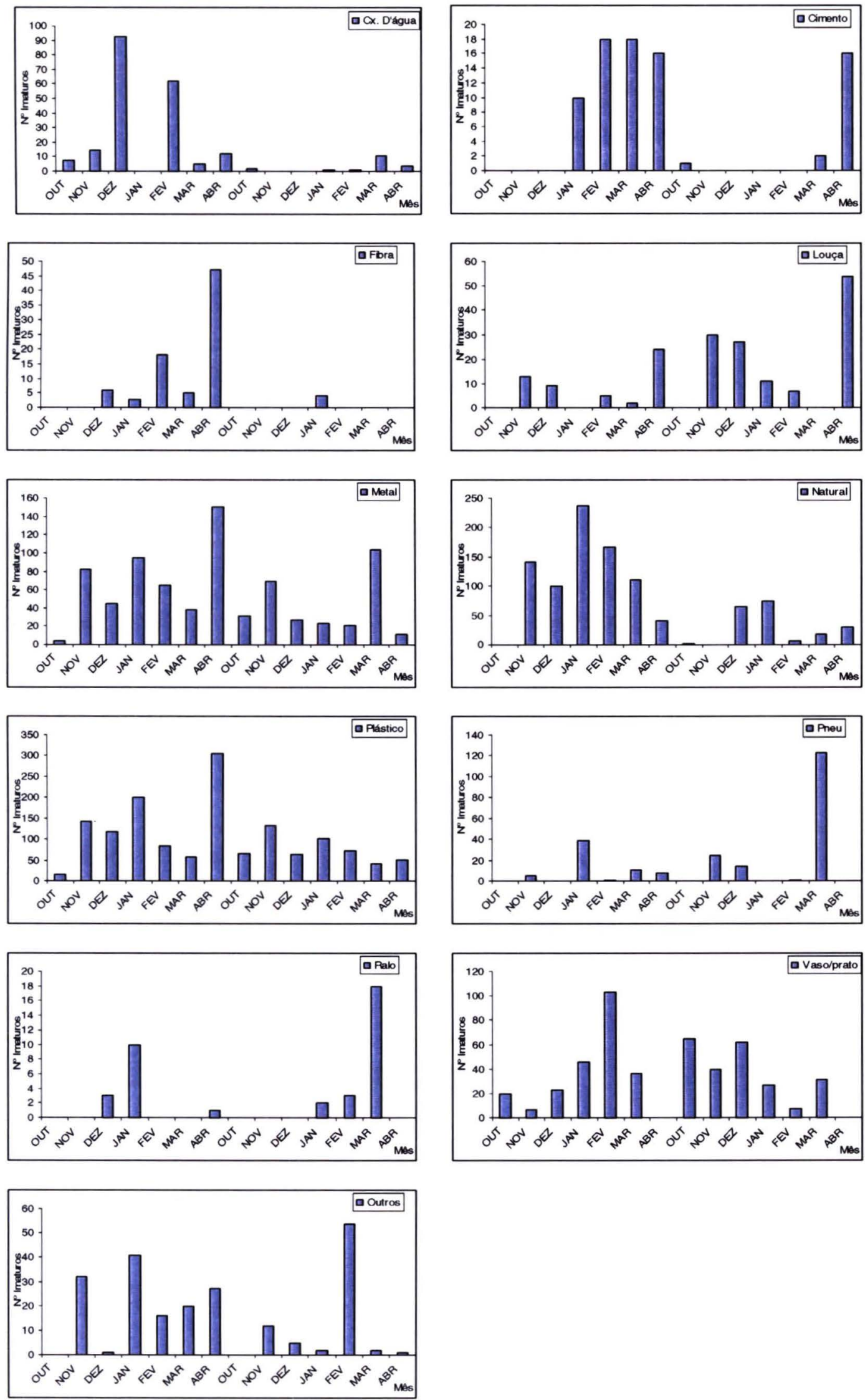
A tabela 10 apresenta a diferença na produção média de larvas de $A e$. albopictus e entre os recipientes segundo a categoria $(\mathrm{n}=527 ; \mathrm{H}=69,97 ; \mathrm{gl}=10$ e p $<0,0001)$. Observa-se na Figura 8 os recipientes que em média produziram mais larvas, metal, plástico, natural e vaso/prato de vaso. Para a produção média de pupas de Ae. aegypti também houve diferença entre as categorias de recipiente ( $\mathrm{n}=190 ; \mathrm{H}=44,36 ; \mathrm{gl}=10$ e $\mathrm{p}<0,0001)$, a categoria dos plásticos foi a que apresentou diferença em relação as demais (Tabela 11 e Figura 9).

Tabela 10 - Comparação entre a produção média de larvas de Aedes albopictus por categoria de recipiente, em São Sebastião, São Paulo, Brasil, no período de 10/2002 a 04/2003 e de 10/2003 a 04/2004.

Kruskal - Wallis $-H=69,97 \quad p<0,0001(n=527)$

\begin{tabular}{lc} 
Comparações entre grupos: Teste de Dwass-Steel-Chritchlow-Flingner $(\alpha<0,05)$ \\
\hline Metal X Caixa d'água & $p=0,043$ \\
Metal X Cimento & $p=0,002$ \\
Metal X Fibra & $p=0,001$ \\
Metal X Pneu & $p=0,032$ \\
Metal X Ralo & $p=0,000$ \\
Plástico X Caixa d'água & $p=0,013$ \\
Plástico X Cimento & $p=0,001$ \\
Plástico X Fibra & $p=0,000$ \\
Plástico X Louça & $p=0,005$ \\
Plástico X Pneu & $p=0,006$ \\
Plástico X Ralo & $p=0,000$ \\
Plástico X Planta & $p=0,038$ \\
Plástico X Outros & $p=0,003$ \\
Natural X Fibra & $p=0,050$ \\
Natural X Ralo & $p=0,015$ \\
Vaso X Cimento & $p=0,046$ \\
Vaso X Fibra & $p=0,025$ \\
Vaso X Ralo & $p=0,009$ \\
\hline
\end{tabular}

* Apenas os resultados com significância estatística. 


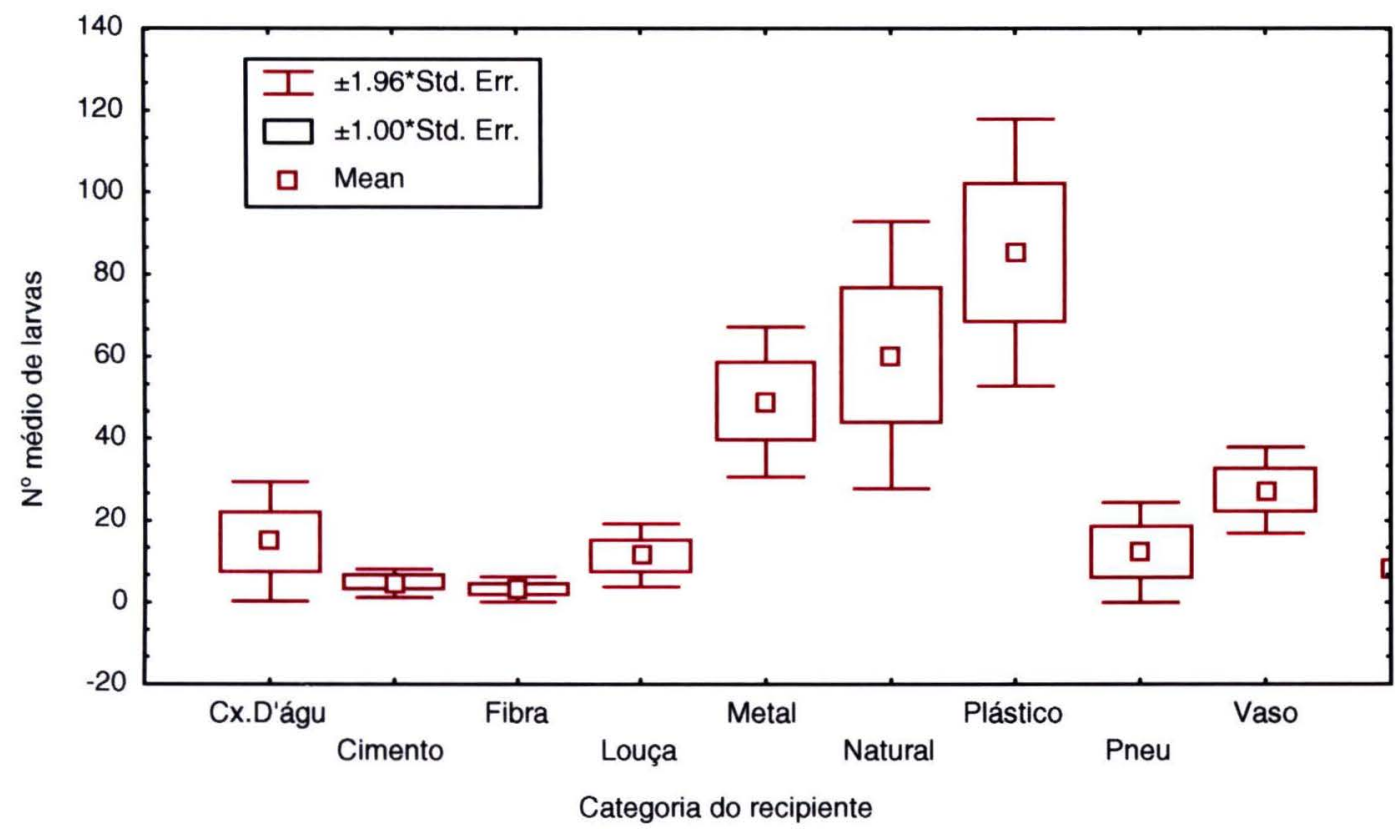

Figura 8 - Produção de larvas de Aedes albopictus segundo categoria do recipiente em São Sebastião, São Paulo, Brasil, no período de 10/02 a 04/03 e de 10/03 a 04/04.

Tabela 11 - Comparação da produção média mensal de pupas de Aedes albopictus por categoria de recipiente, em São Sebastião, São Paulo, Brasil, no período de 10/02 a $04 / 03$ e $10 / 03$ a $04 / 04$.

Kruskal - Wallis $-H=44,36 \quad p<0,0001(n=190)$

Comparações entre grupos: Teste de Dwass - Steel - Chritchlow - Flingner $(\alpha<0,05)$

\begin{tabular}{ll} 
Plástico X Cx. D'água & $\mathrm{p}=0,001$ \\
Plástico X Cimento & $\mathrm{p}=0,001$ \\
Plástico X Fibra & $\mathrm{p}=0,007$ \\
Plástico X Louça & $\mathrm{p}=0,003$ \\
Plástico X Pneu & $\mathrm{p}=0,015$ \\
Plástico X Ralo & $\mathrm{p}=0,001$ \\
Plástico X Outros & $\mathrm{p}=0,001$ \\
\hline
\end{tabular}

* Apenas os resultados com significância estatística. 


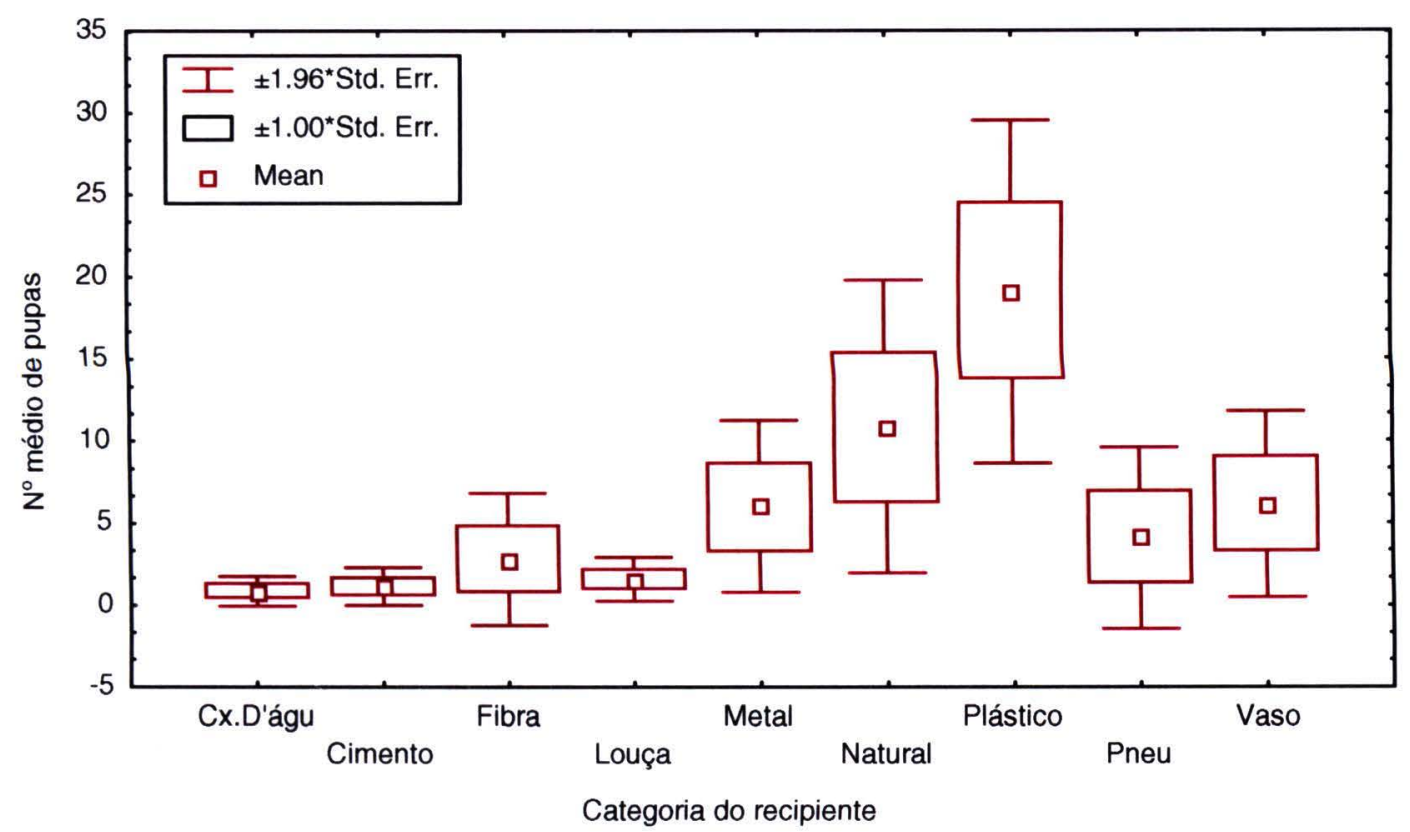

Figura 9 - Produção de pupas de Aedes albopictus segundo categoria do recipiente em São Sebastião, São Paulo, Brasil, no período de 10/2002 a 04/2003 e de 10/2003 a $04 / 2004$.

\subsection{3 - Recipientes contendo ambas as espécies}

Destacaram-se recipientes com maiores percentuais de positividade nesta situação, as categorias: plástico $(29,4 \%)$, natural $(17,8 \%)$ e metal $(15,6 \%)$. As larvas de Ae. aegypti foram mais abundantes em fibra $(27,8 \mathrm{lv} / \mathrm{rec})$, planta aquática $(19 \mathrm{lv} / \mathrm{rec})$ e metal $(17,6 \mathrm{lv} / \mathrm{rec})$. As pupas tiveram as maiores médias nas categorias fibra, ralo e pneu $(27,2 ; 8,0$ e $4,5 \mathrm{pp} / \mathrm{rec}$. respectivamente). Já para a espécie Ae. albopictus, as médias de larvas foram distribuídas na maior parte dos recipientes sem muita diferença, sendo a maior média nos pneus (11 lv/rec). Para a fase pupal, as maiores médias foram nos pneus $(8,3 \mathrm{pp} / \mathrm{rec})$ e na categoria fibra $(6,4$ $\mathrm{pp} / \mathrm{rec}$ ). Do total de recipientes, 63\% eram passíveis de remoção. Observa-se que mesmo em situação de coexistência, Ae. aegypti estava em maior número que Ae. albopictus (Tabela 12). 
Tabela 12 - Distribuição do nº $\%$ de recipientes fixos e removíveis segundo categoria e do $\mathrm{n}^{\circ}$ e média de larvas e pupas por espécie em situação de coexistência, no período de 10/2002 a 04/2003 e 10/2003 e 04/2004, em São Sebastião, SP, Brasil.

\begin{tabular}{|c|c|c|c|c|c|c|c|c|c|c|c|c|c|c|c|}
\hline \multirow{3}{*}{$\frac{\text { CATEGORIA }}{\text { Fixos }}$} & \multicolumn{2}{|c|}{ Recipientes } & \multicolumn{4}{|c|}{ Aedes aegypti } & \multicolumn{4}{|c|}{ Aedes albopictus } & \multicolumn{5}{|c|}{ Total de imaturos } \\
\hline & \multirow[t]{2}{*}{$\mathrm{N}^{\circ}$} & \multirow[t]{2}{*}{$\%$} & \multicolumn{2}{|c|}{ Larvas } & \multicolumn{2}{|c|}{ Pupas } & \multicolumn{2}{|c|}{ Larvas } & \multicolumn{2}{|c|}{ Pupas } & \multicolumn{2}{|c|}{ Ae. aegypti } & \multicolumn{2}{|c|}{ Ae. albopictus } & \multirow{2}{*}{$\begin{array}{r}\text { Ambos } \\
\text { Total }\end{array}$} \\
\hline & & & $\mathrm{N}^{\circ}$ & Lv/rec & $\mathrm{N}^{\circ}$ & Pp/rec & $\mathrm{N}^{\circ}$ & Lv/rec & $\mathrm{N}^{\circ}$ & $\mathrm{Pp} / \mathrm{rec}$ & $\mathrm{N}^{\circ}$ & $\%$ & $\mathrm{~N}^{\circ}$ & $\%$ & \\
\hline Cx. d'água & 10 & 5,6 & 115 & 11,5 & 10 & 1,0 & 31 & 3,1 & 2 & 0,2 & 125 & 79,1 & 33 & 20,9 & 158 \\
\hline Cimento & 4 & 2,2 & 56 & 14,0 & 3 & 0,8 & 34 & 8,5 & 0 & 0,0 & 59 & 63,4 & 34 & 36,6 & 93 \\
\hline Fibra & 5 & 2,8 & 139 & 27,8 & 136 & 27,2 & 41 & 8,2 & 32 & 6,4 & 275 & 79,0 & 73 & 21,0 & 348 \\
\hline Louça/cerâmica & 13 & 7,2 & 95 & 7,3 & 17 & 1,3 & 114 & 8,8 & 5 & 0,4 & 112 & 48,5 & 119 & 51,5 & 231 \\
\hline Ralo & 3 & 1,7 & 11 & 3,7 & 24 & 8,0 & 3 & 1,0 & 1 & 0,3 & 35 & 89,7 & 4 & 10,3 & 39 \\
\hline Natural & 32 & 17,8 & 239 & 7,5 & 20 & 0,6 & 181 & 5,7 & 26 & 0,8 & 259 & 55,6 & 207 & 44,4 & 466 \\
\hline Subtotal 1 & 67 & 37,2 & 655 & 9,8 & 210 & 3,1 & 404 & 6,0 & 66 & 1,0 & 865 & 64,8 & 470 & 35,2 & 1335 \\
\hline \multicolumn{16}{|l|}{ Removíveis } \\
\hline Metal & 28 & 15,6 & 492 & 17,6 & 93 & 3,3 & 182 & 6,5 & 39 & 1,4 & 585 & 72,6 & 221 & 27,4 & 806 \\
\hline Plástico & 53 & 29,4 & 674 & 12,7 & 44 & 0,8 & 436 & 8,2 & 132 & 2,5 & 718 & 55,8 & 568 & 44,2 & 1286 \\
\hline Planta aquática & 2 & 1,1 & 38 & 19,0 & 0 & 0,0 & 3 & 1,5 & 0 & 0,0 & 38 & 92,7 & 3 & 7,3 & 41 \\
\hline Pneu & 6 & 3,3 & 54 & 9,0 & 27 & 4,5 & 66 & 11,0 & 50 & 8,3 & 81 & 41,1 & 116 & 58,9 & 197 \\
\hline Vaso/prato planta & 22 & 12,2 & 254 & 11,5 & 28 & 1,3 & 85 & 3,9 & 15 & 0,7 & 282 & 73,8 & 100 & 26,2 & 382 \\
\hline Vidro & 1 & 0,6 & 19 & 19,0 & 2 & 2,0 & 12 & 12,0 & 7 & 7,0 & 21 & 52,5 & 19 & 47,5 & 40 \\
\hline Outros & 1 & 0,6 & 3 & 3,0 & 1 & 1,0 & 22 & 22,0 & 1 & 1,0 & 4 & 14,8 & 23 & 85,2 & 27 \\
\hline Subtotal 2 & 113 & 62,8 & 1534 & 13,6 & 195 & 1,7 & 806 & 7,1 & 244 & 2,2 & 1729 & 62,2 & 1050 & 37,8 & 2779 \\
\hline Total & 180 & 100,0 & 2189 & 12,2 & 405 & 2,3 & 1210 & 6,7 & 310 & 1,7 & 2594 & 63,1 & 1520 & 36,9 & 4114 \\
\hline
\end{tabular}


A produção média de imaturos por tipo de recipiente diferiu com significância estatística, entre as categorias de recipientes tanto para Ae. aegypti ( $\mathrm{n}=$ $577 ; \mathrm{gl}=9 ; \mathrm{H}=39,08$ e $\mathrm{p}<0,000)$ quanto para Ae. albopictus $(\mathrm{n}=488 ; \mathrm{gl}=9 ; \mathrm{H}=$ 42,33 e p $<0,000$ ). Observa-se que os plásticos e os metais produziram em média mais larvas e pupas que as demais categorias, tanto para Ae. aegypti quanto para Ae. albopictus, quando estavam em situação de coexistência (Tabela 13).

Tabela 13 - Comparação da produção média mensal de imaturos de Ae. aegypti e Ae. albopictus em recipientes com ambas as espécies por categoria de recipiente, em São Sebastião, São Paulo, Brasil, no período de 10/2002 a 04/2003 e 10/2003 a 04/2004.

Comparação entre grupos: Teste de Dwass - Steel - Chritchlow - Flingner $(\alpha<0,05)$ Ae. aegypti Ae. Albopictus

\begin{tabular}{llll}
\multicolumn{2}{c}{ Ae. aegypti } & \multicolumn{2}{c}{ Ae. Albopictus } \\
\hline Plástico X Cimento & $p=0,000$ & Plástico X CX. D'água & $p=0,000$ \\
Plástico X Fibra & $p=0,005$ & Plástico X Cimento & $p=0,000$ \\
Plástico X Louça & $p=0,038$ & Plástico X Fibra & $p=0,004$ \\
Plástico X Pneu & $p=0,008$ & Plástico X Louça & $p=0,002$ \\
Metal X Cimento & $p=0,015$ & Plástico X Pneu & $p=0,015$ \\
& & Metal X Cimento & $p=0,016$
\end{tabular}

* Apenas os resultados com significância estatística. 


\section{4 - Emergência de fêmeas}

\subsection{1 - Emergência mensal de fêmeas}

O cálculo da emergência de fêmeas para cada 100 imóveis ao dia foi feito a partir da produção mensal de pupas. A produção de fêmeas de Ae. aegypti cresceu ao longo do período e a de Ae. albopictus diminuiu, em recipientes onde as espécies não estavam em situação de coexistência (Tabela 14).

Houve diferença na comparação da produção média mensal de fêmeas entre as espécies quando em recipientes diferentes (Teste Mann-Whitney; $n=14 ; \mathrm{U}=$ $156,5$ e $p=0,006)$. E em recipientes em situação de coexistência, não houve diferença com significância estatística na produção média de fêmeas das espécies ao longo dos meses (Teste Mann-Whitney; $n=14 ; U=103$ e $p=0,84$ ).

Tabela 14 - Produção média mensal de fêmeas por espécie a cada 100 imóveis/dia, dos criadouros com a espécie isolada e coexistindo. São Sebastião, São Paulo, Brasil, no período de 10/2002 a 04/2003 e 10/2003 a 04/2004.

\begin{tabular}{lrrrr}
\hline & \multicolumn{4}{c}{$\mathrm{N}^{\circ}$ de fêmeas dos criadouros } \\
\cline { 2 - 5 } Mês & c/Aedes & c/Aedes & \multicolumn{2}{c}{ Em coexistência } \\
\cline { 2 - 5 } Outubro & aegypti & albopictus & Ae. aeg. & Ae. alb. \\
Novembro & 82 & 18 & 22 & 18 \\
Dezembro & 142 & 267 & 40 & 40 \\
Janeiro & 204 & 48 & 58 & 25 \\
Fevereiro & 57 & 296 & 22 & 54 \\
Março & 211 & 249 & 76 & 36 \\
Abril & 236 & 57 & 12 & 24 \\
Outubro & 543 & 256 & 385 & 164 \\
Novembro & 305 & 78 & 2 & 5 \\
Dezembro & 237 & 135 & 7 & 117 \\
Janeiro & 117 & 27 & 16 & 5 \\
Fevereiro & 439 & 68 & 7 & 14 \\
Março & 350 & 32 & 55 & 3 \\
Abril & 977 & 111 & 53 & 95 \\
\hline
\end{tabular}




\subsection{2 - Emergência de fêmeas segundo a categoria do recipiente}

Na tabela 15, para todos os recipientes houve aumento na produção média de fêmeas de Ae. aegypti ao longo do período, o que foi bastante evidente nos últimos meses. Foi possível observar maior produção de fêmeas nos plásticos e metais durante todo o período.

A produção de fêmeas de Ae. albopictus apresentou tendência inversa da espécie anterior, verificando-se queda da produção média ao longo do período para todos os tipos de recipientes. Os recipientes das categorias plástico e natural produziram mais fêmeas em média (Tabela 16)

Quando observamos os resultados da produção de fêmeas em criadouros com a presença das espécies coexistindo, notamos tendência de produção semelhante em todo o período. Embora em alguns meses houvesse maior produção média de umas das espécies, não houve diferença com significância estatística na produção média mensal entre elas (Teste Mann-Whitney; $n=14 ; \mathrm{U}=93$ e $\mathrm{p}=$ $0,83)$. Os recipientes que, em média, produziram mais foram aqueles das seguintes categorias: plástico, natural e vaso/prato de planta (Tabela 17). 
Tabela 15 - Emergência diária de fêmeas de Ae. aegypti por categoria de recipiente, São Sebastião, São Paulo, Brasil, no período de $10 / 2002$ a 04/2003 e 10/2003 a 04/2004.

\begin{tabular}{|c|c|c|c|c|c|c|c|c|c|c|c|c|c|}
\hline Mês & $\begin{array}{l}\text { Caixa } \\
\text { D'água } \\
\end{array}$ & Cimento & Fibra & Louça & Metal & Plástico & Natural & $\begin{array}{l}\text { Planta } \\
\text { Aquát. }\end{array}$ & Pneu & Ralo & $\begin{array}{l}\text { Vaso/ } \\
\text { prato }\end{array}$ & Vidro & Outros \\
\hline Outubro & 0,3 & 0,0 & 0,0 & 0,0 & 25,0 & 0,0 & 0,0 & 0,0 & 0,0 & 4,0 & 0,0 & 0,0 & 0,0 \\
\hline Novembro & 0,8 & 0,3 & 0,0 & 0,0 & 16,3 & 33,8 & 0,0 & 0,0 & 0,0 & 0,0 & 0,8 & 1,5 & 0,0 \\
\hline Dezembro & 1,3 & 0,0 & 0,0 & 0,0 & 12,0 & 1,3 & 0,0 & 0,0 & 0,0 & 9,0 & 18,0 & 0,3 & 0,0 \\
\hline Janeiro & 2,0 & 1,3 & 0,0 & 0,0 & 0,0 & 3,0 & 0,0 & 0,0 & 0,0 & 0,0 & 2,3 & 0,0 & 0,3 \\
\hline Fevereiro & 0,0 & 0,0 & 4,5 & 0,8 & 2,5 & 1,0 & 0,0 & 0,0 & 9,8 & 0,3 & 37,5 & 0,0 & 0,0 \\
\hline Março & 0,8 & 0,0 & 28,8 & 0,0 & 52,5 & 1,5 & 0,0 & 0,0 & 0,0 & 0,0 & 0,0 & 5,5 & 0,0 \\
\hline Abril & 0,0 & 0,0 & 585,0 & 0,0 & 52,0 & 0,0 & 0,0 & 0,0 & 0,0 & 1,5 & 0,0 & 0,0 & 0,0 \\
\hline Outubro & 0,0 & 0,0 & 0,5 & 0,0 & 8,0 & 19,5 & 0,0 & 0,0 & 0,0 & 5,0 & 26,5 & 0,0 & 0,0 \\
\hline Novembro & 12,0 & 0,3 & 3,5 & 5,3 & 63,0 & 0,0 & 0,0 & 0,0 & 1,5 & 0,0 & 15,0 & 0,0 & 0,0 \\
\hline Dezembro & 4,8 & 0,0 & 0,0 & 1,5 & 1,0 & 16,0 & 1,0 & 1,0 & 0,0 & 0,0 & 16,0 & 0,0 & 0,0 \\
\hline Janeiro & 0,0 & 15,0 & 0,0 & 0,0 & 15,5 & 41,0 & 0,5 & 1,0 & 0,3 & 92,8 & 0,0 & 0,3 & 5,5 \\
\hline Fevereiro & 0,0 & 19,5 & 0,5 & 0,0 & 3,5 & 0,0 & 0,0 & 13,8 & 0,0 & 12,5 & 0,3 & 0,8 & 0,0 \\
\hline Março & 4,5 & 17,0 & 122,5 & 4,5 & 431 & 36,0 & 8,5 & 6,0 & 14,0 & 0,0 & 0,0 & 0,0 & 0,0 \\
\hline Abril & 6,0 & 39,8 & 6,0 & 19,0 & 112,0 & 27,5 & 0,3 & 48,8 & 0,0 & 9,0 & 0,8 & 0,3 & 0,0 \\
\hline
\end{tabular}


Tabela 16 - Emergência diária de fêmeas de Ae. albopictus por categoria de recipiente, São Sebastião, São Paulo, Brasil, no período de 10/2002 a 04/2003 e $10 / 2003$ a 04/2004.

\begin{tabular}{|c|c|c|c|c|c|c|c|c|c|c|c|}
\hline ês & $\begin{array}{c}\text { Caixa } \\
\text { D'água }\end{array}$ & Cimento & Fibra & Louça & Metal & Natural & Plástico & Pneu & Ralo & $\begin{array}{l}\text { Vasol } \\
\text { prato }\end{array}$ & Outros \\
\hline dtubro & 0,0 & 0,0 & 0,0 & 0 & 0 & 0 & 2,0 & 0,0 & 0,0 & 0,0 & 0,0 \\
\hline Jvembro & 0,3 & 0,0 & 0,0 & 2,3 & 11,5 & 114,0 & 21,0 & 0,0 & 0,0 & 0,0 & 0,0 \\
\hline zzembro & 1,5 & 0,0 & 1,0 & 0,3 & 2,5 & 2,5 & 0,5 & 0,0 & 0,0 & 0,0 & 0,0 \\
\hline Ineiro & 0,0 & 2,0 & 0,0 & 0,0 & 1,0 & 60,0 & 137,3 & 0,0 & 0,0 & 1,8 & 1,5 \\
\hline əvereiro & 1,5 & 1,8 & 0,8 & 0,3 & 0,0 & 66,5 & 3,0 & 0,0 & 0,0 & 0,0 & 0,0 \\
\hline arço & 0,0 & 1,0 & 0,0 & 0,0 & 1,0 & 4,0 & 2,5 & 0,0 & 0,0 & 0,0 & 2,0 \\
\hline Jril & 0,0 & 0,0 & 7,3 & 1,0 & 42,5 & 5,3 & 105,8 & 11,3 & 0,5 & 0,0 & 0,0 \\
\hline utubro & 0,3 & 0,3 & 0,0 & 0,0 & 1,3 & 0,0 & 8,3 & 0,0 & 0,0 & 0,0 & 0,0 \\
\hline Jvembro & 0,0 & 0,0 & 0,0 & 0,5 & 3,0 & 0,0 & 94,5 & 19,3 & 0,0 & 0,0 & 0,0 \\
\hline эzembro & 0,0 & 0,0 & 0,0 & 0,3 & 0,0 & 4,0 & 1,0 & 1,0 & 0,0 & 0,0 & 0,0 \\
\hline ineiro & 0,0 & 0,0 & 0,8 & 0,0 & 0,3 & 5,0 & 36,0 & 0,0 & 0,0 & 1,5 & 0,5 \\
\hline :vereiro & 0,0 & 0,0 & 0,0 & 0,3 & 0,3 & 0,5 & 13,5 & 0,0 & 0,0 & 0,0 & 0,0 \\
\hline arço & 0,0 & 0,0 & 0,0 & 0,0 & 1,5 & 2,0 & 11,3 & 29,3 & 0,0 & 0,0 & 0,0 \\
\hline zril & 0,3 & 0,0 & 0,0 & 1,3 & 0,3 & 0,5 & 6,8 & 0,0 & 0,0 & 0,0 & 0,0 \\
\hline
\end{tabular}


Tabela 17 - Emergência de fêmeas diária por categoria de recipiente com ambas as espécies, São Sebastião, São Paulo, Brasil, no período de 10/2002 a 04/2003 e 10/2003 a 04/2004.

\begin{tabular}{|c|c|c|c|c|c|c|c|c|c|c|c|c|c|c|c|c|c|c|}
\hline \multirow[b]{2}{*}{ Mês } & \multicolumn{2}{|c|}{ Fibra } & \multicolumn{2}{|c|}{ Louça } & \multicolumn{2}{|c|}{ Metal } & \multicolumn{2}{|c|}{ Natural } & \multicolumn{2}{|c|}{ Plástico } & \multicolumn{2}{|c|}{ Pneu } & \multicolumn{2}{|l|}{ Vaso } & \multicolumn{2}{|c|}{ Outros } & \multicolumn{2}{|c|}{ Total } \\
\hline & A & B & A & B & A & B & A & B & A & B & A & B & A & B & A & B & A & B \\
\hline Outubro & 0,0 & 0,0 & 0,0 & 0,0 & 1,8 & 0,0 & 0,0 & 0,0 & 0,8 & 2,0 & 0,0 & 0,0 & 0,0 & 0,0 & 0,0 & 0,0 & 2,5 & 2,0 \\
\hline Novembro & 0,0 & 0,0 & 0,0 & 0,0 & 4,5 & 4,5 & 0,5 & 0,0 & 0,5 & 1,3 & 0,0 & 0,0 & 0,0 & 0,0 & 0,0 & 1,0 & 5,5 & 6,8 \\
\hline Dezembro & 0,0 & 0,0 & 0,0 & 0,0 & 5,0 & 2,5 & 0,8 & 2,5 & 5,0 & 0,5 & 0,0 & 0,0 & 0,0 & 0,0 & 0,0 & 0,0 & 10,8 & 5,5 \\
\hline Janeiro & 0,0 & 0,0 & 0,0 & 0,0 & 0,0 & 0,0 & 1,5 & 4,5 & 2,3 & 6,8 & 0,0 & 0,0 & 1,0 & 0,3 & 0,3 & 0,3 & 5,0 & 11,8 \\
\hline Fevereiro & 0,0 & 0,8 & 0,8 & 0,3 & 0,0 & 0,0 & 2,0 & 1,3 & 0,8 & 0,0 & 0,0 & 0,0 & 9,0 & 1,3 & 0,0 & 0,0 & 12,5 & 3,5 \\
\hline Março & 0,3 & 0,0 & 0,0 & 0,0 & 0,0 & 0,3 & 0,8 & 0,0 & 0,3 & 0,5 & 0,0 & 0,0 & 0,0 & 0,0 & 0,5 & 1,8 & 1,8 & 2,5 \\
\hline Abril & 67,5 & 7,3 & 0,0 & 0,0 & 40,0 & 16,5 & 0,0 & 0,0 & 7,0 & 33,8 & 0,0 & 0,0 & 0,0 & 0,3 & 1,5 & 0,3 & 116,0 & 58,0 \\
\hline Outubro & 0,0 & 0,0 & 0,0 & 0,0 & 0,0 & 0,0 & 0,0 & 0,0 & 0,0 & 0,3 & 0,0 & 0,0 & 0,0 & 0,0 & 0,0 & 0,0 & 0,0 & 0,3 \\
\hline Novembro & 0,0 & 0,0 & 0,5 & 0,5 & 0,0 & 1,0 & 0,0 & 0,0 & 0,0 & 36,0 & 0,3 & 5,5 & 0,3 & 1,5 & 0,0 & 0,0 & 1,0 & 44,5 \\
\hline Dezembro & 0,0 & 0,0 & 0,5 & 0,3 & 0,0 & 0,0 & 0,0 & 0,3 & 0,0 & 0,3 & 0,0 & 0,0 & 1,8 & 0,0 & 0,0 & 0,0 & 2,3 & 0,8 \\
\hline Janeiro & 0,0 & 0,0 & 0,0 & 0,0 & 0,0 & 0,0 & 0,3 & 0,0 & 0,8 & 5,3 & 0,0 & 0,0 & 0,0 & 0,3 & 0,0 & 0,0 & 1,0 & 5,5 \\
\hline Fevereiro & 0,0 & 0,0 & 0,0 & 0,3 & 0,0 & 0,0 & 0,0 & 0,0 & 7,5 & 0,3 & 0,0 & 0,0 & 0,0 & 0,0 & 4,5 & 0,0 & 12,0 & 0,5 \\
\hline Março & 0,0 & 0,0 & 0,0 & 0,0 & 0,0 & 0,0 & 1,5 & 0,8 & 0,0 & 7,0 & 6,5 & 9,8 & 0,0 & 0,0 & 0,0 & 0,0 & 8,0 & 17,5 \\
\hline Abril & 0,0 & 0,0 & 2,5 & 0,0 & 8,0 & 0,3 & 0,0 & 0,5 & 1,0 & 3,0 & 0,0 & 0,0 & 0,0 & 0,0 & 0,0 & 0,0 & 11,5 & 3,8 \\
\hline
\end{tabular}


A comparação entre as categorias de criadouros mostra que existe diferença com significância estatística na produção média de fêmeas de $A e$. aegypti (Kruskal - Wallis: $\mathrm{n}=301 ; \mathrm{H}=54,71 ; \mathrm{gl}=12$ e $\mathrm{p}<0,000$ ). A produção média foi maior nos metais e plásticos em relação as demais categorias (Tabela 18 e Figura $10)$.

Tabela 18 - Comparação do Cálculo de Emergência de fêmea de Ae. aegypti por tipo de recipiente, São Sebastião, São Paulo, Brasil, no período de 10/2002 a 04/2003 e $10 / 2003$ a 04/2004.

\begin{tabular}{ll} 
Kruskal - Wallis: $H=54,71-p<0,000(n=301)$ & \\
Comparações entre grupos - Teste Dwass - Steel - Chritchlow - Flingner $(\alpha<0,05)$ \\
\hline Metal X Louça & $p=0,036$ \\
Metal X Pneu & $p=0,012$ \\
Metal X Vidro & $p=0,003$ \\
Metal X Outros & $p=0,001$ \\
Plástico X Caixa d' água & $p=0,027$ \\
Plástico X Louça & $p=0,010$ \\
Plástico X Planta & $p=0,003$ \\
Plástico X Pneu & $p=0,004$ \\
Plástico X Vidro & $p=0,002$ \\
Plástico X Outros & $p=0,000$ \\
\hline *Apenas os resultados com significância estatistica
\end{tabular}

* Apenas os resultados com significância estatística.

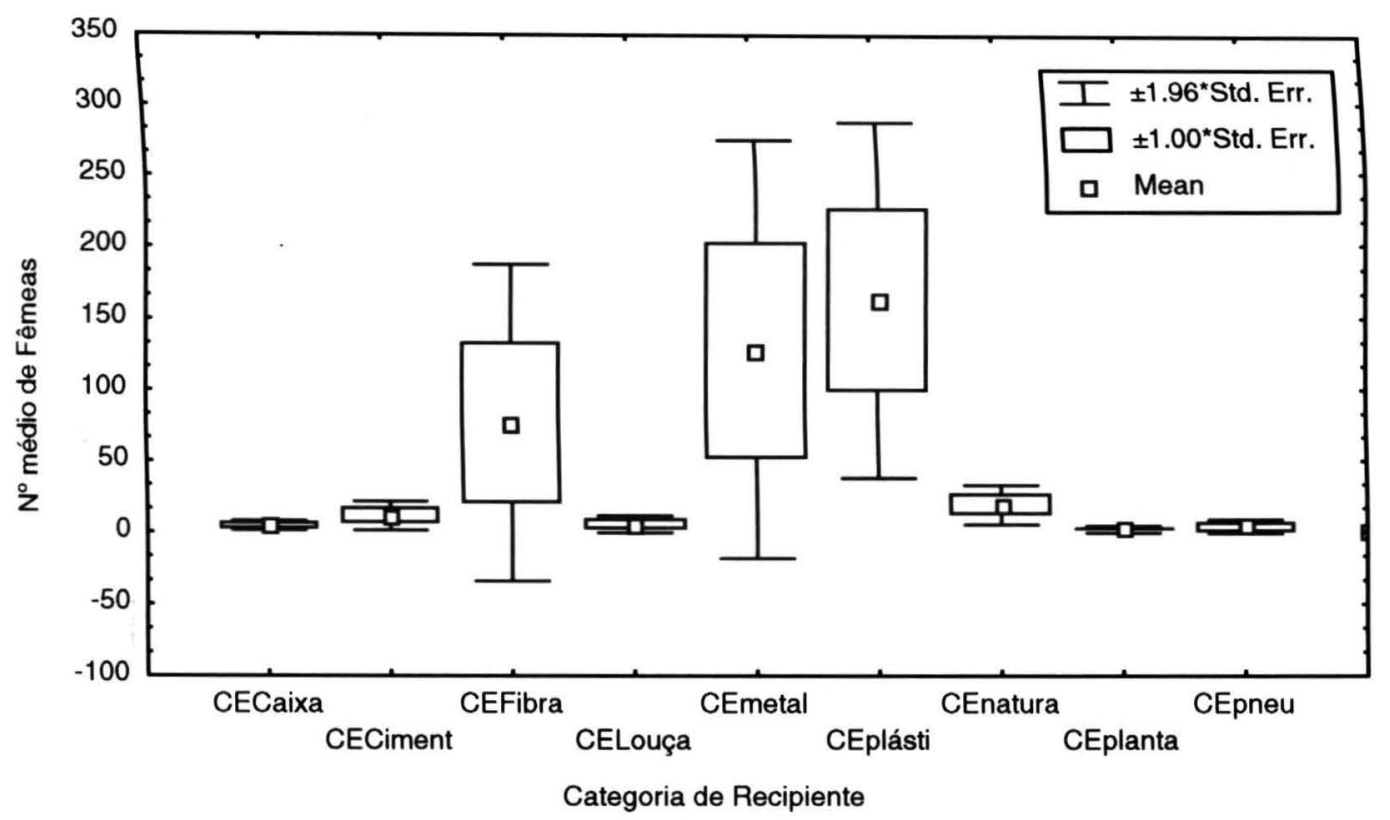

Figura 10 - Produção média de fêmeas de Ae. aegypti por recipiente segundo categoria em São Sebastião, São Paulo, Brasil, no período de 10/2002 a 04/2003 e de $10 / 2003$ a 04/2004. 
A comparação da produção média de fêmeas de Ae. albopictus entre as categorias também apresentou diferença com significância estatística (Kruskal Wallis: $\mathrm{n}=190 ; \mathrm{H}=60,31 ; \mathrm{gl}=10 \mathrm{e} \mathrm{p}<0,000$ ). A produção média foi maior nos plásticos e naturais em relação as demais (Tabela 19 e Figura 11).

Tabela 19 - Comparação entre a Emergência de fêmeas de Ae. albopictus por recipiente segundo a categoria, São Sebastião, São Paulo, Brasil, no período de 10/2002 a 04/2003 e 10/2003 a 04/2004.

$$
\text { Kruskal }- \text { Wallis }-H=60,31 \quad p<0,000 \quad(n=190)
$$

Comparações entre grupos - Teste: Dwass - Steel - Chritchlow - Flingner $(\alpha<0,05)$

\begin{tabular}{ll}
\hline Natural X Ralo & $p=0,021$ \\
Natural X Cimento & $p=0,037$ \\
Plástico X Cimento & $p=0,000$ \\
Plástico X Fibra & $p=0,001$ \\
Plástico X Louça & $p=0,001$ \\
Plástico X Ralo & $p=0,000$ \\
Plástico X Vaso & $p=0,039$ \\
Plástico X Outros & $p=0,001$ \\
\hline
\end{tabular}

* Apenas os resultados com significância estatística.

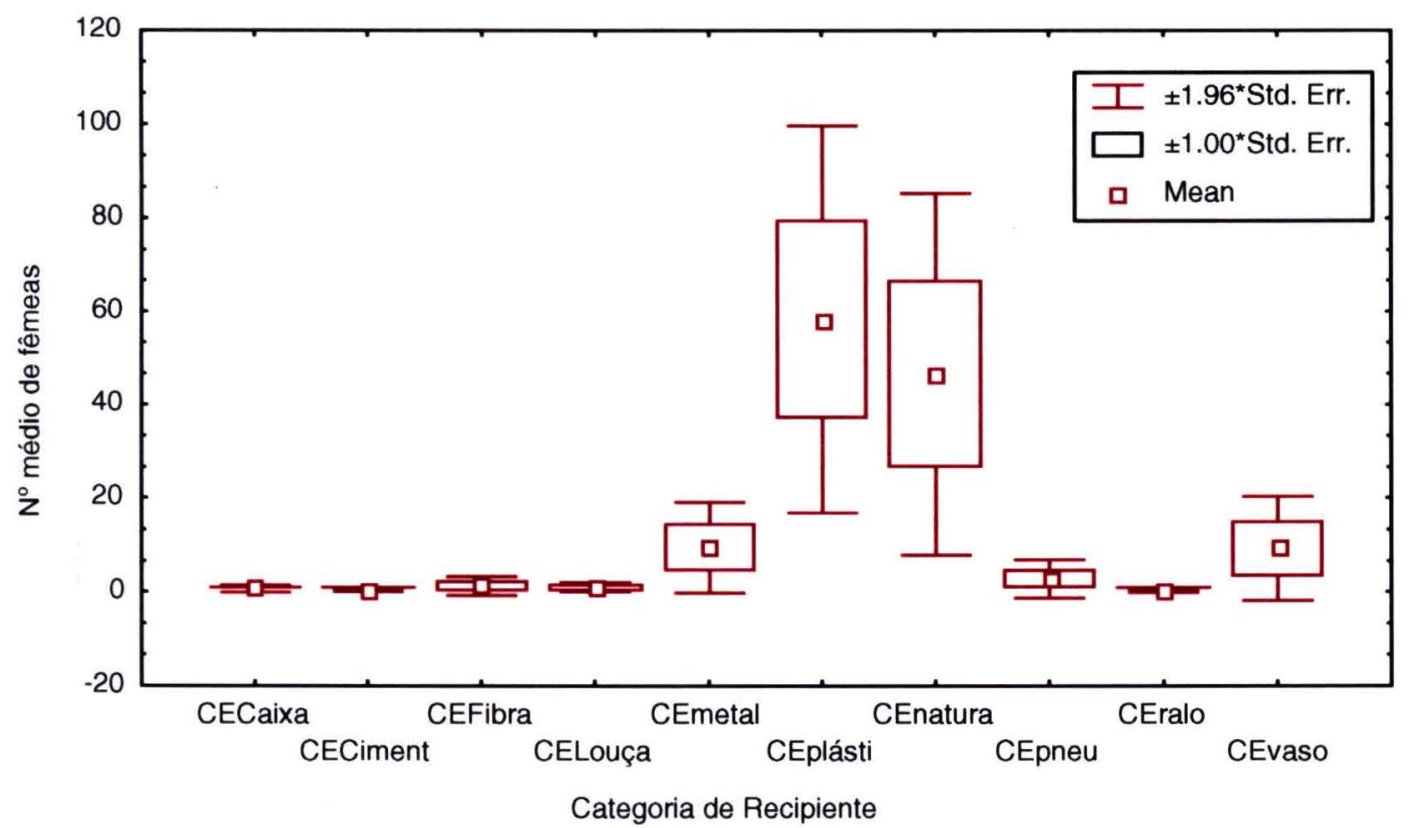

Figura 11 - Produção média de fêmeas de Ae. albopictus por recipiente segundo a categoria em São Sebastião, São Paulo, Brasil, no período de 10/2002 a 04/2003 e de $10 / 2003$ a 04/2004. 


\section{5 - Variáveis físicas e químicas e a associação com abundância e produtividade de imaturos}

\subsection{1 - Descrição dos valores dos parâmetros físicos e químicos da água dos criadouros}

Os recipientes contendo Ae. aegypti e Ae. albopictus foram separados segundo categoria do recipiente.

Para criadouros com ambas as espécies não foi possível fazer esta separação em razão do $n^{\circ}$ de recipientes amostrados $(n=54)$, optou-se então por apresentar os resultados do total de recipientes. Em todos os parâmetros mensurados, houve alta variabilidade, sendo observado menor coeficiente de variação na temperatura, embora esta tenha registrado valor máximo de $35,4^{\circ} \mathrm{C}$ (Tabela 20).

Tabela 20 - Valores máximos, mínimos e coeficientes de variação de volume, temperatura, $\mathrm{pH}$, oxigênio dissolvido, condutividade elétrica, salinidade dos recipientes que continham as espécies em coexistência, em São Sebastião, Litoral Norte de São Paulo, Brasil, no Período de 10/2002 a 04/2003 e 10/2003 a 04/2004.

\begin{tabular}{lrrrrrr}
\hline & $\begin{array}{r}\text { Vol. } \\
(\mathrm{ml})\end{array}$ & $\begin{array}{r}\text { Temp. } \\
\left({ }^{\circ} \mathrm{C}\right)\end{array}$ & $\mathrm{pH}$ & $\begin{array}{c}\text { OD } \\
(\mathrm{mg} / \mathrm{l})\end{array}$ & $\begin{array}{r}\text { Condut. } \\
(\mu \mathrm{S} / \mathrm{cm})\end{array}$ & $\begin{array}{r}\text { Salinid. } \\
(\% \circ)\end{array}$ \\
\cline { 2 - 7 } Máximo & 500000 & $\mathbf{3 5 , 4}$ & 8,9 & 10,30 & 16110,0 & 9,2 \\
Mínimo & 25 & 21,3 & 4,3 & 1,46 & 14,2 & 0 \\
C.V. (\%) & 464,8 & 9,7 & 15,7 & 47,3 & 304,1 & 355,4 \\
\hline
\end{tabular}

Nos criadouros com Ae. aegypti também foi observada alta variabilidade para todos os parâmetros, entretanto, destacam-se os coeficientes de variação do volume, condutividade e salinidade.

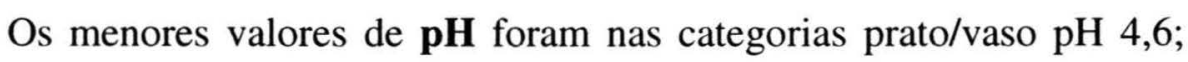
plástico $\mathrm{pH} 4,5$ e natural $\mathrm{pH} 4,3$; nas quais os valores tenderam para o ácido. Valores 
alcalinos com pH entre 8,9 e 9,9 foram obtidos nos seguintes recipientes: ralo, plástico, fibra, cimento, louça e caixa d' água.

Os valores de condutividade e a salinidade foram mais altos nas categorias pneus $22.400,0 \mu \mathrm{S} / \mathrm{cm}$ e $13,5 \%_{0}$, natural $9.749,00 \mu \mathrm{S} / \mathrm{cm}$ e $5,5 \%_{0}$ e fibra $(18.870,0 \mu \mathrm{S} / \mathrm{cm}$ e $11,2 \%$ o).

Foram observados os menores valores de oxigênio dissolvido nas categorias ralo $0,20 \mathrm{mg} / \mathrm{l}$, plástico $0,38 \mathrm{mg} / \mathrm{l}$ e fibra $0,40 \mathrm{mg} / \mathrm{l}$, embora os percentuais de coeficientes de variação das demais categorias também tenham sido altos.

A temperatura foi mais elevada em pneu $34,2^{\circ} \mathrm{C}$, plástico $35,9^{\circ} \mathrm{C}$, natural $35,6^{\circ} \mathrm{C}$ e louça $34,8^{\circ} \mathrm{C}$ (Tabela 21 ).

Em criadouros com Ae. albopictus também foi observada variação em todos os valores dos parâmetros físicos e químicos da água, embora estes tenham sido menores que os da espécie anterior.

Os valores de volume, condutividade e salinidade apresentaram percentuais mais altos de coeficiente de variação.

Observaram-se valores de $\mathbf{p H}$ ácido nos recipientes das categorias: vaso/prato $(\mathrm{pH} \mathrm{4,1)} \mathrm{e} \mathrm{natural} \mathrm{(} \mathrm{pH} 4,0$ ), e levemente alcalinos em fibra $(\mathrm{pH} \mathrm{8,4)} \mathrm{e}$ outros (pH 8,3).

Os maiores valores de condutividade e salinidade foram registrados em pneus $2600,0 \mu \mathrm{S} / \mathrm{cm}$ e $1,2 \%$, natural $5120,0 \mu \mathrm{S} / \mathrm{cm}$ e $2,8 \%_{0}$ e fibra $16110,0 \mu \mathrm{S} / \mathrm{cm}$ e $9,2 \%$.

O oxigênio dissolvido teve o menor valor registrado no ralo $(0,52 \mathrm{mg} / \mathrm{l})$, embora tenha apresentado valores baixos em outras categorias. A temperatura foi mais elevada em plástico $\left(30,5^{\circ} \mathrm{C}\right)$ e caixa d'água $\left(30,7^{\circ} \mathrm{C}\right)$, máximas menores que em criadouros com Aedes aegypti (Tabela 22). 
Tabela 21 - Valores máximos, mínimos e coeficientes de variação de volume, temperatura, $\mathrm{pH}$, oxigênio dissolvido, condutividade elétrica, salinidade nos recipientes com Ae. aegypti, segundo a categoria, São Sebastião, São Paulo, Brasil, no período de 10/2002 a 04/2003 e 10/2003 a 04/2004.

\begin{tabular}{|c|c|c|c|c|c|c|c|}
\hline Categoria/ $n$ & & $\begin{array}{l}\text { Vol. } \\
(\mathrm{ml})\end{array}$ & $\begin{array}{l}\text { Temp. } \\
\left({ }^{\circ} \mathrm{C}\right)\end{array}$ & $\mathrm{pH}$ & $\begin{array}{l}\mathrm{OD} \\
(\mathrm{mg} / \mathrm{l})\end{array}$ & $\begin{array}{l}\text { Condut.. } \\
(\mu \mathrm{S} / \mathrm{cm})\end{array}$ & $\begin{array}{r}\text { Salinid. } \\
(\% \circ)\end{array}$ \\
\hline vaso/prato & Máximo & 2000 & 30,7 & 7,5 & 8,37 & 759,0 & 0,6 \\
\hline \multirow[t]{2}{*}{$(n=18)$} & Mínimo & 80 & 20,8 & 4,6 & 0,86 & 59,1 & 0,0 \\
\hline & C.V. (\%) & 60,7 & 9,5 & 11,6 & 54,67 & 73,2 & 147,8 \\
\hline ralo & Máximo & 6500 & 27,9 & 9,1 & 6,40 & 3400,0 & 1,8 \\
\hline \multirow[t]{2}{*}{$(n=20)$} & Mínimo & 100 & 23,5 & 6,1 & 0,20 & 28,9 & 0,0 \\
\hline & C.V. (\%) & 97,0 & 5,1 & 9,6 & 58,8 & 106,7 & 141,4 \\
\hline pneu & Máximo & 25000 & 34,2 & 8,1 & 7,61 & 22400,0 & 13,5 \\
\hline \multirow[t]{2}{*}{$(n=11)$} & Mínimo & 50 & 21,9 & 6,0 & 1,06 & 49,2 & 0,0 \\
\hline & C.V. $(\%)$ & 254,5 & 11,5 & 9,8 & 48,9 & 173,4 & 192,1 \\
\hline plástico & Máximo & 250000 & 35,9 & 9,0 & 9,40 & 2960,0 & 1,5 \\
\hline \multirow[t]{2}{*}{$(n=63)$} & Mínimo & 15 & 22,1 & 4,5 & 0,38 & 4,0 & 0,0 \\
\hline & C.V. (\%) & 411,5 & 10,6 & 10,8 & 53,6 & 145,2 & 202,6 \\
\hline Planta aqu. & Máximo & 3000 & 28,1 & 6,8 & 5,52 & 572,0 & 0,2 \\
\hline \multirow[t]{2}{*}{$(n=7)$} & Mínimo & 350 & 24,2 & 5,7 & 1,87 & 37,2 & 0,0 \\
\hline & C.V. (\%) & 72,4 & 6,5 & 5,8 & 35,3 & 116,9 & 137,7 \\
\hline natural & Máximo & 2450 & 35,6 & 8,3 & 7,87 & 9740,0 & 5,5 \\
\hline \multirow[t]{2}{*}{$(n=30)$} & Mínimo & 30 & 21,8 & 4,3 & 0,81 & 4,0 & 0,0 \\
\hline & C.V. $(\%)$ & 154,5 & 11,7 & 16,2 & 51,6 & 202,3 & 217,6 \\
\hline Metal & Máximo & 200000 & 29,1 & 8,3 & 8,50 & 1146,0 & 0,5 \\
\hline \multirow[t]{2}{*}{$(n=16)$} & Mínimo & 30 & 21,8 & 5,1 & 1,14 & 5,0 & 0,0 \\
\hline & C.V. (\%) & 344,7 & 8,0 & 11,0 & 46,5 & 100,9 & 151,6 \\
\hline Fibra & Máximo & 500000 & 30,8 & 9,4 & 9,00 & 18870,0 & 11,2 \\
\hline \multirow[t]{2}{*}{$(n=40)$} & Mínimo & 20 & 22,8 & 5,2 & 0,40 & 33,0 & 0,0 \\
\hline & C.V. $(\%)$ & 389,7 & 6,7 & 10,6 & 52,3 & 193,3 & 209,6 \\
\hline Cimento & Máximo & 200000 & 31,1 & 9,1 & 7,00 & 3110,0 & 1,6 \\
\hline \multirow[t]{2}{*}{$(n=9)$} & Mínimo & 640 & 23,5 & 6,4 & 2,94 & 226,0 & 0,0 \\
\hline & C.V. (\%) & 164,2 & 9,3 & 11,2 & 35,2 & 128,4 & 203,4 \\
\hline Louça & Máximo & 3000 & 34,8 & 8,9 & 7,41 & 422,0 & 0,1 \\
\hline \multirow[t]{2}{*}{$(n=9)$} & Mínimo & 250 & 24,5 & 5,4 & 2,37 & 26,0 & 0,0 \\
\hline & C.V. $(\%)$ & 5,1 & 3,4 & 5,8 & 5,7 & 26,1 & 57,7 \\
\hline Cx. D’água & Máximo & 10000000 & 29,5 & 9,9 & 8,73 & 1804,0 & 0,9 \\
\hline \multirow[t]{2}{*}{$(n=14)$} & Mínimo & 230000 & 18,0 & 5,7 & 3,78 & 61,9 & 0,0 \\
\hline & C.V. $(\%)$ & 182,5 & 10,8 & 17,0 & 33,1 & 205,5 & 374,2 \\
\hline
\end{tabular}

1- Vasos/pratos de planta e xaxim. 2- Objetos de plástico. 3- Bromélias,ocos de árvore e bambús.

4- Várias peças de metal e carros. 5- Barcos/botes/caiaque e peças de fibra.

6- Canaletas/lajes/caixas de areia. 7- Vasos sanitários e outras peças de cerâmica e louça. 
Tabela 22 - Valores máximos, mínimos e coeficientes de variação de: volume, temperatura, $\mathrm{pH}$, oxigênio dissolvido, condutividade elétrica, salinidade nos recipientes com Ae. albopictus, segundo a categoria, São Sebastião, São Paulo, Brasil, no período de 10/2002 a 04/2003 e 10/2003 a 04/2004.

\begin{tabular}{|c|c|c|c|c|c|c|c|}
\hline Categoria/ n & & $\begin{array}{l}\text { Vol. } \\
(\mathrm{ml})\end{array}$ & $\begin{array}{r}\text { Temp. } \\
\left({ }^{\circ} \mathrm{C}\right) \\
\end{array}$ & $\mathrm{pH}$ & $\begin{array}{r}\text { OD } \\
(\mathrm{mg} / \mathrm{l})\end{array}$ & $\begin{array}{l}\text { Condut. } \\
(\mu \mathrm{S} / \mathrm{cm})\end{array}$ & $\begin{array}{r}\text { Salinid. } \\
(\% \circ) \\
\end{array}$ \\
\hline \multirow[t]{2}{*}{ Vaso/prato/planta ${ }^{1}$} & Máximo & 2000 & 27,1 & 7,5 & 8,37 & 446,0 & 0,2 \\
\hline & Mínimo & 75 & 21,3 & 4,1 & 0,86 & 34,8 & 0,0 \\
\hline$(n=10)$ & C.V. $(\%)$ & 91,0 & 6,5 & 19,2 & 59,89 & 116,4 & 255,0 \\
\hline \multirow[t]{2}{*}{ Ralo/cimento ${ }^{2}$} & Máximo & 10000 & 27,4 & 7,8 & 2,94 & 293,0 & 0,1 \\
\hline & Mínimo & 650 & 24,0 & 6,8 & 0,52 & 89,0 & 0,0 \\
\hline$(n=4)$ & C.V. (\%) & 106,2 & 5,6 & 6,6 & 55,43 & 51,8 & 200,0 \\
\hline \multirow[t]{2}{*}{ Pneu } & Máximo & 550 & 27,0 & 7,9 & 6,07 & 2600,0 & 1,2 \\
\hline & Mínimo & 170 & 21,4 & 6,5 & 3,71 & 416,0 & 0,2 \\
\hline$(n=5)$ & C.V. $(\%)$ & 48,7 & 8,8 & 7,5 & 17,11 & 77,0 & 78,2 \\
\hline \multirow{2}{*}{ Recip./plástico ${ }^{3}$} & Máximo & 3000 & 30,5 & 7,3 & 5,66 & 596,0 & 0,3 \\
\hline & Mínimo & 160 & 22,3 & 5,2 & 0,98 & 50,0 & 0,0 \\
\hline$(n=32)$ & C.V. (\%) & 284,7 & 11,3 & 10,0 & 69,18 & 82,1 & 213,2 \\
\hline \multirow[t]{2}{*}{ Natural $^{4}$} & Máximo & 2450 & 27,8 & 7,1 & 3,80 & 5120,0 & 2,8 \\
\hline & Mínimo & 75 & 21,8 & 4,0 & 0,80 & 15,5 & 0,0 \\
\hline$(n=29)$ & C.V. $(\%)$ & 104,5 & 8,1 & 18,6 & 93,72 & 81,6 & 85,6 \\
\hline \multirow[t]{2}{*}{ Recipientes/ metal ${ }^{5}$} & Máximo & 16000 & 28,6 & 7,9 & 5,00 & 288,0 & 0,1 \\
\hline & Mínimo & 550 & 21,8 & 5,9 & 2,30 & 114,3 & 0,0 \\
\hline$(n=7)$ & C.V. $(\%)$ & 124,1 & 8,0 & 9,2 & 32,58 & 39,8 & 124,7 \\
\hline \multirow[t]{2}{*}{ Recipientes/fibra ${ }^{6}$} & Máximo & 500000 & 27,0 & 8,4 & 7,00 & 16110,0 & 9,2 \\
\hline & Mínimo & 1450 & 24,6 & 6,5 & 1,05 & 54,2 & 0,0 \\
\hline$(n=5)$ & C.V. $(\%)$ & 204,9 & 3,8 & 10,4 & 64,54 & 160,0 & 166,7 \\
\hline \multirow[t]{2}{*}{ Outros materiais $^{7}$} & Máximo & 610 & 26,3 & 8,3 & 7,20 & 710,0 & 0,3 \\
\hline & Mínimo & 80 & 24,4 & 6,4 & 2,31 & 96,0 & 0,0 \\
\hline$(n=4)$ & C.V. $(\%)$ & 95,6 & 3,1 & 11,0 & 42,23 & 69,1 & 85,7 \\
\hline \multirow[t]{2}{*}{ Recip. louça/cerâmica ${ }^{8}$} & Máximo & 2000 & 29,2 & 7,0 & 4,23 & 436,0 & 0,2 \\
\hline & Mínimo & 25 & 24,0 & 6,0 & 2,00 & 137,5 & 0,0 \\
\hline$(n=6)$ & C.V. $(\%)$ & 93,5 & 13,5 & 14,7 & 28,07 & 41,3 & 102,1 \\
\hline \multirow[t]{2}{*}{ Cx. D'água(amianto) } & Máximo & 700000 & 30,7 & 8,0 & 9,40 & 446,0 & 0,2 \\
\hline & Mínimo & 100000 & 24,7 & 6,0 & 6,40 & 65,8 & 0,0 \\
\hline$(n=4)$ & C.V. (\%) & 55,9 & 9,8 & 12,2 & 17,1 & 92,5 & 200,0 \\
\hline
\end{tabular}

1- Vasos/prato de planta e xaxim. 2- Ralo e canaleta/caixa de areia. 3- Objetos de plástico. 4- bromélia, oco de árvore e bambú. 5- Peças de metal e carros. 6- Barcos/botes/caiaque e outras peças de fibra.

7- Vidro/madeira/papel e tetrapark. 8- Vaso sanitário e outras peças de cerâmica e louça. 
Em razão da grande variação nos valores do volume de água dos criadouros, estes foram classificados em tamanhos: Ae aegypti (Pequeno, Intermediário, Médio e Grande) e para Ae. albopictus (Pequeno, Médio e Grande).

Nas análises dos valores de parâmetros físicos e químicos da água do criadouro entre os tamanhos de recipiente com Ae. aegypti, observou-se que houve diferença com significância estatística para temperatura (Kruskal - Wallis: $n=239$; $\mathrm{H}=9,69 ; \mathrm{gl}=3$ e $\mathrm{p}=0,021$ ) e oxigênio dissolvido (Kruskal - Wallis: $\mathrm{n}=239 ; \mathrm{H}=$ $14,73 ; \mathrm{gl}=3$ e $\mathrm{p}=0,002)$, de modo que, a temperatura foi importante para os criadouros pequenos e o oxigênio dissolvido, para os grandes (Figuras 12 e 13).

Entre os tamanhos de recipientes com Ae. albopictus verificaram-se diferenças significantes em Condutividade (Kruskal-Wallis: $\mathrm{n}=105 ; \mathrm{H}=6,49$; $\mathrm{gl}=$ 2 e $\mathrm{p}=0,019)$ e Salinidade (Kruskal-Wallis: $\mathrm{n}=105 ; \mathrm{H}=11,10 ; \mathrm{gl}=2$ e $\mathrm{p}=$ $0,004)$, ressaltando que em criadouros pequenos, estes parâmetros tiveram menor variação (Figuras 14 e 15).

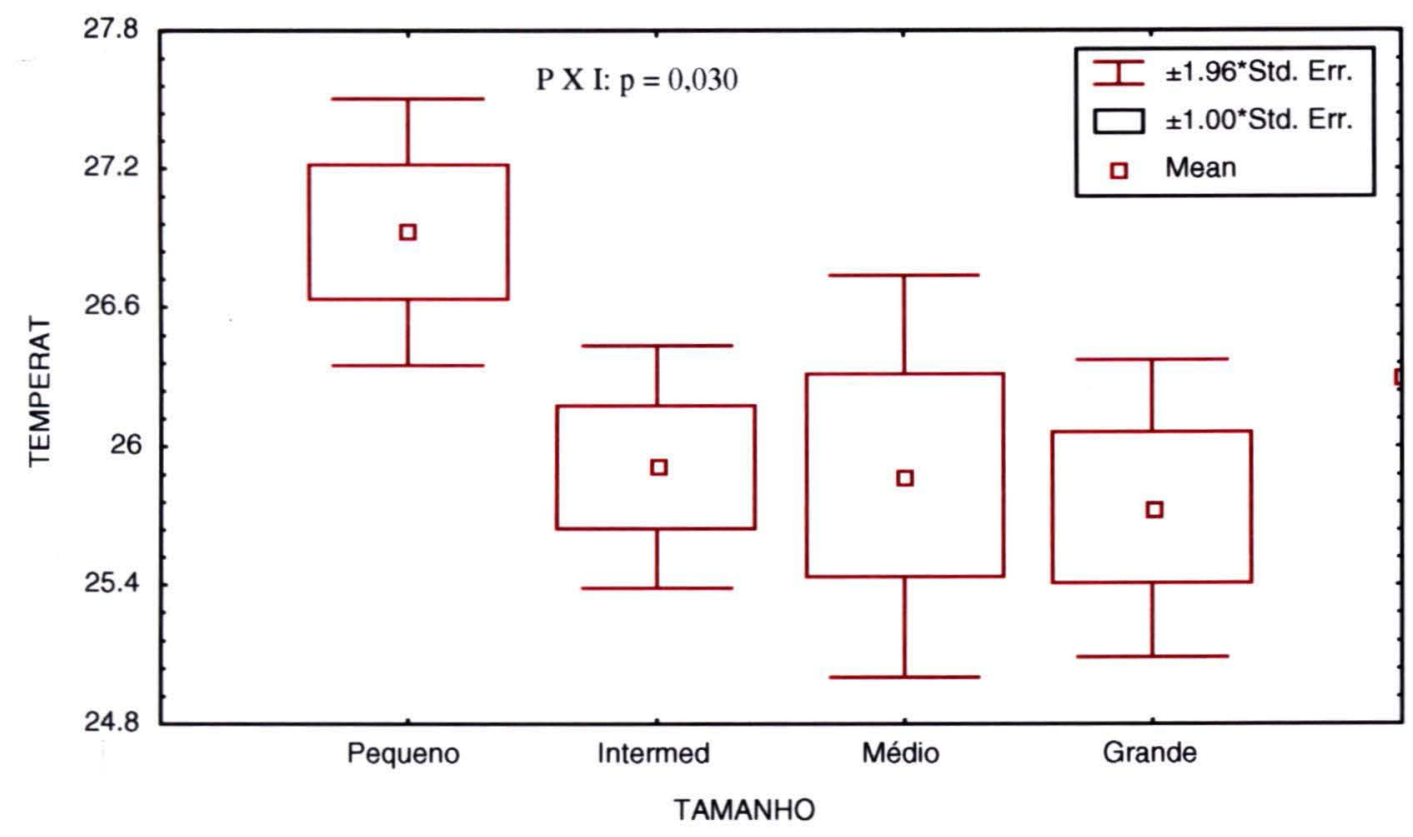

Figura 12 - Temperatura $\left({ }^{\circ} \mathrm{C}\right)$ segundo o tamanho de criadouro de Ae. aegypti em São Sebastião, São Paulo, Brasil, no período de 10/2002 a 04/2003 e de 10/2003 a 04/2004. 


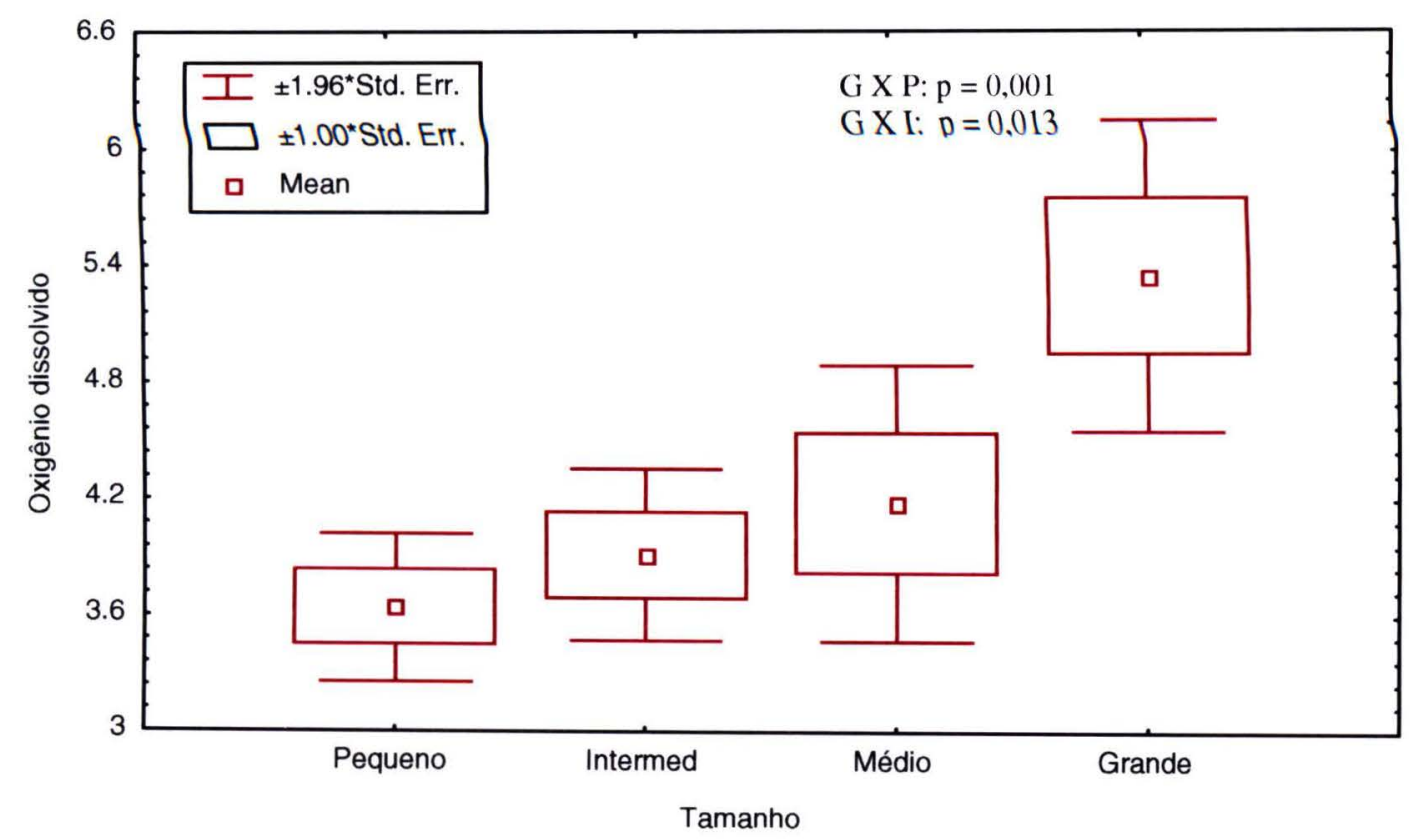

Figura 13 - Oxigênio dissolvido segundo o tamanho de criadouro de Ae. aegypti em São Sebastião, São Paulo, Brasil, no período de 10/2002 a 04/2003 e de 10/2003 a 04/2004.

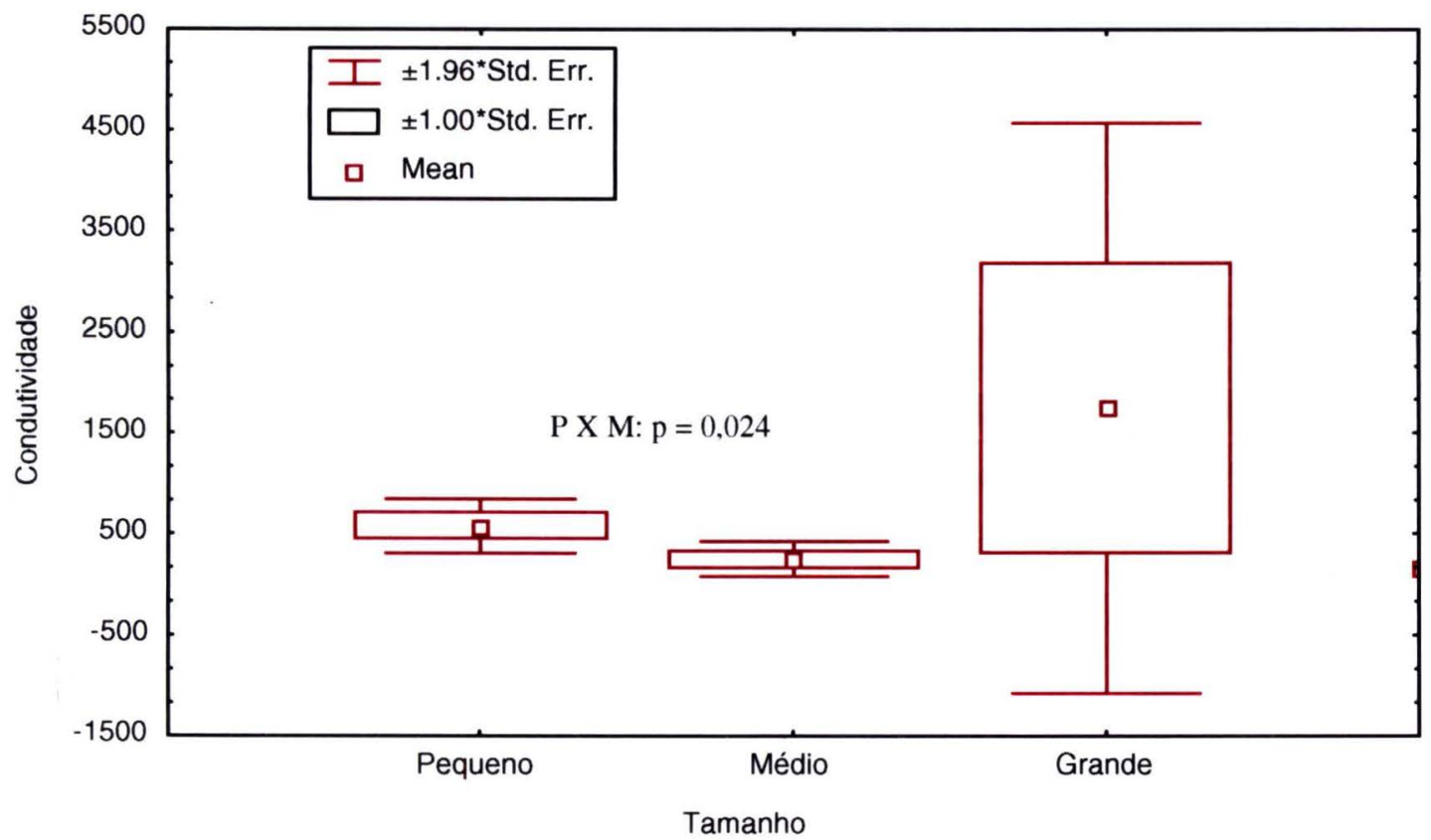

Figura 14 - Condutividade elétrica $(\mu \mathrm{S} / \mathrm{cm})$, segundo tamanho de criadouro de $A e$. albopictus em São Sebastião, São Paulo, Brasil, no período de 10/2002 a 04/2003 e de $10 / 2003$ a 04/2004. 


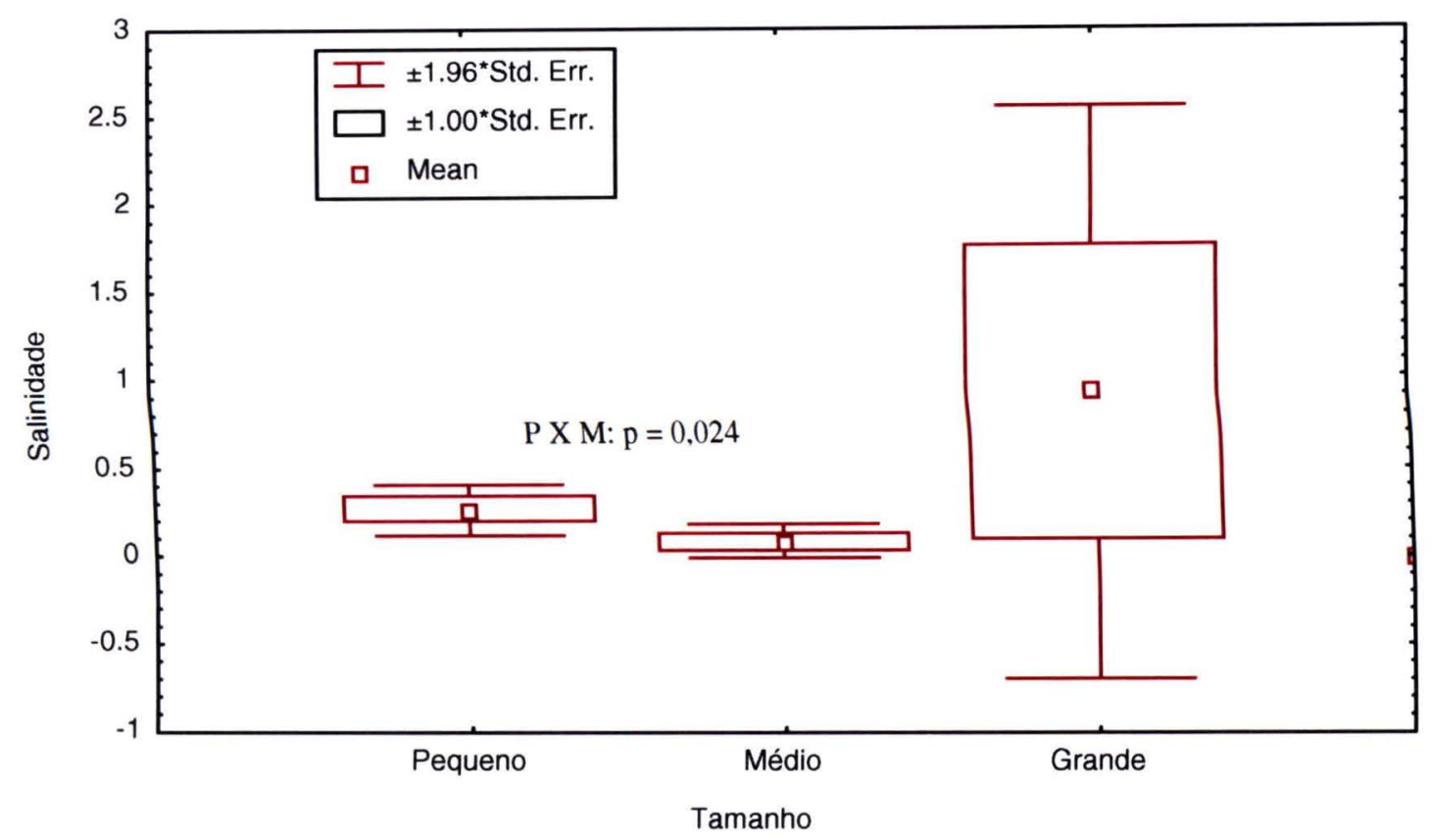

Figura 15 - Salinidade $\left(\%_{0}\right)$, segundo tamanho de criadouro de Ae. albopictus em São Sebastião, São Paulo, Brasil, no período de 10/2002 a 04/2003 e de 10/2003 a 04/2004.

\subsection{2 -Temperatura ambiente e Índices pluviométricos}

Foi considerada a média dos valores de temperatura ambiente e dos índices pluviométricos referentes aos 15 dias que antecederam as coletas.

Os recipientes com presença de pelo menos uma das espécies, estavam presentes durante todos os meses de estudo e, aparentemente, não sofreram grande influência da temperatura e da chuva (Figura 16A).

$\mathrm{O}$ número de recipientes com Ae. aegypti mostrou tendência a aumentar quando a temperatura foi mais alta, ao menos no final do período estudado; entretanto a chuva não pareceu ser fator determinante na ocorrência de criadouros positivos para esta espécie (Figura 16B).

As médias quinzenais dos índices pluviométricos pareceram ter mais associação com criadouros com Ae. albopictus que as de temperatura (Figura 16C).

A ocorrência de recipientes com ambas as espécies parece não ter tido muita influência tanto da chuva, quanto da temperatura (Figura 16D). 

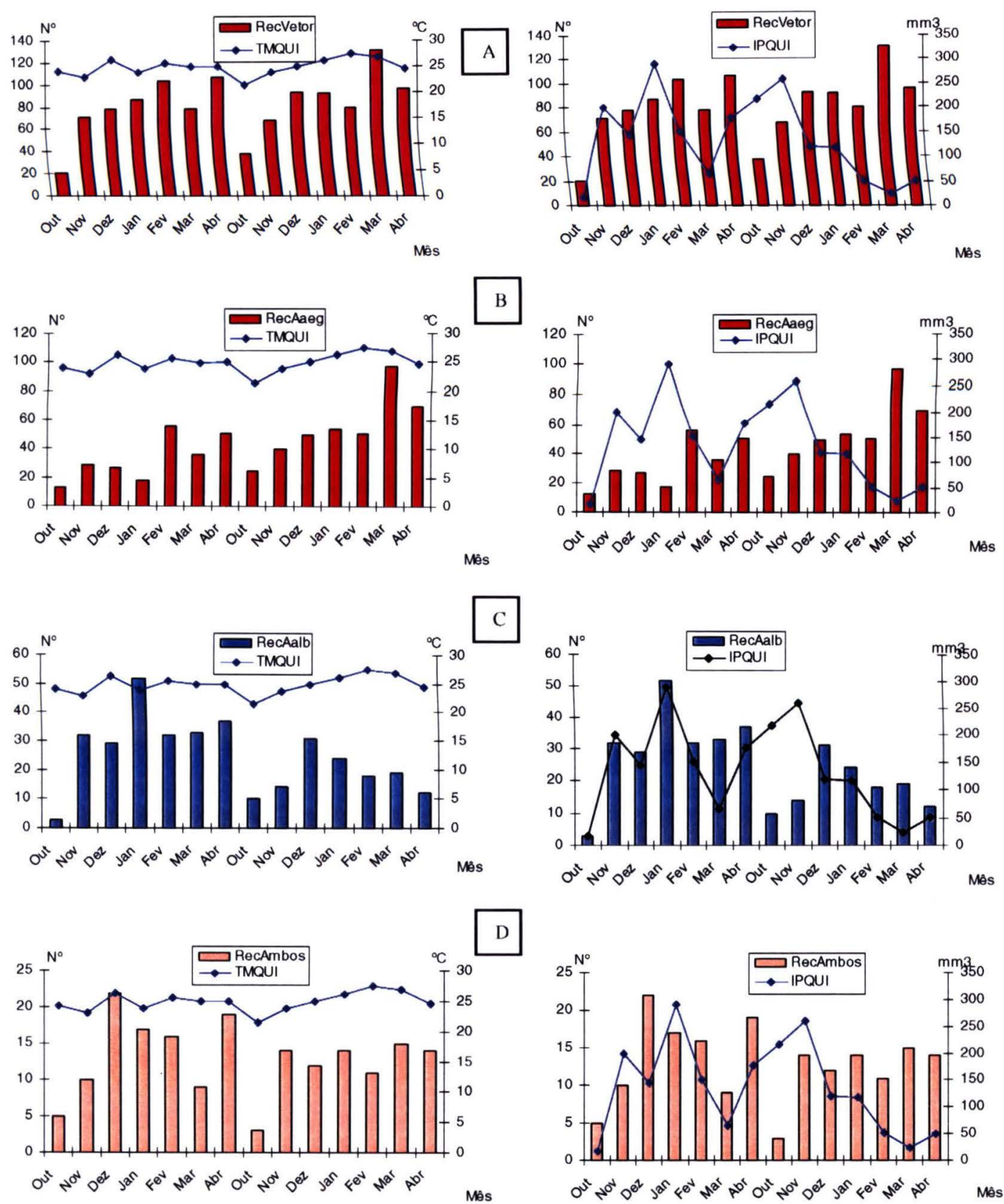

$\mathrm{A}=$ Total recipiente positivo para as duas espécies; $\mathrm{B}=$ Ae. aegypti $; \mathrm{C}=$ Ae. albopictus; $\mathrm{D}=$ Ambas espécies TMQui = Temperatura média quinzenal; IPQui = Índices Pluviométricos/ média quinzenais

Figuras 16 - Distribuição mensal do número de recipientes com o total das duas espécies, com elas isoladas e em coexistência, e as médias quinzenais de temperatura e índices pluviométricos. 


\subsection{3 - Associação entre a produção média de imaturos e os parâmetros físicos e químicos da água do criadouro}

Quando foi considerado o total de recipientes, analisando a associação entre a produção média de imaturos e os valores dos parâmetros físicos e químicos da água do criadouro, foram verificadas algumas associações positivas e fracas mas com significância estatística, em relação ao $\mathrm{pH}$, a condutividade e a salinidade. Isto em criadouros com Ae. aegypti, Ae. albopictus e com ambas as espécies (Tabela 23).

Tabela 23 - Associação entre a produção média de larvas e pupas do total de recipientes e os parâmetros físico-químicos, São Sebastião São Paulo, Brasil, no período de 10/02 a 04/03 e de $10 / 03$ a $04 / 04$.

Teste de Correlação de Spearman $(\alpha<0,05)$

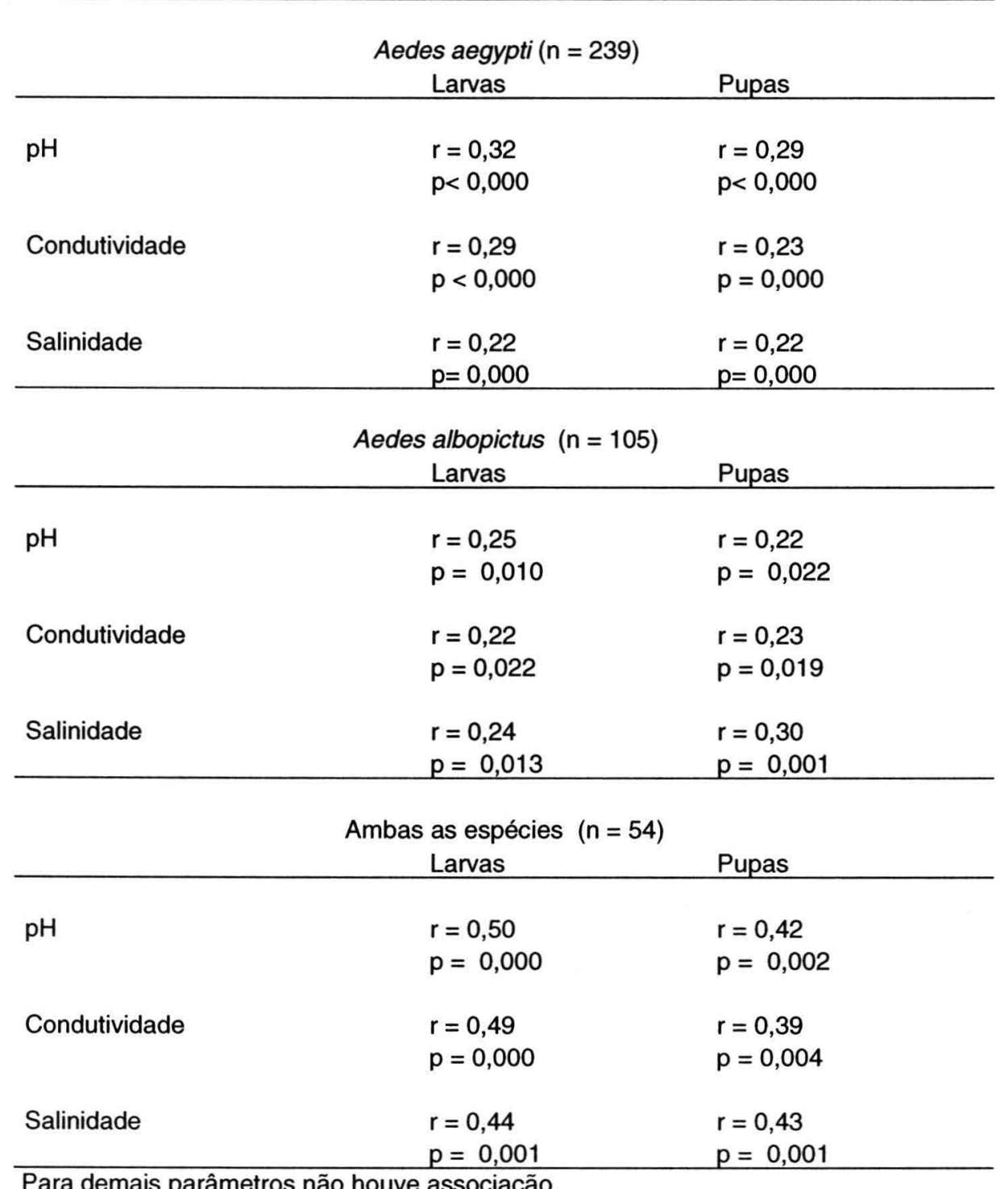

Para demais parâmetros não houve associação. 
Quando a associação foi analisada segundo a categoria de recipiente, foram obtidas poucas associações com significância estatística em criadouros com Ae. aegypti, entre as categorias plástico e natural e os parâmetros $\mathrm{pH}$, condutividade e salinidade. Estas foram consideradas fracas. (Tabela 24). Para as categorias dos criadouros de Ae. albopictus e de ambas as espécies não houve associação significante com nenhum dos parâmetros analisados.

Tabela 24 - Associação entre a produção média de larvas e pupas de Ae. aegypti e os parâmetros por categoria do recipiente, São Sebastião São Paulo, Brasil, no período de 10/2002 a 04/2003 e de 10/2003 a 04/2004.

\begin{tabular}{|c|c|c|c|c|}
\hline \multicolumn{5}{|c|}{ Teste de Correlação de Spearman $(\alpha<0,05)$} \\
\hline & \multicolumn{2}{|c|}{ Plástico $(n=63)$} & \multicolumn{2}{|c|}{ Natural $(n=30)$} \\
\hline & Larvas & Pupas & Larvas & Pupas \\
\hline $\mathrm{pH}$ & * & $\begin{array}{l}r=0,25 \\
p=0,041\end{array}$ & $\begin{array}{l}r=0,41 \\
p=0,026\end{array}$ & $\begin{array}{l}r=0,60 \\
p=0,000\end{array}$ \\
\hline Condutividade & * & $\begin{array}{l}r=0,26 \\
p=0,040\end{array}$ & $\begin{array}{l}r=0,50 \\
p=0,005\end{array}$ & $\begin{array}{l}r=0,44 \\
p=0,016\end{array}$ \\
\hline Salinidade & * & $\begin{array}{l}r=0,28 \\
p=0,027\end{array}$ & $\begin{array}{l}r=0,46 \\
p=0,011\end{array}$ & $\begin{array}{l}r=0,44 \\
p=0,017\end{array}$ \\
\hline $\mathrm{O}_{2}$ dissolvido & * & $\begin{array}{l}r=-0,36 \\
p=0,003\end{array}$ & * & * \\
\hline
\end{tabular}

* não houve associação

\subsection{4 - Associação entre a produção média de imaturos, a temperatura ambiente e os Índices pluviométricos}

Foram poucas as associações entre a produção média de imaturos de Ae. aegypti e as médias quinzenais de temperatura e dos índices pluviométricos, segundo a categoria do recipiente. Em criadouros com Ae. albopictus as associações encontradas, foram em menor número e somente com relação aos índices pluviométricos (Tabela 25). 
Tabela 25 - Associação entre a produção média mensal de imaturos e as médias quinzenais de temperatura ambiente e índices pluviométricos por categoria do recipiente e espécie, em São Sebastião, São Paulo, Brasil, no período de 10/2002 a 04/2003 e de 10/2003 a 04/2004.

\begin{tabular}{lllll}
\multicolumn{5}{c}{ Correlação de Spearman $(\alpha<0,05)$} \\
\hline & Aedes aegypti $(n=14)$ & \\
\hline & Planta & Vaso & Cimento & Ralo \\
\hline & Larvas & Pupas & Larvas & Larvas \\
\hline & $r=0,62$ & $*$ & $r=0,55$ & $*$ \\
Temperatura & $p=0,017$ & & $p=0,042$ & \\
Média Quinzenal & $*$ & $r=0,55$ & $*$ & $r=-0,53$ \\
Índices Pluviométricos & & $p=0,045$ & & $p=0,050$ \\
Média Quinzenal & & & &
\end{tabular}

^ Não houve associação.

Aedes albopictus $(\mathrm{n}=14)$

\begin{tabular}{|c|c|c|}
\hline & Plástico & Vaso \\
\hline & Larvas & Pupas \\
\hline
\end{tabular}

Índices Pluviométricos

Média Quinzenal

$$
\begin{array}{ll}
r=0,77 & r=0,64 \\
p=0,001 & p=0,015
\end{array}
$$




\section{6 - Associação entre Índices entomológicos utilizados na rotina, Indicadores de densidade de larvas e pupas em imóveis e recipientes e Emergência de fêmeas}

Para a espécie Ae. aegypti, os Índices de Densidades de Larvas, tanto de recipientes quanto de imóveis, apresentaram associações positivas significantes em relação aos Índices utilizados na rotina. O Índice de Densidade de Pupas em Imóveis demonstrou fraca associação, apenas com Índice Predial e Índice de Breteau. Não houve associação entre o Índice de Densidade de Pupa em Recipiente e os Índices utilizados na rotina (Tabela 26).

Tabela 26 - Comparação dos Índices de Densidade e os Índices Entomológicos tradicionais, para Ae aegypti em São Sebastião, São Paulo, Brasil, no período de 10/2002 a 04/2003 e 10/2003 a 04/2004.

\begin{tabular}{|c|c|c|c|}
\hline \multicolumn{4}{|c|}{ Teste de Correlação de Spearman ( $n=14) \quad(\alpha<0,05)$} \\
\hline & IR & IP & IB \\
\hline \multirow[t]{2}{*}{ DLR } & $r=0,90$ & $r=0,58$ & $r=0,61$ \\
\hline & $p<0,000$ & $p=0,03$ & $p=0,02$ \\
\hline DPR & * & * & * \\
\hline \multirow[t]{2}{*}{ DLI } & $r=0,80$ & $r=0,70$ & $r=0,79$ \\
\hline & $p=0,001$ & $p=0,01$ & $p=0,001$ \\
\hline \multirow[t]{2}{*}{ DPI } & * & $r=0,56$ & $r=0,58$ \\
\hline & & $p=0,04$ & $p=0,03$ \\
\hline
\end{tabular}

IR= Índice de Recipiente, IP= Índice predial, IB= Índice de Breteau, DLR= Densidade de larvas por recipiente, $\mathrm{DPR}=$ Densidade de pupas por recipiente; $\mathrm{DLI}=$ Densidade de larvas por imóveis, DPI= Densidade de pupas por imóveis. * Não houve associação.

Para a espécie Ae. albopictus, também foi encontrada associação significante entre os índices utilizados na rotina e os indicadores de densidade de pupas. Contudo, para os indicadores de densidade de larvas, as associações foram mais fortes. (Tabela 27). Para as espécies em coexistência, houve número maior de associações, entretanto também foi observada a tendência de associações mais fortes com os indicadores de densidade de larvas (Tabela 28). 
Tabela 27 - Comparação dos Índices de Densidade e os Índices Entomológicos tradicionais, para Ae. albopictus em São Sebastião, São Paulo, Brasil, no período de $10 / 2002$ a 04/2003 e 10/2003 a 04/2004.

\begin{tabular}{llll}
\hline \multicolumn{4}{c}{ Corelação de Spearman $(n=14)(\alpha<0,05)$} \\
\hline IR & \multicolumn{1}{c}{ IP } & IB \\
\hline DLR & $r=0,92$ & $r=0,85$ & $r=0,92$ \\
& $p<0,000$ & $p=0,000$ & $p<0,000$ \\
DPR & $r=0,66$ & $*$ & $r=0,63$ \\
& $p=0,03$ & & $p=0,02$ \\
DLI & $r=0,90$ & $r=0,88$ & $r=0,94$ \\
& $p<0,000$ & $p=0,000$ & $p<0,000$ \\
DPI & $r=0,62$ & $*$ & $r=0,61$ \\
& $p=0,02$ & & $p=0,02$ \\
\hline
\end{tabular}

$\mathrm{IR}=$ Índice de Recipiente, $\mathrm{IP}=$ Índice predial, $\mathrm{IB}=$ Índice de Breteau, $\mathrm{DLR}=$ Densidade de larvas por recipiente, DPR= Densidade de pupas por recipiente; DLI= Densidade de larvas por imóveis, DPI= Densidade de pupas por imóveis. * Não houve associação.

Tabela 28 - Comparação entre Índices de Densidade e os Índices Entomológicos tradicionais para criadouros com ambas as espécies, em São Sebastião, São Paulo, Brasil, no período de 10/2002 a 04/2003 e 10/2003 a 04/2004.

\begin{tabular}{|c|c|c|c|}
\hline \multicolumn{4}{|c|}{ Corelação de Spearman (n=14) $(\alpha<0,05)$} \\
\hline & IR & IP & IB \\
\hline \multirow[t]{2}{*}{ DLR } & $r=0,90$ & * & $r=0,83$ \\
\hline & $p<0,000$ & & $p=0,000$ \\
\hline \multirow[t]{2}{*}{ DPR } & $r=0,72$ & $r=0,63$ & $r=0,77$ \\
\hline & $p=0,01$ & $p=0,02$ & $p=0,00$ \\
\hline \multirow[t]{2}{*}{ DLI } & $r=0,84$ & $r=0,69$ & $r=0,89$ \\
\hline & $p=0,000$ & $p=0,01$ & $p<0,000$ \\
\hline \multirow[t]{2}{*}{ DPI } & $r=0,61$ & $r=0,55$ & $r=0,68$ \\
\hline & $p=0,03$ & $p=0,04$ & $p=0,01$ \\
\hline
\end{tabular}

$\mathrm{IR}=$ Índice de Recipiente, $\mathrm{IP}=$ Índice predial, $\mathrm{IB}=$ Índice de Breteau, $\mathrm{DLR}=$ Densidade de larvas por recipiente, $\mathrm{DPR}=$ Densidade de pupas por recipiente; $\mathrm{DLI}=$ Densidade de larvas por imóveis, DPI= Densidade de pupas por imóveis. * Não houve associação. 
Nas comparações entre os valores de Emergência Mensal (EM) e os Índices de Densidade ocorreram associações fortes e estatisticamente significantes entre a produção mensal de fêmeas e os indicadores que utilizaram a fase pupal, tanto para as espécies em situação de coexistência ou não. Em relação à associação entre a Emergência Mensal e os Índices utilizados em rotina, houve associação com o Índice de Breteau, porém, foi mais fraca que as associações encontradas entre a Emergência Mensal e os Indicadores de Densidade de Pupas, isto para a espécie Ae. aegypti (Tabela 29).

Para Ae. albopictus, houve associação com significância estatística entre a Emergência Mensal e todos os indicadores entomológicos, embora as associações com os índices de uso em rotina tenham sido mais fracas (Tabela 29).

Para as espécies em coexistência foram observadas correlações significantes com os indicadores de densidade e, em relação aos índices utilizados em rotina, a correlação foi verificada somente com Índice de Breteau (Tabela 29).

Tabela 29 - Comparações entre os Indicadores Entomológicos e a Emergência Mensal de Fêmeas de Ae. aegypti, Ae. albopictus e ambas as espécies, São Sebastião, São Paulo, Brasil, no período de 10/2002 a 04/2003 e 10/2003 a 04/2004.

Correlação de Spearman $(\alpha<0,05)$

\begin{tabular}{llll}
\hline & \multicolumn{3}{c}{ Emergência de Fêmeas (EM) } \\
\cline { 2 - 4 } Índice Entomológico & Ae. aegypti & Ae. albopictus & Ambos \\
\hline DLR & $*$ & $r=0,81$ & $r=0,56$ \\
& & $p=0,000$ & $p=0,036$ \\
DPR & $r=0,95$ & $r=0,98$ & $r=0,90$ \\
& $p<0,000$ & $p<0,000$ & $p<0,000$ \\
DLI & $*$ & $r=0,76$ & $r=0,63$ \\
& & $p=0,002$ & $p=0,017$ \\
DPI & $r=0,98$ & $r=0,98$ & $r=0,98$ \\
& $p<0,000$ & $p<0,000$ & $p<0,000$ \\
ÍR & $*$ & $r=0,66$ & $*$ \\
& & $p=0,012$ & $*$ \\
ÍP & $*$ & $r=0,55$ & \\
& & $p=0,042$ & $r=0,58$ \\
ÍB & $r=0,59$ & $r=0,63$ & $p=0,030$ \\
\hline & $p=0,03$ & $p=0,016$ &
\end{tabular}

DLR $=$ Densidade de larvas por recipiente, $D P R=$ Densidade de pupas por recipiente; DLI= Densidade de larvas por imóveis, DPI= Densidade de pupas por imóveis, IR= Índice de Recipiente, $\mathrm{IP}=$ Índice predial, IB= Índice de Breteau. * Não houve associação. 


\section{DISCUSSÃO}

\section{1 - Composição da fauna de culicídeos imaturos encontrados nos criadouros}

A atividade humana sobre o ambiente altera-o profundamente resultando em ecossistemas com certo grau de empobrecimento da sua parte abiótica e biótica tanto animal quanto vegetal, e assim, favorecendo espécies oportunistas, que traduz muitas vezes na diminuição da diversidade primitiva (FORATTINI 2004). A composição da fauna de culicídeos encontrada em criadouros em áreas urbanas geralmente é composta por número reduzido de espécies. Isto pode ser interpretado em parte porque o grande número de recipientes que abriga os imaturos de culicídeos em ambiente urbano é de origem artificial. Nesse tipo de criadouro, a teia alimentar é baseada na decomposição de detritos, portanto, a redução da produção primária implicaria no limite do número de níveis tróficos e isto, conseqüentemente, reduziria o suporte do número de espécies (WASHBURN 1995). É de se supor que tal situação estaria favorecendo espécies com grande capacidade de explorar esse tipo de hábitat, como Ae. aegypti e Ae. albopictus.

O número de espécies encontrado (30) comparado ao encontrado em outros estudos realizados em ambiente urbano foi considerado relativamente grande (LOPES e col. 1993; PEREIRA 2001); entretanto a maior riqueza foi verificada em criadouros classificados como natural (Tabela 1) e neste, a bromélia foi o criadouro predominante $(80 \%)$. A riqueza geral encontrada pode, em parte, ser entendida pela grande oferta deste tipo de hábitat, pois, é geralmente colonizado por número variado de espécies de culicídeos. $\mathrm{O}$ volume d'água destes microhabitats é mantido constante e isto favorece a utilização destes vegetais como locais de procriação de insetos. MARQUES e col. (2001) encontraram mais de 30 espécies de culicídeos em bromélias de áreas urbanas e periurbanas em São Paulo. 
A espécie Ae. aegypti foi a mais freqüente, com $44 \%$ do total de imaturos coletados, sendo encontrada nas 12 categorias de criadouros, em 8 delas estava em maior número do que as demais espécies presentes (Tabela 1). Espécies como Ae. aegypti e Ae. albopictus são consideradas do tipo generalista, ou seja, com grande capacidade de explorar diversos tipos de criadouros artificiais e naturais em ambientes urbanos (LAIRD 1988; FORATTINI 2002).

Ambas já foram assinaladas explorando criadouros de origem vegetal e em várias situações (LAIRD 1988; O’MEARA e col. 1993; O’MEARA e col. 1995; NATAL e col. 1997; CHADEE e col. 1998; FORATTINI e MARQUES 2000; LOUNIBOS e col. 2003). Os ecótopos naturais podem existir em grande oferta em ambientes urbanos e, nesse particular, na região em estudo, é comum o encontro de vegetais da família Bromeliaceae, pois são plantas nativas da Mata Atlântica, com a qual a área urbana de São Sebastião guarda proximidade.

As bromélias foram bastante freqüentes, abrigando formas imaturas de Ae. aegypti, Ae. albopictus e as espécies em situação de coexistência (Anexos 1 a 3, Tabelas 30 a 32). Estavam dispostas no ambiente como plantas remanescentes, ou seja, aquelas que permaneceram no ambiente após as alterações resultantes da urbanização. Em outros casos foram colocadas com fins ornamentais. Estas últimas geralmente estavam em jardins e em vasos próximos ou no interior das residências. Ainda que neste estudo estas plantas fossem incluídas dentro da categoria de criadouros naturais, em determinada situação podem ser consideradas como criadouros artificiais, como no caso daquelas para fins ornamentais (FORATTINI e col. 1998a).

Já houve outros registros de Ae. aegypti colonizando bromélias (CHADEE e col. 1998; FORATTINI e MARQUES 2000; CUNHA e col. 2002; LOUNIBOS e col. 2003; VAREJÃO e col. 2005). No litoral norte, este evento parece ser recente. Em estudo realizado em área urbana de São Sebastião no período de 1996 a 2001 por PASSOS e col. (2003), não foi feito registro de bromélia com presença de Ae. aegypti. Contudo, há que se salientar a freqüência desta espécie neste microhabitat no presente estudo, considerando a recente exploração da bromélia por Ae. aegypti, o número foi relativamente alto em relação às demais espécies presentes (Tabela 1). 
A segunda espécie mais freqüente foi Ae. albopictus (17\%) que também estava presente em todas as categorias de recipiente, mas o total de exemplares coletados corresponde a menos da metade da espécie anterior. Apenas na categoria natural apresentou discretamente maior número, sendo neste caso, mais freqüente entre todas as espécies presentes (Tabela 1). BRAKS e col. (2004), concluíram que esta espécie teve melhor desempenho que Ae. aegypti ao explorar folhas em decomposição como recurso e, no caso de criadouros naturais, onde supõe-se que este tipo de material seja farto.

O'MEARA e col. (1993) relatam intensa ocupação de bromélias por Ae. albopictus em Gainesville na Flórida. Igualmente MARQUES e FORATTINI (2005), descreveram a exploração de bromélias por esta espécie em ambiente urbano de Ilhabela, também no litoral norte do Estado de São Paulo; os autores já apontavam a importância deste microhabitat na propagação de espécies de culicídeos em áreas urbanas da região. Em incremento a isto, o fato de que esta espécie foi encontrada explorando estes vegetais em ambiente de mata residual e preservada, o coloca com possibilidade de envolver-se em ciclo zoonótico de agentes patogênicos e posteriormente, envolver o homem (NATAL e col. 1997; FORATTINI e col. 1998a; ALBUQUERQUE 2000).

Segundo os resultados aqui apresentados, esta situação tem grande probabilidade de ocorrer na região, sendo que a espécie encontra-se na área urbana de São Sebastião, e esta guarda estreita proximidade com mata preservada, onde pode ocorrer a circulação de vírus.

CHADEE e col. (1998), sugerem que a ocupação de criadouros naturais na margem de mata próxima a ambientes urbanos poderia manter populações de $A e$. aegypti em período de controle químico. Esta situação seria responsável pela rápida reinfestação das áreas urbanas após o efeito residual dos inseticidas ter passado, desencadeando posteriormente, novos surtos inter-epidêmicos. LOURENÇO-deOLIVEIRA e col. (2004) também apontam para fenômeno semelhante ocorrendo em área de floresta urbana do Rio de Janeiro. Dado o encontro das duas espécies em recipientes naturais e a proximidade da área urbana com a mata natural, seria permitido supor que tal situação tenha possibilidade de ocorrer na região de São Sebastião. 
Ae. albopictus está presente desde 1989 em São Sebastião com ampla distribuição; já Ae. aegypti, a partir de 1996, iniciou sua expansão e atualmente é a espécie mais freqüente no ambiente urbano. Em particular nos resultados deste estudo, observa-se que Ae. aegypti teve maior freqüência na ocupação de quase todas as categorias de recipientes artificiais e foi a espécie dominante. Todavia, Ae. albopictus ainda continua a explorar intensamente os ecótopos artificiais dispostos no ambiente urbano (Tabela 1), o que nos leva a pensar que existem fatores que permitem esta situação de coexistência na região, e que precisam ser investigados.

Ainda em relação à fauna de culicídeos, há que salientar o encontro numeroso de representantes da espécie Culex quinquefasciatus em todas as categorias de criadouros (Tabela 1). A característica altamente antropofílica e sua adaptação ao ambiente antrópico é bastante conhecida, entretanto, sabe-se de sua preferência por criadouros com água altamente poluída, dotada de altos teores de matéria orgânica em decomposição, em alguns casos em processo de fermentação (FORATTINI 2002). Neste estudo, como esta espécie foi encontrada coexistindo com Ae. aegypti e Ae. albopictus, é possível supor que muitos destes criadouros apresentavam certo grau de poluição orgânica.

Limatus durhami só não estava presente em ralos (Tabela 1), entretanto o encontro freqüente em recipientes artificiais próximos ao ambiente urbano já tem sido relatado por diversos autores que atribuem à este comportamento caráter indicativo de domiciliação (LOPES e col. 1993). Esta espécie apresenta hábito de predador em situação de falta de alimento (FORATTINI 2002), atividade que poderia realizar na maior parte dos criadouros onde não foram registradas espécies predadoras, o que poderia ser considerado como uma vantagem para sua manutenção na comunidade em relação às demais espécies.

A mudança qualitativa de comportamento no uso de recipientes como criadouros por parte de espécies que conservavam preferências a ecótonos naturais, chama atenção para o potencial de adaptabilidade das populações de culicídeos (FORATTINI 1998b). Isto pôde ser observado por várias espécies encontradas nos criadouros inspecionados ao longo deste estudo. É o caso do registro de Oc. scapularis, 
An. evansae e An. argyritarsis em recipientes de plástico e em caixas d'água (Tabela 1), sendo esta última foi assinalada em situação semelhante por FORATTINI e col. (1998c).

Esta pesquisa não objetivou discutir as interações ecológicas, entre as espécies de culicídeos que ocorrem em ambiente antrópico, para tanto serão necessários outros estudos que visem conhecer melhor estas interações. Os conhecimentos adquiridos poderão contribuir para o melhor entendimento do comportamento e abundância de Ae. aegypti e Ae. albopictus nestas áreas, assim como as implicações epidemiológicas que estas possam ter sobre a saúde da população humana local. 


\section{2 - Imóveis e recipientes positivos}

Atualmente, a categorização dos imóveis quanto ao padrão de uso e ocupação do solo, ou seja, o tipo de atividade a qual se destinam os imóveis, tem se tornado aspecto de utilização cada vez mais freqüente em estudos de planejamento e avaliação em ambientes urbanos.

A estratificação das espécies vetoras segundo o padrão dominante do uso do solo, ou seja, a distribuição e freqüência delas nas categorias de imóveis, é a informação que permite diferenciar, priorizar e direcionar as atividades de controle. TUN-LIN e col. (1995) apontaram a necessidade de identificação de imóveis chaves para a avaliação da produção de Ae. aegypti e conseqüente direcionamento do controle.

Dentre as atividades do programa de controle de Ae. aegypti do Estado de São Paulo, podemos citar ao menos duas que direcionam a vigilância e o controle em determinados imóveis. A primeira é denominada Pesquisa em Ponto Estratégico, onde são selecionados imóveis que reúnem características as quais favorecem a geração e a dispersão ativa ou passiva do vetor. A segunda atividade compreende as Pesquisas em Imóveis Especiais, imóveis não residenciais de médio e grande porte que apresentam maior importância na disseminação do vírus de dengue, geralmente locais com grande aglomeração de pessoas (SESSP/SUCEN 2002).

A residência térrea e sobrado, aqui denominada casa, foi o tipo de imóvel onde mais freqüentemente encontrou-se recipientes com Ae. aegypti (77,5\%), Ae. albopictus $(95,3 \%)$ e com ambas as espécies $(89,5 \%)$ (Tabela 2). Em São Sebastião, a área comercial está mais concentrada na região central, embora existam também algumas residências. No entanto, a grande parte dos imóveis residenciais está distribuída ao longo da malha urbana, evidenciando ampla distribuição das duas espécies. SCHREIBER e col. (1992) registraram maior parte dos focos em residências, atribuindo a esta característica de alta infestação, o que corrobora com os dados apresentados.

PEREIRA (2001) registrou maior positividade de recipientes em imóveis não residenciais, na região de Santos, litoral sul do Estado de São Paulo. Embora as duas 
regiões estejam localizadas no litoral do mesmo Estado, provavelmente as diferenças de uso e ocupação do solo e a intensidade de urbanização estariam determinando a divergência desses resultados. As regiões podem apresentar diferentes características relativas a atividade antrópica, com reflexo na distribuição das espécies no ambiente urbano, o que deve ser considerado nas ações de controle.

O segundo tipo de imóvel com maior freqüência da espécie Ae. aegypti $(5,3 \%)$, estava entre aqueles que geralmente não são muito comuns e, portanto, é normalmente classificado na rotina das atividades como "Outros" (Tabela 2). Embora o percentual seja muito inferior ao primeiro tipo, ressalta-se aqui a inclusão de imóveis que servem como garagem de embarcações e que localmente são chamadas de marinas. São grandes áreas que abrigam, às vezes, centenas de barcos.

Na região, as marinas são muito comuns, sendo que há 25 apenas no município de São Sebastião. Nestes imóveis foi encontrado número representativo de recipientes positivos para esta espécie. Estes criadouros eram embarcações dos mais variados tipos e padrões (Anexo 1, Tabela 30). As larvas e pupas geralmente eram encontradas no compartimento próximo ou abaixo do motor e muitas vezes a água apresentava resíduo de óleo. De certa maneira, isto explica a ampla variedade de criadouros utilizados pelas fêmeas de Ae. aegypti que vão desde água limpa até intensamente poluída (FORATTINI 2002).

Tais criadouros se configuram como locais de difícil acesso e isto impõe situações que podem comprometer as atividades de controle local. Cabe ressaltar que os barcos estacionados nessas garagens são de propriedade particular, portanto, de difícil inspeção por parte das equipes de controle, sendo necessária a autorização e o acompanhamento de profissional responsável pela guarda e que muitas vezes não está disponível no momento da visita.

Dentro da classificação de Imóveis Especiais feita pelo programa de controle, destacam-se os hotéis, pousadas, hospitais, clínicas entre outros. Os hospitais e hotéis também foram imóveis com presença de Ae. aegypti (Tabela 2), sendo que estes últimos existem em número considerável, pois a região é bastante visitada por turistas. Considerando a presença de Ae. aegypti em hospitais, unidades de saúde e clínicas e o 
fato de serem estes os locais para onde geralmente afluem os casos de dengue, ressaltase a necessidade de orientação adequada das autoridades de vigilância e controle quanto ao risco que representa a ocupação destes tipos de imóveis por esta espécie.

A distribuição da espécie Ae. albopictus nos tipos de imóveis foi mais restrita a imóveis residenciais, embora tenha sido encontrada em menores percentuais também em imóveis como comércio e construção (Tabela 2). BRAKS e col. (2003) sugerem haver segregação de hábitats entre as duas espécies em relação a cobertura vegetal, os autores relatam que a Ae. aegypti foi mais prevalente em áreas altamente urbanizadas e Ae. albopictus em área suburbana e rural, embora presente em áreas urbanas com vegetação.

A área urbana de São Sebastião é caracterizada por extensão estreita entre a serra e o mar e é permeada por vegetação. A parte central é constituída por construções mais antigas e predomina o comércio com menor concentração de vegetação (Anexos 12 a 14, Figuras 19 a 23). Considerando a ocupação dos recipientes artificiais pelas duas espécies, a feição paisagística do ambiente urbano e a distribuição das espécies nos tipos de imóveis, podemos assumir que ambas as espécies estavam presentes em toda a área urbana, podendo ainda estar valendo-se da localização destes recipientes em relação á presença e variação da vegetação.

Era esperada a existência de grande oferta de recipientes artificiais em ambiente urbano, o que foi observado na área de estudo (Tabela 3), entretanto, agrava-se o fato de que o tipo de imóvel mais freqüentemente positivo foi o residencial. Embora apenas $10 \%$ destes abrigassem imaturos de culicídeos, $80 \%$ dos imóveis com culicídeos registraram ao menos uma das duas espécies vetaras (Figura 2). O aumento do número de espécies na comunidade determina o número de níveis tróficos e, conseqüentemente a dominância das espécies nesta comunidade diminui. Por outro lado, hábitats com comunidade menos diversa limita os níveis tróficos e há o aumento da população dominante pela liberação ecológica, ou seja, expansão do hábitat e do uso de recursos (RICKLEFS 2001).

A espécie Ae. aegypti foi a mais freqüente em todas as categorias de recipientes artificiais, $70 \%$ do total foi coletado em criadouros que não apresentavam 
outros culicídeos e apenas $15,2 \%$ e $14,5 \%$ continha Ae. albopictus e outros culicídeos respectivamente. Por outro lado Ae. albopictus foi solitária em apenas $41 \%$ dos criadouros, $23 \%$ em situação de coexistência com a primeira e $36 \%$ com outros culicídeos.

Os recipientes artificiais possuem geralmente poucos níveis tróficos, a nítida predominância de Ae. aegypti tanto no número de recipientes quanto na situação em que foi o único culicídeo no criadouro, permite supor que esteja havendo o processo de liberação ecológica com dominância desta espécie. Contudo, a maior freqüência apenas não é o único aspecto para atribuição do status de espécie dominante, pois, muitas espécies tornam-se dominantes pela capacidade em explorar com mais eficiência os recursos disponíveis (FORATTINI 2004). Neste particular, Ae. albopictus já foi apontado por diversos autores como sendo excelente competidor em determinadas circunstâncias. Podemos citar como exemplos, ao alimentar-se com folhas em decomposição, em áreas com vegetação abundante e quando em alta densidade (BARRERA 1996; JULIANO 1998; BRAKS e col. 2004; SERPA 2004).

Em que pese Ae. albopictus estar presente em todas as categorias de recipiente, o número de criadouros apresentou queda ao longo do período de estudo (Tabela 1 e Figura 3), o que sugere declínio da população desta espécie, e mais uma vez contrapondo á alta freqüência de Ae. aegypti, evidenciando o seu predomínio. Entretanto, é interessante ressaltar que recipientes com presença das duas espécies manteve o número em todos os meses, portanto não descarta-se a coexistência destas duas espécies na região. FORATTINI (2004) argumenta que na coexistência competitiva, a disputa por recursos pode resultar, em alguns casos, no estado de equilíbrio entre duas populações. Havendo um ajustamento que pode ser entendida por separação ecológica, esta pode ser definida de diversas maneiras ou por ocupação de lugares diferentes ou por utilização de recursos diferentes entre outras.

DAUGHERTY e col. (2000) sugerem que o acúmulo de carcaças de invertebrados pode reduzir a competição de recursos entre mosquitos, por ser um importante tipo de alimento em muitos tipos de comunidades de recipientes. Os variados tipos de criadouros encontrados neste estudo e a ocorrência das duas espécies em todas 
as categorias pode, em alguns casos, ser resultado de fatores como a exploração de alimentos diferentes ou o acúmulo do mesmo. No entanto, tal hipótese carece de investigações mais detalhadas.

Vários autores discutem aspectos que sugerem a existência de competição entre estas espécies em várias partes do mundo (GILOTRA 1967; O'MEARA e col. 1993; BARRERA 1996; JULIANO 1998; LOUNIBOS e col. 2002; BRAKS e col. 2004; SERPA 2004), apontando ora sob um aspecto a favor de Ae. aegypti, ora a favor de Ae. albopictus.

Este estudo não teve a pretensão de comprovar teorias acerca deste assunto, contudo, admite-se que na discussão da produtividade de criadouros em áreas de simpatria destas espécies é necessário tecer considerações sobre as interações ecológicas que ocorrem no ambiente, uma vez que, tais aspectos podem ter reflexos diretos na produtividade de cada população e, conseqüentemente, na interpretação dos resultados alcançados. Vale ressaltar que $80 \%$ dos municípios infestados no Estado de São Paulo apresenta situação de coexistência destas espécies. 


\section{3 - Abundância e produção segundo a categoria do recipiente}

A abundância de imaturos é característica importante a ser considerada na avaliação da produtividade, entretanto, é necessário analisá-la em conjunto com outros aspectos tais como a freqüência relativa de recipientes, a produção de larvas e pupas em relação ao tipo de criadouro e sua situação no ambiente.

TUN-LIN e col. (1995) argumentam que os recipientes podem contribuir de forma desigual para a população de adultos. FOCKS e col. (1981), estudando a produtividade de Ae. aegypti em New Orleans, encontraram maior freqüência de pequenos recipientes no ambiente (50\%), entretanto estes estavam contribuindo apenas com 7\% da produção de imaturos e número reduzido de grandes reservatórios estavam produzindo os maiores percentuais. Tais informações estão diretamente ligadas aa decisões de intervenção e controle, pois, podem influenciar na definição e priorização das ações.

Nos resultados das avaliações realizadas para imaturos de Ae. aegypti, a freqüência de recipientes apontou as categorias, plástico, natural e metal nesta seqüência como tendo sido os mais abundantes no ambiente. Entretanto, quando consideramos os números relativos, a fibra e o cimento passam a ser mais importante que a categoria natural, abrigando percentual maior de larvas e de pupas (Tabela 6). Se considerássemos apenas a freqüência de criadouros, a categoria fibra, que não foi muito freqüente, poderia não ter a atenção merecida, pois, somou apenas $8 \%$ do total mas, na produção de imaturos foi importante tanto para larvas quanto para pupa. Neste caso, se a amostragem do criadouro principal desta categoria, ou seja, o barco, tivesse sido maior, os resultados poderiam ser diferentes. Como já discutido anteriormente, geralmente são de difícil acesso e em alguns casos seria possível não terem sido inspecionados.

Houve aumento no número de recipientes e de imaturos ao longo do estudo (Figuras 2 e 3 ) e isto pode estar relacionado ao fato de que a incidência de casos a partir de 2003 ter caído de maneira drástica (Anexo 10, Tabela 38), o que poderia levar a população local a relaxar e deixar estes recipientes dispostos no ambiente. Isto, também 
pode ter contribuído para que recipientes das categorias, plásticos e metais tenham sido os criadouros mais produtivos, pois, apresentaram diferença significante para a produção de larvas e pupas, enquanto que as demais categorias apresentaram produção semelhante (Tabelas 7 e 8, Figuras 5 e 6).

Apenas quatro tipos de recipientes de plástico somaram 16,7\% dos criadouros resultando em $19,4 \%$ e $14,2 \%$ de larvas e pupas respectivamente (pote, balde, lona e peças plásticas). E entre os metais as latas e os tambores corresponderam a 9,5\% dos recipientes, $14,9 \%$ e $12,5 \%$ de larvas e pupas (Anexo 1, Tabela 30). Tanto a freqüência quanto a produção, neste caso, parecem ter colaborado para esses resultados.

$\mathrm{Na}$ área de estudo, os recipientes de plásticos são muito comuns, pois em razão de características do ambiente, como a freqüente oxidação dos metais devido a maresia, os recipientes de plásticos são preferenciais, e isto nos mais diversos usos, tais como calhas, lonas, baldes etc. As latas e tambores geralmente são utilizados em construções para acondicionar água. Como se trata de região de litoral e de turismo, a expansão urbana é constante, resultando em grande número de construções ao longo da malha urbana.

VEZZANI e SCHWEIGMANN (2002), estudando recipientes segundo o tipo de material na Argentina, apontaram os recipientes plásticos como os mais freqüentemente positivos para $A e$. aegypti, mesmo quando a oferta destes era menor que outro tipo. Contudo, a média de imaturos entre os tipos de recipientes segundo o material foi semelhante, ou seja, os recipientes plásticos, embora mais freqüentes, não eram os mais produtivos.

A distribuição dos recipientes contendo Ae. albopictus também apresentou mudança na importância das categorias entre as análises. As categorias dos recipientes naturais, metais e plásticos foram os mais freqüentes, respectivamente, enquanto a média de imaturos por recipiente foi maior nas categorias de metal, pneu e caixa d'água para larvas, e fibra e pneu para pupas (Tabela 9).

$\mathrm{Na}$ análise de produção, as categorias de plástico, metal, vaso e natural foram, nesta ordem, significantemente diferente em relação as demais (Tabelas 10 e 11, Figuras 8 e 9). Estes dados corroboram em parte com os encontrados por BRITO e 
FORATTINI (2004) em estudo realizado na região do Vale do Paraíba no Estado de São Paulo, no qual eles apontam as latas, potes, pneus, caixa d'água e tambores como sendo os recipientes mais produtivos para esta espécie.

Pelos resultados aqui apresentados, fica evidente que a ordem de importância muda, dependendo da análise, pois, alguns recipientes menos freqüentes também continham maior percentual de imaturos, tanto para larvas como para pupas, em categorias diferentes. Na simples análise da freqüência de recipientes, poderíamos não detectar a importância de algumas categorias para a produção de larvas e pupas.

Interessante notar que as duas espécies estavam presentes em todas as categorias de criadouros e tiveram o plástico e o metal como as categorias mais produtivas (Tabelas $7,8,10$ e 11), evidenciando a presença das duas espécies no ambiente urbano. Sugerindo que distribuição das espécies, neste ambiente, pode ter dependido da localização do criadouro em relação a vegetação. Em observações realizadas no Rio de Janeiro e Flórida, a maior abundância de Ae. albopictus foi registrada em áreas rurais, sub-urbananas e em áreas urbanas com vegetação, enquanto que Ae. aegypti predominava apenas em áreas altamente urbanizadas (BRAKS e col. 2003).

Em recipientes com a presença das duas espécies, também foi possível identificar resultados diferentes entre as análises, sendo os recipientes mais freqüentes plástico, natural e metal, nesta ordem. As larvas de Ae. aegypti foram mais abundantes em fibra, planta aquática e metal, as pupas, em fibra, ralo e pneu. Também na análise de abundância de larva e pupa na categoria, a fibra passa a ter importância maior que as demais categorias. As larvas de Ae. albopictus estavam distribuídas em quase todas as categorias, os maiores percentuais de pupas foram em fibra e pneu (Tabela 12).

Algumas categorias que foram menos freqüentes também estavam abrigando altos percentuais de imaturos. Mesmo em situação de coexistência, os recipientes com produção média para as duas espécies foram de origem artificial, sendo das categorias plásticos e metais (Tabela 13), sugerindo mais uma vez que as duas espécies estavam presentes em todo o ambiente urbano. A co-ocorrência das duas espécies também foi registrada num inesperado e elevado número em armadilhas em 
todos os ambientes avaliados, ou seja, no urbano, no rural e no sub-urbano de acordo com estudo realizado no Rio de Janeiro e na Flórida (BRAKS e col. 2003).

A redução do número recipientes potenciais do ambiente, com vistas a diminuir os locais de procriação desses mosquitos, é uma das premissas básicas da maior parte dos programas de controle de vetores de dengue.

A educação e participação da comunidade têm sido incorporadas como um importante componente destes programas (OPAS 1991; MS/FNS 1996; SESSP/SUCEN 2002). Portanto, a remoção de recipientes do ambiente é imprescindível para o sucesso de qualquer programa de vigilância e controle. No entanto, segundo dados aqui apresentados, o maior percentual de recipientes positivos foram classificados como removíveis (Tabelas 6, 9 e 12), ou seja, poderiam ser facilmente retirados do ambiente. Estes dados corroboram com os apresentados por BRITO e KITA (2003) em estudo no mesmo município, sobre a associação da reciclagem de resíduos e criadouros de Ae. aegypti. Os autores relatam que $58 \%$ do total de recipientes recicláveis eram criadouros desta espécie.

É consenso que a retirada e inutilização de recipientes não dependem somente do poder público, mas deve ser uma conduta incorporada à cultura da comunidade, ainda mais aquelas que já vivenciaram epidemias de dengue, como São Sebastião (Anexo 10, Tabela 38). Entretanto, tanto o número de recipiente quanto o de imaturos aumentaram ao longo desse estudo (Figuras 2 a 4 e 7), demonstrando que muito provavelmente a comunidade deixou de fazer a sua parte na redução de criadouros.

Vários autores ressaltam a necessidade de mudanças nos hábitos e costumes da população frente a estas questões, assim como o melhor entendimento que esta deve ter de sua responsabilidade social no risco de epidemias de dengue (FAJARDO e col. 2001; LEFREVE e col. 2004; KAY e VU 2005; TEIXEIRA e col. 2002). SANCHEZ e col. (2005) argumentam que a incorporação de cientistas sociais promoveu mudanças na gerência do programa, o que facilitou a mobilização social e como retorno uma significante mudança no conhecimento, atitudes e práticas da população, relacionadas á dengue. 
Estudos que tenham como desígnio conhecer os motivos pelos quais as estratégias de comunicação utilizadas e as atividades de educação aplicadas pelos programas não desencadeiam mudanças permanentes nas atitudes e práticas da comunidade são necessárias para subsidiar planejamentos e estratégias de prevenção e controle mais eficazes.

Diante do exposto, se houvesse a retirada dos recipientes removíveis, restariam aqueles que foram aqui classificados como recipientes fixos, portanto não sendo possível ou de difícil remoção do ambiente. FORATTINI e BRITO (2004) classificam tais criadouros como sendo permanentes, ou seja, aqueles que podem estar constantemente sendo explorados como locais de criação por esses vetores. Neste estudo, os recipientes corresponderam em média $40 \%$ do total de recipientes positivos (Tabelas 6, 9 e 10). Dentre eles, os mais produtivos foram aqueles classificados como naturais e os da categoria fibra.

Ainda em relação aos recipientes fixos, persiste o caráter particular dos criadouros naturais, que foram em sua maioria bromélias, e dos de fibra, tendo este os barcos como principal representante. Sendo abundantes e próprios da região, a retirada dos recipientes descartáveis pode elevar ainda mais a importância destes criadouros, pois, ambos podem manter populações destas espécies ao longo do ano, a despeito das ações de controle sobre os demais recipientes (CHADEE e col. 1998). O primeiro, devido à sua característica de manter o volume líquido e que, em muitas ocasiões, exerce papel semelhante aos artificiais (FORATTINI e col. 1998a), pois, foram comuns em jardins e em vasos, submetidos a regas e manipulações constantes. $\mathrm{O}$ segundo, em razão da grande oferta e dificuldade de acesso para inspeção e controle.

Os vasos sanitários foram os recipientes mais freqüentes dentro da categoria louça/cerâmica (Anexos 1a 3, Tabelas 30 a 32). Em regiões de litoral é muito comum o encontro destes recipientes abrigando larvas e pupas destes mosquitos, pois, geralmente estão localizados no interior de casas que são utilizadas apenas em alguns meses do ano, não sendo alcançados pelas atividades de controle.

Os ralos também foram criadouros comuns nestes imóveis. Este foi um dos principais criadouros de Ae. aegypti e aquele que produzia pupas em maior número e 
tamanho em Santos, São Paulo (PEREIRA 2001), devendo portanto, devem ser alvos de ação direcionada de controle.

Os resultados aqui apresentados apontam para algumas categorias de criadouros que podem estar contribuindo para a população adulta destas espécies na região. Entretanto, são necessárias outras observações sistemáticas que permitam distinguir a dinâmica de ocupação dos diferentes criadouros em função da freqüência destes no ambiente e da capacidade de exploração dos mesmos por parte dos vetores.

A incorporação de análises de produtividade na atividade de Avaliação de Densidade dos programas poderá contribuir no acompanhamento ao longo do tempo, incrementando as informações para melhor direcionamento das ações de controle de cada região. 


\section{4 - Emergência de fêmeas}

A estimativa da densidade de adultos a partir da coleta de fêmeas seria a informação mais apropriada para avaliar o risco de epidemias. Contudo, a dificuldade operacional e as implicações éticas para estudo em campo inviabilizam a obtenção sistemática tal informação.

Atualmente, vários estudos têm buscado alternativas que possibilitem a estimativa de adultos utilizando a produtividade de criadouros, ou seja, a contribuição dos criadouros para a população adulta. O cálculo de emergência foi proposto, levandose em conta o número de pupas coletadas nos recipientes (FOCKS e col. 1981).

Em estudo conduzido com Ae. albopictus no Vale do Paraíba, São Paulo, foi observado perfil de produção semelhante entre os testes estatísticos e os resultados da emergência de adultos (BRITO e FORATTINI 2004). FOCKS e CHADEE (1997) concluíram que a estimativa da produtividade de adultos, fornecida pela contagem de pupas, seria a mais indicada para monitorar o risco de transmissão e de fácil operacionalização, pois, a contagem total é possível na maioria dos criadouros.

Neste estudo a emergência mensal de fêmeas das duas espécies teve tendência semelhante aos resultados obtidos com os imaturos, ou seja, aumento de $A e$. aegypti e queda de Ae. albopictus, sendo que esta diferença foi estatisticamente significante (Teste Mann-Whitney; $n=14 ; \mathrm{U}=156,5$ e $\mathrm{p}=0,006$ ). Mais uma vez ocorreu a predominância da primeira espécie sobre a segunda. Entretanto, em criadouros em situação de coexistência, a emergência foi curiosamente semelhante (Teste MannWhitney; $\mathrm{n}=14 ; \mathrm{U}=103$ e $\mathrm{p}=0,84$ ), ou seja, os recipientes contendo ambas as espécies estavam produzindo, em média, o mesmo número de fêmeas para as duas espécies.

Condições relacionadas a densidade; capacidade exploratória da variedade, tipo e quantidade de alimento; excreção de substância químicas; localização do criadouros em relação à vegetação, podem ser fatores determinantes para esta situação de coexistência (MORI 1979; BARRERA 1996; JULIANO 1998; DAUGHERTY e col. 2000; BRAKS e col. 2004; JULIANO e col. 2004). 
A emergência mensal de fêmeas para cada 100 imóveis ao dia não representa a estimativa da população total de adultos na área, mas indica uma estimativa da produção média de fêmeas ao dia dos recipientes, no intervalo de tempo avaliado.

$\mathrm{Na}$ comparação de emergência de fêmeas de Ae. aegypti entre as categorias de criadouros foi observado que os plásticos e metais também apresentaram maior emergência durante todo o período do estudo (Tabelas 15 e 18). É razoável assumir que estas categorias foram as mais produtivas para esta espécie.

Para Ae. albopictus, as categorias plástico e natural foram as que em média produziram mais fêmeas (Tabelas 16 e 19). A identificação da categoria que em média estaria produzindo mais fêmeas nos dias da coleta poderia contribuir para o direcionamento do controle destes criadouros na ocasião.

Segundo MORRISSON e col. (2004a), a vigilância pupal e demográfica pode melhorar a informação sobre os vetores, podendo ter imediato benefício no programa de controle, principalmente para desenvolver estudos de controle específico de criadouros e de educação em saúde para a comunidade local. Os mesmos autores afirmam que a estimativa de pupas por hectare foi o índice mais robusto e estável e semelhante ao índice de adulto por hectare, recomendando o seu uso em rotina, pois, estes índices fornecem estimativa imediata de risco de transmissão do vírus de dengue (MORRISSON e col. 2004b).

Seguindo esta linha de raciocínio, podemos admitir que a produção de fêmeas a partir da contagem total de pupas dos criadouros é factível em avaliações sistemáticas, sendo que na maior parte dos recipientes é possível a inspeção de todo o volume.

Os resultados permitiriam indicar a importância e a contribuição da produção média de fêmeas para a população adulta, segundo o tipo e freqüência do criadouro no lapso de tempo em que é realizada a avaliação, ou seja, cinco dias. Tais informações contribuiriam para avaliação mais aprimorada e direcionada das ações de controle em diferentes regiões. Levando-se em conta as características de cada região, considerando os criadouros e áreas como diferentes, pois dependendo da avaliação 
sistemática e do direcionamento das ações os resultados podem diferir ao longo do tempo. 


\section{5 - Variáveis físicas e químicas}

O hábitat define o lugar de um organismo na natureza e é nele que se observa a variedade de condições sob as quais os organismos estão expostos. $\mathrm{O}$ nicho representa o conjunto de intervalos de condições que determinado organismo pode tolerar (RICKLEFS 2001). Portanto, as condições físicas e químicas, suas variações no ambiente e microambiente e suas relações com as populações de mosquitos podem conter informações elucidativas sobre sua bioecologia. Os conhecimentos gerados em estudos ecológicos devem ser considerados para a elaboração de estratégias de vigilância, controle e avaliação de mosquitos vetores (SERVICE 1992).

As variáveis consideradas para análise em relação ao microambiente do criadouro foram: pH, temperatura da água, oxigênio dissolvido, condutividade elétrica, salinidade e volume líquido. Quanto ao macroambiente, considerou-se a temperatura média e índices pluviométricos dos 15 dias que antecederam a coleta.

Houve um gradiente amplo para todos os parâmetros físicos e químicos da água dos criadouros das duas espécies, estando estas ou não em situação de coexistência (Tabelas 20, 21 e 22). Os fatores físicos e químicos da água do criadouro podem variar de acordo com a densidade de imaturo (SINHA 1976). RICHARDSON (1999) estudando a ecologia de comunidades de organismos nas bromélias, concluiu que a matéria orgânica, a abundância animal e riqueza de espécies foram correlacionadas positivamente com tamanho da planta. Portanto, o volume líquido, a interação de outras espécies presentes nos criadouros, assim como as densidades das populações de cada uma, podem influenciar estes resultados, fatores não avaliados neste trabalho.

Contudo, podemos sugerir que as amplas variações observadas nesses resultados não foram determinantes para a presença ou ausência das duas espécies aqui estudadas isoladas ou quando em coexistência. Segundo estas considerações, seria lícito afirmar que as duas espécies puderam tolerar amplo gradiente de variação de todos os parâmetros mensurados. 
- Volume líquido

O volume líquido encontrado nos criadouros sugere o espaço circunscrito deste microhabitat para as fases imaturas dos culicídeos. Deste modo, o tamanho do corpo d'água reflete sua capacidade de saturação tanto dos organismos como das substâncias físicas e químicas que o compõe. O volume de água pode caracterizar um criadouro como permanente ou transitório, assim sendo, a densidade de adultos sofrerá flutuação decorrente da produtividade destes criadouros, ao menos, em parte, independente das precipitações de chuva (FORATTINI 2002).

Neste estudo, o volume não foi medido na totalidade dos recipientes, restringindo assim, a análise da produtividade para este parâmetro. Os recipientes pequenos corresponderam a 58 e $52 \%$ do total para Ae. aegypti e Ae. albopictus, respectivamente. Não houve diferença na produção de larvas e pupas entre os tamanhos de recipientes para as duas espécies. Portanto, ao considerarmos o tamanho, os pequenos mesmos sendo em maior percentual, estavam produzindo em média igualmente aos recipientes médios e grandes (Anexos 8 e 9, Tabelas 36 e 37).

Os resultados aqui apresentados concordam com os encontrados por TUN-LIN e col. (1995). Estes autores relatam que um poço e um tanque foram responsáveis por $28 \%$ imaturos de Ae. aegypti, com o volume d'água fortemente associado à produtividade de larvas. Eles consideraram esses criadouros como recipientes chaves e afirmam que pode haver recipientes com baixa freqüência e alta produtividade e situação inversa, como naquele estudo. PEREIRA (2001) relata que o volume de 1 a 10 litros contribuiu mais, tanto para a produção de larvas quanto para a produção de pupas de Ae. aegypti em Santos, São Paulo.

ABE e col. (2005), estudando a produção de Aedes spp. em recipientes na Venezuela, afirmam que os recipientes com maior proporção de pupas $(46,7 \%)$, eram aqueles com volume entre 1 a 5 litros. ARDUINO (2001) relata que recipientes grandes e médios estavam em menores percentuais mas foram responsáveis por maior produtividade, corroborando com os resultados encontrados no presente estudo. Outras pesquisas precisam ser realizadas para melhor entendimento da produtividade em relação ao volume líquido. 
Como já foi assinalada, a variação dos componentes físicos e químicos da água dos criadouros reveste-se de importância e os resultados apontaram para a influência do volume nos parâmetros mensurados. Na análise da amostra coletada foi possível observar que houve variação estatisticamente significativa da temperatura da água em pequenos criadouros e na concentração de oxigênio dissolvido em grandes criadouros de Ae. aegypti (Figuras 12 e 13) Para os demais parâmetros, não houve evidência estatística que permitisse considerar diferenças entre os tamanhos de recipientes. Para criadouros de Ae. albopictus, as diferenças significativas foram observadas nos valores de salinidade e condutividade (Figuras 14 e 15) em recipientes pequenos.

ARRIVILLAGA e BARRERA (2004) afirmaram que a limitação de alimento em recipientes para armazenamento de água estava produzindo adultos pequenos, entretanto a redução de imaturos nestes recipientes poderia resultar em adultos maiores e mais fecundos. Ou seja, haveria pouco alimento disponível no volume líquido comumente encontrado na caixa d'água para o número de larvas existente naquele estudo, mas com a redução do número de larvas, o alimento dissolvido seria suficiente para produção de adultos maiores. HONÓRIO e LOURENÇO-DEOLIVEIRA (2001) também encontraram nítida relação entre a freqüência de larvas de Ae. aegypti e o volume de água em pneus, o que não foi constatado para Ae. albopictus.

\section{- Potencial Hidrogeniônico (pH)}

A manutenção da composição iônica e do equilíbrio do meio interno do corpo- a homeostase -é de importância crítica para organismos aquáticos. Por causa disto, a composição iônica e $\mathrm{pH}$ do ambiente são fatores que podem limitar as distribuições de organismos nestes hábitats (CLARK e col. 2004a). Larvas de mosquitos são capazes de tolerar grande gama de $\mathrm{pH}$ no ambiente, mais do que outros animais aquáticos (CLEMENTS 1992).

Os resultados de $\mathrm{pH}$ registrados nesse estudo em criadouros de $\boldsymbol{A} \boldsymbol{e}$. aegypti (Tabela 21) corroboram com os dados apresentados por outros autores. Como exemplo, podem-se mencionar as observações levadas a efeito no atol de Nukulaelae em 
1981, onde foram registradas leituras de $\mathrm{pH}$ extremamente altas em algumas amostras de tambores de acondicionamento de água: um com $\mathrm{pH} 9,4$ e o outro $\mathrm{pH} 11,7 \mathrm{com}$ a presença de larvas de Ae. aegypti (LAIRD 1988). Este autor discute o quanto a larva deste vetor pode tolerar níveis bastante altos de poluição orgânica e alcalinidade.

TUN-LIN e col. (1995), estudando a produtividade de criadouros, afirmaram que não houve evidência estatística para sugerir que o número de larvas foi influenciado pelas variações de $\mathrm{pH}(5,5$ a 11,3). Em estudos conduzidos na Venezuela foram registradas variações de $\mathrm{pH}$ em criadouros com espécies do gênero Aedes entre 6,5 a 10,5 embora não tenham apresentado os dados em separado para Ae. aegypti, os autores relatam que esta espécie representou $47 \%$ do total de culicídeos (ABE e col. 2005).

Em experimentos laboratoriais, CLARK e col. (2004a) demonstraram que Ae. aegypti foi bastante tolerante a concentrações alcalinas e ácidas, completando o desenvolvimento larval com sucesso em água com gama de $\mathrm{pH} 4$ a 11, fato corroborado por este estudo que registrou variação entre $\mathrm{pH} \mathrm{4,3} \mathrm{e} \mathrm{9,9.} \mathrm{Os} \mathrm{mesmos} \mathrm{admitem} \mathrm{que}$ talvez a tolerância a ampla gama de $\mathrm{pH}$ possa favorecer estas espécies na exploração de variedade maior de recipiente.

Houve fraca correlação entre a produção de larvas e pupas e o pH (Tabela 23). Provavelmente isto se deve justamente a ampla variação encontrada. HONÓRIO e LOURENÇO-de-OLIVEIRA (2001), estudando a freqüência de imaturos de Ae. aegypti e Ae. albopictus em pneus no Rio de Janeiro, afirmam que a variação do $\mathrm{pH}$ não influenciou a densidade de larvas das duas espécies.

A espécie Ae. albopictus também foi tolerante, embora a gama tenha sido um pouco menor que a registrada para Ae. aegypti, com variação de $\mathrm{pH}$ de 4,0 a 8,4 (Tabela 22). ESTRADA-FRANCO e CRAIG JR (1995), apontaram estudos cujo gradiente de $\mathrm{pH}$ para desenvolvimento desta espécie variou de 2,0 a 12. As bromélias foram microhabitats freqüentes para as duas espécies, entretanto Ae. albopictus foi mais freqüente e em maior número que Ae. aegypti neste microhabitat (Anexos 1 e 2, Tabelas 30 e 31). 
RICHARDSON (1999) relata como resultados de suas observações que o $\mathrm{pH}$ em bromélias tenha variado entre 4,9 a 5,9. Embora no presente estudo o $\mathrm{pH}$ da bromélia variou de 4,0 a 7,2, os dados sugerem que Ae. albopictus parece tolerar melhor ambientes ácidos. Ae. aegypti esteve presente em criadouros com gama maior de $\mathrm{pH}$, o que pode indicar uma situação de vantagem. De qualquer maneira são necessários outros estudos para elucidar tais diferenças.

Em recipientes com ambas as espécies, o pH variou de 4,3 a 8,9 (Tabela 20). Este gradiente foi muito próximo do encontrado para Ae. albopictus, o que pode sugerir que são criadouros ocupados por esta espécie e também explorados por $A e$. aegypti. Segundo FORATTINI (2002), as fêmeas de Ae. aegypti mostraram-se sensíveis à atração representada pelas formas imaturas de Ae. albopictus e parece que o inverso não acontece, o que indica vantagem da primeira espécie sobre a segunda. Portanto, os criadouros onde há coexistência podem ter sido resultado da seleção feita por fêmeas de Ae. aegypti e não por fêmeas de Ae. albopictus.

Contudo, Ae. albopictus tem demonstrado superioridade competitiva em situação de coexistência, tanto em laboratório quanto em campo (BARRERA 1996; JULIANO 1998; BRAKS e col. 2004; JULIANO e col. 2004). Este bom desempenho em diversas situações pode ser fator que o favoreça a espécie e contribua para situação de equilíbrio, ou seja, a produção semelhante das duas espécies quando em situação d coexistência (Tabelas 14 e 17).

\section{- Temperatura da água}

A temperatura influencia os processos da vida e possui efeito positivo na produtividade biológica. No entanto, os organismos possuem amplitude de temperatura que abaixo da qual podem paralisar os processos biológicos ou, acelerar até o limite máximo, acima do qual pode inviabilizar a vida (RICKLEFS 2001).

Neste trabalho a variação da temperatura também foi ampla e corrobora com os dados encontrados por outros autores. A amplitude de temperatura em criadouros com Ae. aegypti foi maior que para Ae. albopictus: 18 a $35,9^{\circ} \mathrm{C}$ e 21,3 a $30,7^{\circ} \mathrm{C}$ respectivamente (Tabelas 20 e 21). Em resultados registrados na Austrália, as larvas de 
Ae. aegypti foram encontradas desenvolvendo-se em faixa de temperatura de 21,7 a $27^{\circ} \mathrm{C}$ (TUN-LIN e col. 1995). Em estudos conduzidos na Colômbia, larvas desta espécie estavam em criadouros que registravam máxima de $30^{\circ} \mathrm{C}$ e mínima de $24^{\circ} \mathrm{C}$ (ROMEROVIVAS e FALCONAR 2005). No atol de Nukulaelae, tambores com larvas de Ae. aegypti registravam de 20 a $35^{\circ} \mathrm{C}$ (LAIRD 1998) .

Recipientes com menores volumes são mais suscetíveis à variação de temperatura do que os demais. Pois houve diferença significante $(p=0,030)$ na temperatura em recipientes pequenos em relação aos demais tamanhos (Figura 12). Entretanto, não havendo associação entre a temperatura e a produção média de larvas e pupas. Estes resultados condizem com a variação encontrada nos criadouros e levam à hipótese de que a temperatura não foi fator limitante para a ocorrência e produção de formas imaturas de Ae. aegypti na região.

Sob condições de laboratório, Ae. albopictus teve desenvolvimento afetado pela temperatura, que variou entre 20 e $30^{\circ} \mathrm{C}$, com menor tempo a $30^{\circ} \mathrm{C}$ (ESTRADA-FRANCO e CRAIG JR 1995). Como esses dados são próximos dos registrados neste estudo em campo, o qual variou entre 21,3 a $30,7^{\circ} \mathrm{C}$ (Tabela 22), sugere-se aqui que os criadouros de Ae. albopictus provavelmente estavam em locais ao abrigo do sol, portanto com faixa de temperatura menor que a de Ae. aegypti, mais uma vez corroborando a hipótese de que os criadouros da primeira espécie poderiam estar em áreas com vegetação mais densa. Contudo, não foi registrada associação entre a temperatura e a produção média de larvas e pupas desta espécie, sugerindo que $A e$. albopictus também não teve a temperatura como fator limitante para seu desenvolvimento na região.

A gama de temperatura registrada em recipientes em situação de coexistência das duas espécies foi de 21,3 e 35,4 (Tabela 20). Estudos sobre competição entre estas espécies, realizados em laboratório e campo, levaram a conclusão de que a temperatura não influenciou na competição entre estas espécies no intervalo entre $24 \mathrm{e}$ $30^{\circ} \mathrm{C}$ (LOUNIBOS e col. 2002; JULIANO e col. 2004; BRAKS e col. 2004). Portanto, é lícito pensar que a temperatura da água não foi fator limitante para estas espécies em coexistência. 


\section{- Salinidade}

O equilíbrio da água de organismos aquáticos está intimamente ligado às concentrações de sais e outros solutos em seus tecidos corporais e no ambiente aquático, mantido pelo mecanismo da osmorregulação (RICKLEFS 2001). Larvas de mosquitos podem ser incluídas entre os mais eficientes organismos reguladores aquáticos que se encontram no reino animal (FORATTINI 2002). Em razão disto, são consideradas altamente hábeis para explorar as mais diversas condições de hábitats aquáticos que vão desde água doce até altamente salinas, muitas vezes inóspitas a muitos organismos aquáticos. Espécies de regiões de costa ou beira-mar podem ser expostas a condições osmóticas muitos severas.

Em água doce, a osmose em mosquitos é responsável em ganhar sais e perder água; em águas salinas ela é responsável em perder sais e ganhar água. Estes fluxos acontecem imediatamente na hemolinfa, mas a larva pode regular a composição da hemolinfa dentro de limites estreitos. Todas as espécies parecem capazes de regular os sais quando em água doce, algumas podem regular em água doce e salgada, e outras em água doce e altamente salina (CLEMENTS 1992).

Existem três estratégias distintas de osmorregulação em larvas de mosquitos: a) Osmorreguladoras de água doce - são larvas que se especializaram em manter o equilíbrio de sais em seu meio interno, devido a menor concentração no ambiente aquático; muitas espécies de Aedes são exclusivas de água doce. b) Eurialinas osmorreguladoras - espécies adaptadas a diferentes gradientes de concentração de sal, conseguindo manter o equilíbrio interno a custa de estruturas adaptadas especificamente para este fim, como exemplo Ochlerotatus taeniorhynchus; esta espécie possui na estrutura retal uma segunda parte que seria a responsável pela regulação da entrada de íons em ambientes aquáticos com altas concentrações salinas. 3) Eurialinas osmoconformistas - larvas que geralmente habitam água doce, mas podem tolerar situações de concentrações de sal, embora menores que as espécies da classificação anterior, à custa de capacidade de aclimatação que a coloca em conformidade com tal situação, mantendo o equilíbrio interno (Bradley, citado por CLARK e col. 2004b, p.2289). 
$A e$. aegypti e Ae. albopictus são consideradas espécies de osmorregulação em água doce. No entanto, Ae. aegypti tem sido apontada como osmoconformista. Quando a salinidade ultrapassa um certo nível, ela tem maior tolerância a alta pressão osmótica na hemolinfa. Esta estratégia de sobrevivência é também conhecida como aclimatação, que seria a mudança no intervalo de tolerância fisiológica do indivíduo em resposta a mudança ambiental, e tem caráter reversível (RICKLEFS 2001).

Quando transferidas diretamente de água doce para 37\% água do mar as larvas de Ae aegypti morreram mas, se a concentração de sal fosse elevada gradualmente, elas poderiam sobreviver em 50\% da água de mar (CLEMENTS 1992), sugerindo a estratégia de aclimatação.

Os resultados aqui apresentados mostraram que as duas espécies foram encontradas em criadouros com salinidade elevada, em microhabitats em situação de coexistência ou não (Tabelas 20 a 22), sugerindo que as duas espécies tiveram capacidade de se desenvolver mesmo em condições tão adversas. WOODHIL (1941) já relatava que Ae. aegypti fazia postura de ovos em água com concentrações a partir de $17,5 \%$ mas a postura aumentava com o declínio da concentração de sal.

Outros estudos experimentais sobre tolerância a salinidade têm apontado esta espécie como capaz de aclimatação sob diferentes condições (GRUEBER e BRADLEY 1994; BEYENBACH 2003; CLARK 2004b). LAIRD (1988) relata que Ae. aegypti foi encontrada em coleções de água registrando $1800 \mu \mathrm{S}$ e $1450 \mu \mathrm{S}$ e que as larvas deste vetor podem tolerar níveis bastante altos de poluição orgânica.

Em experimentos de laboratório, Hughes e col. (1991) citado por DEREK (1996, p.529), demonstraram que Ae. albopictus realizou posturas em água com concentração $55 \%$ da água do mar e sobreviveu bem em concentração de $20 \%$, considerando que a concentração de sal na água do mar seja de $33 \%$, as fêmeas fizeram postura em água com $18,2 \%_{\mathrm{o}}$ e as larvas sobreviveram em $6,6 \%_{\mathrm{o}}$ naquele estudo.

Atualmente o sal marinho é recomendado como alternativa no controle de larvas de Ae. aegypti em ralos e canaletas de chuva no Estado de São Paulo, na concentração de 2\% (SES/SUCEN, 2002), em áreas de litoral, esta orientação pode não ter o efeito desejável e, conseqüentemente, permitir a proliferação destes vetores. 
Em experimentos realizados para observação do desenvolvimento de $A e$. aegypti em diferentes concentrações de salinidade, onde houve aumento na duração da fase larval e diminuição da taxa de crescimento em maiores concentrações de sal, mas as larvas chegaram à fase adulta. Os autores argumentam que isto pode ser resultado do uso de parte da energia no mecanismo da osmorregulação (CLARK e col. 2004b). GRUEBER e BRADLEY (1994), avaliando a tolerância de Ae. aegypti à salinidade, mostraram que houve aumento da mortalidade a partir de $30 \%$ da água do mar e que a capacidade de aclimatação em concentrações salinas, ou osmoconformismo, pode dar suporte para separação filogenética das espécies.

Em face aos resultados aqui apresentados, seria lícito admitir a existência de população tolerante na região de estudo. Contudo estudos mais detalhados objetivando estes aspectos são necessários para esclarecer seu efeito na produtividade e contribuição destes criadouros para a população de adultos.

\section{- Oxigênio Dissolvido (OD)}

As concentrações de oxigênio na água podem variar com a quantidade de matéria orgânica e organismos que a decompõe, portanto, com o aumento destes últimos poderá haver redução de oxigênio dissolvido (RICKLEFS 2001). Embora as larvas de mosquitos geralmente utilizem oxigênio atmosférico, a redução deste gás em criadouros pode ser indicativa de excesso de matéria orgânica ou poluição. URBINATTI (2004) estudando a fauna associada de criadouros de mosquitos, afirma que a redução das concentrações de oxigênio dissolvido pode ter reflexos indiretos na densidade de imaturos, pois, agiria sobre organismos que fazem parte da alimentação das larvas.

Muitas espécies podem sobreviver em tais condições, embora seja reconhecida a preferência em explorar água com pouca matéria orgânica, por parte destas duas espécies. Em barcos, Ae. aegypti esteve presente muitas vezes em água com resíduo de óleo de motor o que pode justificar o registro de $0,40 \mathrm{mg} / \mathrm{l}$ de OD nesta categoria (Tabela 21).

POPE e WOOD (1981), em experimento de laboratório, relatam resistência de Ae. aegypti em água poluída. Os autores já discutiam a possibilidade de 
mudanças no comportamento de espécies vetoras devido ao uso de inseticidas em criadouros contendo água limpa, o que poderia favorecer a seleção de linhagens tolerantes a água contaminada, se não houver alternativa. TUN-LIN e col. (1995), estudando a produtividade de criadouros, relatam que a qualidade da água foi fortemente associada com o número de larvas de Ae. aegypti, ou seja, houve maior número de imaturos em recipientes com folhas e material orgânico.

Os mosquitos do subgênero Stegomyia são originários de ocos de árvores, criadouros com grande concentração de matéria orgânica (LAIRD, 1988). Ae. albopictus já foi encontrado em ocos de árvores em concentrações que variaram entre 0,6 e 2,4mg/l (ESTRADA-FRANCO e CRAIG JR 1995).

Segundo estudos de RICHARDSON (1999), em bromélias, a concentração de matéria orgânica teve correlação positiva com tamanho da planta, ou seja, plantas com volumes menores tiveram maior concentração de matéria orgânica. Este microhabitat foi freqüente neste estudo, registrando variação de oxigênio dissolvido de 0,8 a 6,3 e 0,8 a 9,7mg/l para Ae. aegypti e Ae. albopictus, respectivamente (Tabelas 21 e 22), o que leva à hipótese de que em algumas situações haveria grande concentração de matéria orgânica e organismos que estariam consumindo este gás. Por outro lado, a exposição destas plantas às chuvas e regas constantes, estaria permitindo variação e aumento dos valores de oxigênio dissolvido devido ao movimento da água.

A categoria de recipiente com maiores concentrações deste gás foi caixa d' água (Tabelas 21 e 22), que muitas vezes estavam dispostas sobre as casas e eram servidas de água que vinha diretamente de fonte natural, situação que pode explicar em parte os altos valores encontrados.

Os ralos geralmente são recipientes que podem apresentar poluição, como sabão e matéria orgânica. Neste estudo a concentração mínima de oxigênio registrada foi de 0,20 a $0,52 \mathrm{mg} / \mathrm{l}$ (Tabelas 21 e 22) para Ae. aegypti e Ae. albopictus, respectivamente.

Os registros deste estudo apresentam variação considerável para a concentração de oxigênio dissolvido, o que nos leva a sugerir que em várias situações as duas espécies poderiam se desenvolver em água com certo grau de poluição. Esta situação mostra a plasticidade encontrada nestas espécies e isto lhes confere maior 
capacidade de manter populações em ambientes diversos, o que influencia diretamente na produção do número de indivíduos adultos, independente das condições impostas pelo homem.

\section{- Condutividade Elétrica}

SINHA (1976), em estudo realizado com Cx. quinquefasciatus, afirma que os fatores físicos e químicos da água do criadouro podem variar de acordo com a densidade de imaturos. Quando consideramos a produção de larvas e pupas, o resultado das correlações para os valores de $\mathrm{pH}$, condutividade e salinidade, indicou associação positiva, porém fracas, em recipientes com as espécies estando ou não em situação de coexistência (Tabela 23).

COSTANZO e col. (2005) relatam associação positiva entre a abundância de Ae. albopictus e condutividade em condições de laboratório. A mesma análise, considerando a categoria de criadouros de Ae. aegypti, resultou em poucas associações para $\mathrm{pH}$, condutividade, salinidade e oxigênio dissolvido em algumas categorias, mais uma vez corroborando com a ampla variação destes parâmetros encontrada em todas as categorias (Tabela 21).

Os resultados aqui apresentados sugerem que as duas espécies, na região em questão, apresentaram indicativo de que possuem amplo intervalo de tolerância para todos os parâmetros mensurados e que a produtividade de imaturos nos criadouros foi pouco associada com os parâmetros. Por outro lado, ressalta-se que fatores como volume, tipo de alimentação existente, a fauna associada, entre outros precisam ser estudados para melhor compreensão da bioecologia destas espécies na região.

\section{- Temperatura ambiente e Índices pluviométricos}

A maioria dos aspectos do clima é de difícil previsão. Freqüentemente vemos determinado ano particularmente mais seco ou mais frio em comparação com os outros. Embora tais condições extremas aconteçam com menos freqüência, nos últimos tempos temos visto o aumento da ocorrência destes eventos e isto pode afetar os organismos desproporcionalmente (RICKLEFS 2001). 
As variações do tamanho da população de acordo com as estações do ano são chamadas de sazonalidade, diferem de região para região e em zonas tropicais caracterizam-se pela alternância, ao longo do ano, de período chuvoso e seco. Pode-se dizer que a flutuação populacional de culicídeos encontra-se marcada sob a influência dos níveis de temperatura e de precipitações pluviais (FORATTINI 2002).

O presente estudo foi realizado entre os meses de outubro e abril em dois anos consecutivos, portanto compreendendo os meses com temperaturas mais elevadas e maior freqüência de chuvas. Embora não tenha sido o principal objetivo deste trabalho, a análise da produção de larvas e pupas em relação a estas variáveis foi realizada em parte.

Foi possível ver a tendência de aumento da quantidade de criadouros de Ae. aegypti em relação à temperatura ambiente e de Ae. albopictus em relação aos índices pluviométricos (Figuras 16 B e 16C). As associações de produção foram poucas e fracas para a primeira espécie, e para a segunda, só houve associação com os índices pluviométricos.

A temperatura afeta o desenvolvimento larval de Ae albopictus entretanto, a prevalência sazonal tem mais relação com a chuva, ou seja, a maior abundância é observada na estação chuvosa, com alta mortalidade no inverno (ESTRADA-FRANCO e CRAIG JR 1995). Em contraste, GLASSER e GOMES (2002), estudando a distribuição destas duas espécies no Estado de São Paulo, concluíram que a temperatura foi fator preponderante para expansão de Ae. aegypti em todo o Estado, correlacionando maiores médias de temperatura com processos mais rápidos de ocupação das cidades.

Alguns autores argumentam que os períodos de seca e temperaturas amenas estariam favorecendo Ae. aegypti, que apresenta maior resistência à dessecação de ovos, enquanto que ovos de Ae. albopictus teriam menor resistência e maior mortalidade. Por outro lado, em período de altas precipitações, Ae. albopictus seria favorecido pela melhor capacidade competitiva e exploração de recursos, assim como maior tolerância a altas densidades e diversidade de fauna e flora (O'MEARA 1993; JULIANO e col. 2002; JULIANO e col. 2004; COSTANZO e col. 2005). 
BRAKS e col. (2004) apontam que a segregação de hábitats entre estas espécies estaria associada à cobertura vegetal mais farta, mesmo em áreas urbanas. São Sebastião tem longos períodos de chuva com temperatura média de $25^{\circ} \mathrm{C}$ e curto período de seca com temperatura média acima de $18^{\circ} \mathrm{C}$ e a cobertura vegetal na malha urbana é farta, exceto na área central (Anexos 11 a 13, Figuras 19 a 23), a diversidade de espécies de culicídeos é incrementada em razão da existência de grande oferta de microhabitat natural, principalmente bromélias (Anexos 1 a 3, tabelas 30 a 32). Deste modo seria possível supor que tais características corroboram os argumentos desses autores e isto poderia permitir a permanência de Ae. albopictus, apesar das altas temperaturas no verão. A mortalidade diferencial de Ae. albopictus em período de seca com temperaturas não muito baixas poderia inverter a vantagem competitiva e favorecer Ae. aegypti, o que aliviaria os efeitos de competição larval de Ae. albopictus por mortalidade diferencial de ovos deste último.

JULIANO e col. (2002) sugeriram que fatores abióticos também podem contribuir para a segregação de hábitat, sendo que áreas urbanas com vegetação podem abrigar recipientes que estariam com temperatura inferiores. Ae. aegypti e Ae. albopictus freqüentemente foram encontradas em São Sebastião em toda área urbana e a faixa de temperatura da água dos criadouros de Ae. albopictus foi menor que a dos criadouros de Ae. aegypti, sugerindo localização diferenciada dos criadouros das duas espécies em relação à vegetação (Tabelas 21 e 22).

BRAKS e col. (2004) argumentam que não é provável que temperaturas altas sejam o único fator para a segregação de hábitat, pois as duas espécies são encontradas em várias partes do mundo, cobrindo um gradiente amplo de temperatura. Além disso, a urbanização é geralmente associada a mudanças temporais de espaço, tipo e quantidade de vegetação, densidade de população humana, número de edifício, e poluição.

No litoral sul do Estado de São Paulo Ae. aegypti foi a espécie dominante e foram poucos os registros de Ae. albopictus (PEREIRA 2001), diferentemente dos resultados aqui apresentados para São Sebastião, apesar de estarem no litoral do mesmo Estado. Considerando a diferença de urbanização das duas regiões, ou seja, Santos é 
altamente urbanizado, densamente habitado e com muitas construções verticais, enquanto São Sebastião apresenta urbanização típica de cidades pequenas com maioria dos imóveis térreos, muita vegetação e densidade populacional muito inferior à de Santos. Tais fatores devem ter influído na diferença da distribuição encontrada nas duas regiões.

A intensidade de urbanização pode refletir diretamente na distribuição e abundância destes mosquitos. Ae. aegypti, ao menos nas Américas, é considerada espécie essencialmente domiciliada, estando mais associada aos locais próximos ou no interior do domicílio; tendo preferência ao sangue humano e utilizando muito bem os recipientes do tipo artificial (FORATTINI 2002). Em contraste, Ae. albopictus é considerada mais eclética para alimentar-se de sangue, utilizando-se de diversas fontes, além de ter preferência pelo peridomicílio e áreas com maior vegetação (HAWLEY 1988).

THAVARA e col. (2001) discutem a coexistência da espécie invasora Ae. aegypti e a nativa Ae. albopictus nas ilhas Samui na Tailândia e sugerem que, em razão do aspecto não urbanizado da ilha, a primeira estaria em recipientes de reservatório dentro das casas enquanto a segunda estaria fora e em sua maioria, em recipientes naturais sendo esta última o principal vetor de dengue na região.

JULIANO e col. (2004) defendem que não existe diferença sistemática dentro das condições dos hábitats larvários que tenha determinado a coexistência ou exclusão como resultado da competição, naquele estudo. Além disso, que o padrão de abundância local e co-ocorrência destas espécies pode ser determinado por diferenças ambientais que atuam na fase de ovo e não na fase larvária. Os resultados do presente trabalho corroboram com esta hipótese, uma vez que as duas espécies foram encontradas nos mais diversos criadouros e nas mais diversas condições de hábitats, considerando os aspectos físicos e químicos da água do criadouro.

Parece não existir uma única resposta para a pergunta sobre os processos ecológicos que predominam para determinar o sucesso de invasão de uma espécie, sendo os efeitos de competição interespecífica entre estas espécies são evidentes. A limitação climática parece ser importante mas a evolução das características durante a história de 
vida e adaptações locais podem superar esta limitação (JULIANO e col. 2005). Como dito antes, este estudo não teve a pretensão de esclarecer ou responder tais questões, contudo, não seria possível discutir a produtividade de criadouros sem ressaltar o leque de fatores que podem influir nos resultados apresentados em razão das interações ecológicas entre estas duas espécies que certamente ocorrem na região.

“Ao longo de sua evolução, os mosquitos desenvolveram a qualidade de se comporem sob diferentes condições abióticas dos criadouros. Esse apreciável valor de adaptação às diversas situações, traduz-se atualmente pela multiplicidade de capacidade de desenvolvimento de suas formas imaturas. Tal ecletismo lhes permite resultados positivos de sobrevivência ao meio modificado pelo homem" (FORATTINI 2002).

Os resultados do presente estudo apontaram para vários aspectos que sugerem tais adaptações para ambas espécies, tanto no macro quanto no microhabitat. Assim, a necessidade de se conhecer os aspectos que envolvem as complexas interações ecológicas que ocorrem entre estas espécies em distintos locais e regiões e o potencial de produtividade delas, é fundamental para subsidiar as atividades de ações preventivas e de controle desses vetores. 


\section{6 - Associação entre Índices Entomológicos de uso em rotina, Indicadores de Densidade de Larvas e Pupas em Imóveis e Recipientes e Emergência de} Fêmeas

Dos desafios enfrentados por entomologistas e técnicos, em programas de controle de mosquitos vetores, a avaliação de densidade para o monitoramento estão entre os mais complexos. A dificuldade operacional e a diversidade de informações ecológicas que as distintas fases do desenvolvimento do ciclo de vida dos mosquitos trazem, torna uma tarefa quase impossível.

Os indicadores de densidade mais utilizados hoje são os resultantes de coleta das formas larvárias em recipientes. São os índices de uso em rotina: Índice de Recipientes, Índice Predial e Índice de Breteau, e continuam sendo as principais ferramentas nas atividades de monitoramento do controle. Recentemente estes, estão sendo considerados inadequados por não medir o risco de transmissão ou a eficácia das operações de controle; além disso, eles não fornecem orientação com relação a esforços de controle de criadouros, por considerá-los todos iguais, ou seja, atribui o mesmo valor a recipientes com 1 exemplar e com milhares. Consideram somente a positividade dos criadouros (TUN-LIN 1995; FOCKS e CHADEE 1997).

A interpretação dos indicadores em relação ao risco de transmissão é difícil, pode haver poucos recipientes com larvas e produzindo muitos adultos. Tal situação poderia indicar que o controle não seja necessário e a população humana estaria exposta a altas taxas de picadas. Além disso, não há mecanismos para usar estes índices e ajustar a avaliação de risco ou estimar os níveis de supressão necessários e com segurança suficiente que impeça a transmissão.

Entomologistas de diferentes partes do mundo compararam vários índices larvais mas chegaram a conclusões diferentes sobre seus valores e não encontraram nenhuma correlação consistente com a transmissão. Estes índices são criticados por assumir a existência de correlação entre a densidade de larvas e de adultos (TUN-LIN e col. 1995; SULAIMAN e col. 1996; FOCKS e CHADEE 1997; GETIS e col. 2003; 
MORRISSON e col. 2004a; MORRISSON e col. 2004b; ROMERO-VIVAS e FALCONAR 2005).

TUN-LIN e col. (1995) discutindo a produtividade de criadouros demonstraram claramente que a aceitação de igualdade de locais de procriação baseado em imóveis infestados e número de recipientes como admitidos nos índices utilizados na rotina pode levar a programas de controle generalizados que carecem de precisão.

Vários autores apontam a contagem de pupas como a atividade mais adequada para avaliar o risco e operacionalizar o controle, fornecendo melhores estimativas imediatas de risco de transmissão de vírus de dengue e podendo ter imediato benefício no programa de controle, principalmente para desenvolver estudos de controle específico de criadouros e de educação em saúde para a população local (FOCKS e CHADEE 1997; FOCKS e col., 2000; MORRISSON e col, 2004a; MORRISSON e col, 2004b). FOCKS e col. (1981) propuseram o uso da contagem de pupas para estimar a emergência de fêmeas adultas em determinada área.

No presente estudo foram realizadas análises de associações entre os índices utilizados em rotina, os indicadores de densidade e a emergência de fêmeas adultas a partir da fase pupal. Os resultados apontaram para associações mais forte entre os índices utilizados em rotina e os de densidade de larvas de Ae. aegypti. Entretanto, o índice de densidade de pupas e a emergência não tiveram associação ou, estas foram fracamente associadas aos índices de rotina (Tabelas 26 e 29). Em estudo conduzido na Colômbia ROMERO-VIVAS e FALCONAR (2005) apontaram para a não associação dos índices de rotina e os índices de densidade de larvas, de pupas e de ovos.

As associações para a espécie Ae. albopictus apresentaram o mesmo perfil, ou seja, os índices de uso em rotina tiveram associações mais fortes com a fase larval. Contudo, as associações foram mais fortes que para a espécie anterior. Os resultados obtidos para ambas as espécies foram curiosamente mais fracas que os de $A e$. albopictus sozinha. O que chama a atenção para a possibilidade de que a baixa correlação da primeira espécie esteja influenciando nestes resultados (Tabelas 26 a 28).

Vários autores utilizaram a contagem de pupas tanto em estudos da produtividade (FORATTINI e col. 1997; PEREIRA 2001; BRITO e FORATTINI 2004) 
como em estudos de modelos matemáticos para estimar a distribuição espacial de vetores (FOCKS e CHADEE 1997; STRICKMAN e KITTAYAPONG 2003; MORRISON e col. 2004a; MORRISON e col. 2004b). A contagem de pupas é factível na maioria dos recipientes e o cálculo de emergência pode ser utilizado para determinar não somente a contribuição dos recipientes para a população adulta de mosquitos, como pode dar um indicativo da estimativa de fêmeas que seriam produzidas para cada 100 imóveis ao dia na área estudada, no período da avaliação. Embora não dê a densidade total de adultos, esta informação se aproxima mais da estimativa da população na fase adulta e dá um parâmetro para o controle de criadouros.

ABE e col. (2005) calcularam o potencial de produtividade de adultos em determinada área a partir de contagem de pupas. MORRISON e col. (2004a), estudando a distribuição espacial de vetores e os índices que poderiam ser empregados, concluíram que o índice de pupas por hectare foi o mais robusto e estável, semelhante ao Índice de adulto, podendo ser utilizado em rotina. A vigilância pupal associada a dados demográficos pode melhorar a informação trazendo benefícios imediatos para as ações de controle de criadouros (MORRISON e col. 2004b).

A produção de adultos pode ser incorporada às avaliações entomológicas dos programas, porém vários são os fatores a serem ponderados além da vigilância entomológica.

O uso do máximo de informações que em atividades de avaliação de densidade de vetores auxiliará na interpretação dos resultados fornecendo incremento às ações de vigilância e controle. Muitas destas informações podem ser levantadas facilmente e aplicadas ao menos em avaliações periódicas para cada região, estas permitiriam adequar ações direcionadas às especificidades existentes nas diferentes áreas geográficas.

GOMEZ e col. (2001) encontraram correlações negativas entre os índices larvários usados na rotina do programa e a temperatura alta em período de seca; os autores argumentam que os resultados foram mais suscetíveis às precipitações de chuva que a temperatura e que, a soma das duas estaria exercendo papel mais importante na 
maior produção de larvas, ou seja, os valores de temperatura e chuva juntos, foram mais associados aos índices.

SULAIMAN e col. (1996) relatam que não houve correlação entre os casos de dengue e os índices utilizados na rotina em Kuala Lumpur na Malásia. Casos de dengue e dengue hemorrágico ocorreram em todos os bairros com Índice de Breteau e Índice Predial baixos. Os autores ainda fazem referência a outros trabalhos que registraram situação semelhante. São situações que chamam a atenção para a limitação dos índices sem avaliação detalhada da produtividade.

TEIXEIRA e col. (2002) realizaram estudos em Salvador na Bahia, onde verificaram baixa densidade de vetor (IP $\leq 3 \%$ ) e alta soroprevalência $(54,6 \%)$. Os autores sugerem a ocorrência de epidemia silenciosa. Apesar de ser percebida pelos serviços de vigilância e ser considerado período de baixa endemicidade, estava havendo forte e rápida transmissão de dengue clássico na cidade. Neste caso, o índice utilizado não foi suficiente para detectar tal situação, e o risco de futuras epidemias de dengue hemorrágico poderia não ser devidamente percebido.

KAY e VU (2005) desenvolveram programa de controle integrado onde, somados a identificação periódica da freqüência e dos tipos mais produtivos de criadouros, educação em saúde levando em conta a compreensão da comunidade a respeito do problema, o controle biológico e trabalhos voluntários com profissionais de várias áreas, conseguiram sucesso de redução e eliminação da transmissão no Vietnã central. Os autores incorporaram, com sucesso, várias áreas do conhecimento no programa de controle local.

Sem dúvida, há necessidade de incremento de ações de vigilância e controle nas avaliações entomológicas, assim como em outras áreas do conhecimento que devem estar envolvidas no problema, tais como educação, saneamento, vigilância sanitária e epidemiológica entre outras. Contudo, é importante que as informações entomológicas sejam aprimoradas, incorporando a produtividade, distribuição espacial das espécies e da vegetação, temperatura ambiente, índices pluviométricos, características bioecológicas do vetor na região o que poderia melhorar substancialmente 
sua contribuição para a compreensão global da transmissão de dengue em cada região, buscando assim mecanismo que possa reduzir risco e incrementar o controle. 


\section{CONCLUSÕES}

\section{Composição da Fauna:}

Ae. aegypti foi a espécie mais freqüente nos criadouros $(44,1 \%)$ e $A e$. albopictus foi a segunda $(17,5 \%)$ das 30 espécies encontradas, demonstrando a predominância de Ae. aegypti nos criadouros. As espécies Li. durhami e Cx. quinquefasciatus coexistiram em criadouros de Ae. aegypti e de Ae. albopictus, e estavam presentes em quase todas as categorias. Foram encontrados exemplares de $A n$. evansae, An. argyritarsis e Och. scapularis em recipientes artificiais, criadouros não comuns para estas espécies.

Imóveis e criadouros

As casas e sobrados foram os imóveis que apresentaram maiores freqüências das duas espécies isoladas e também em situação de coexistência. Ae. aegypti a mais freqüente no total de imóveis positivos; a espécie também foi registrada em hospitais, em clínicas e em hotéis, sendo imóveis onde pode haver concentração portadores do vírus de dengue em ocasião de transmissão.

A quantidade de recipientes potenciais e com água foi grande em todo o período de estudo. Dos recipientes com culicídeos, $70 \%$ em média, abrigavam imaturos de uma das espécies estudadas. Ae. aegypti foi encontrada mais vezes em situação isolada no criadouro, sendo menos freqüente em situação de coexistência com $A e$. albopictus e com outros culicídeos.O número de recipientes contendo Ae. aegypti aumentou, os que continham Ae. albopictus diminuiu e naqueles em que as duas espécies estavam presentes mantiveram a média ao longo do período estudado, evidenciando a presença das duas espécies no município, com predomínio de Ae. aegypti.

Em média 56\% dos criadouros eram recipientes passíveis de remoção, demonstrando a falta de preocupação da população com o controle de vetores e a 
necessidade de incrementar ações que promovam a mudança de atitudes e práticas da comunidade.

A categoria natural foi importante por ser abundante no ambiente urbano e também na mata natural, a qual está localizada próxima deste ambiente, podendo, no futuro, servir de abrigo para estas espécies no ambiente silvestre, com risco de envolvimento de transmissão de agentes que estejam circulando neste ambiente. Esta categoria abrigou maior número de espécies, sendo a bromélia o tipo mais freqüente e muito explorado pelas duas espécies sozinhas e em situação de coexistência.

Abundância e produtividade

As categorias de recipientes mais produtivas para Ae. aegypti foram: plásticos, metais e fibra e de Ae. albopictus plásticos, metais e naturais. Em coexistência, plásticos e metais também foram as mais produtivas, embora a fibra e pneus tenham sido importantes. Na maior parte, eram recipientes descartáveis e que poderiam ser facilmente removidos do ambiente.

As bromélias e os barcos foram os mais importantes criadouros categorizados como fixos, sendo abundantes e característicos da região, tendo caráter de criadouro permanente, podem se tornar ainda mais importantes se os recipientes removíveis forem retirados do ambiente. Dos recipientes fixos, as categorias louça e ralos também foram importantes, pois, geralmente estão em imóveis fechados de uso apenas em algumas épocas do ano. Se não forem devidamente alcançados pelo controle, podem desempenhar papel importante na manutenção das populações das duas espécies.

Emergência de fêmeas

Para emergência de fêmeas, as categorias mais produtivas foram os plásticos e metais tanto em recipientes contendo Ae. aegypti quanto contendo Ae. albopictus. A produção média diária de fêmeas para cada 100 imóveis foi significantemente maior e cresceu ao longo do período de estudo para a espécie Ae. aegypti quando estava isolada no criadouro, enquanto que para Ae. albopictus ocorreu o contrário. Sendo que em criadouros com situação de coexistência, a emergência foi 
semelhante para as duas espécies. A estimativa de fêmeas a partir da freqüência de pupas dá a contribuição dos recipientes para a população adulta no momento da avaliação, podendo ser incorporada as avaliações de rotina.

\section{Variáveis físicas e químicas}

Das variáveis físicas e químicas, $\mathrm{pH}$, condutividade e salinidade tiveram associações fracas com a freqüência de larvas e pupas. $O$ gradiente de variação foi amplo para todos os parâmetros físicos e químicos em recipientes com as espécies em coexistência ou não. Esta variação não foi fator limitante para a ocorrência das espécies na região;

Os gradientes de: $\mathrm{pH}$, temperatura, condutividade, oxigênio dissolvido e salinidade foram mais amplos para a espécie Ae. aegypti. O volume foi importante na variação dos parâmetros aferidos. A temperatura ambiente foi fracamente associada com a produção de Ae. aegypti. E os índices pluviométricos parecem ter maior influência na produção de Ae. albopictus.

\section{Índices e Indicadores}

$\mathrm{Na}$ análise dos dados das duas espécies, os índices utilizados na rotina do programa foram mais associados aos indicadores de densidade de larvas, não tiveram associação ou foram fracamente associados com os indicadores de densidade de pupas. Os índices também não tiveram associação ou foram fracamente associados com a emergência de fêmeas. A emergência de fêmeas foi fortemente correlacionadas aos indicadores de densidade de pupas. Evidenciando a insuficiência de índices baseados na positividade de recipientes contendo larvas, na avaliação da densidade de adultos, e a necessidade de incrementar as informações das avaliações com a estimativa da produtividade dos criadouros a partir da fase pupal. 


\section{COMENTÁRIOS FINAIS}

Ao longo da discussão, houve o deliberado propósito de discorrer e ponderar sobre as possíveis interações ecológicas que ocorrem entre estas duas espécies na região. Contudo, o assunto não foi explorado em sua totalidade, mas permitiu mostrar aspectos que evidenciaram a necessidade de mais investigações sobre a bioecologia destes mosquitos para compreender os mecanismos que controlam os impactos e as barreiras das invasões com permanência, coexistência ou exclusão destas espécies.

Acredita-se que tais estudos podem contribuir para melhor interpretação das avaliações de densidade e produtividade destas populações de mosquitos, assim como o entendimento do papel destas espécies na transmissão dos vírus da dengue e de outros agentes patogênicos que possam vir a ocorrer na região.

A incorporação da produtividade de criadouros, considerando a fase pupal, tanto na análise de produção quanto na emergência de fêmeas, é factível na rotina da avaliação de densidade e, com poucas alterações na metodologia atual. Estas análises permitem avaliar as contribuições absolutas e relativas de fêmeas das várias classes de recipientes para a população adulta, o que forneceria o incremento das informações, resultando em ações mais direcionadas e específicas para cada região. 


\section{REFERÊNCIAS}

Abe M, McCall PJ, Lenhart A, Villegas E, Kroeger A. The Buen Pastor cemetery in Trujillo, Venezuela: measuring dengue vector output from a public area. Trop Med Public Health 2005; 10(6): 597-603.

Albuquerque CMR, Melo-Santos MAV, Bezerra MAS, Barbosa RMR, Silva DF, Silva E. Primeiro registro de Aedes albopictus em área de Mata Atlântica, Recife, PE, Brasil. Rev Saúde Pública 2000; 34: 314-5.

Almeida APG, Baptista SSSG, Sousa CAGCC, Novo MTLM, Ramos HC, Panella NA, Godsey M, Simões MJ, Anselmo ML, Komar N, Mitchell CJ, Ribeiro H. Bioecology and vectorial capacity of Aedes albopictus (Diptera: Culicidae) in Macao, China, in relation to dengue virus transmission. J Med Entomol 2005; 42(3): 419-28.

Alves MCGP. Plano de amostragem utilizado no Programa de Controle de dengue e febre amarela do Estado de São Paulo: proposta de simplificação. [Dissertação de Mestrado apresentada ao Departamento de Epidemiologia da Faculdade de Saúde Pública da Universidade de São Paulo, 1995].

Arduino MB. Produtividade de criadouros de Aedes albopictus (Diptera:Culicidae) no Vale do Paraíba, São Paulo, Brasil. [Dissertação de Mestrado, apresentada ao Departamento de Epidemiologia da Faculdade de Saúde Pública da Universidade de São Paulo, 2001].

Arrivillaga J, Barreta R. Food as a limiting factors for Aedes aegypti in water-storage containers. J Vect Ecol 2004; 29(1):11-20. 
Barrera R, Avila J, Gonzalez-Tellez S. Unreliable supply of potable water and elevated Aedes aegypti larval indices: a causal relationship? J Am Mosq Contr Assoc 1993; 9:189-95.

Barrera R. Competition and resistance to starvation in larvae of container-inhabiting Aedes mosquitoes. Ecol Entomol 1996; 21: 117-27.

Beyenbach KW. Transport mechanisms of diuresis in Malpighian tubules of insects. J Exp Biol. 2003 Nov;206(Pt 21):3845-56.

Braks MAH, Honório NA, Lounibos LP, Lourenço-de-Oliveira R, Juliano SA. Interespecific competition between two invasive species of container mosquitoes, Aedes aegypti and Aedes albopictus (Diptera: Culicidae), in Brasil. Ann Entomol Soc Am 2004; 97(1): 130-9.

Braks MAH, Honório NA, Lourenço-de-Oliveira R, Juliano AS, Lounibos LP. Convergent habitat segregation of Aedes aegypti and Aedes albopictus (Diptera: Culicidae) in Southeastern Brazil and Florida. J Med Entomol 2003; 40(6): 784-94.

Brito M, Marques GRAM, Marques CA, Tubaki RM. Primeiro Encontro de Aedes (Stegomyia) albopictus (Skuse) no Estado de São Paulo (Brasil). Rev Saúde Pública 1986; 20(6): 489.

Brito M, Kita AT. Reciclagem de resíduos sólidos e criadouros de vetores de dengue em São Sebastião, litoral norte paulista. [In: Anais do I Congresso Interamericano de Saúde Ambiental, 2004 abr 27 a 29; Porto Alegre, Rio Grande do Sul. Porto Alegre: Associação Brasileira de Engenharia Sanitária e Asociación Interamericana de Ingeniaría Sanitária y Ambiental, 2004. p. 41.

Brito M, Forattini OP. Produtividade de criadouros de Aedes albopictus no Vale do Paraíba, SP, Brasil. Rev Saúde Pública 2004; 38(2): 209-15. 
Chadee DD, Ward RA, Novak RJ. Natural habitats of Aedes aegypti in the Caribbean: a review. J Am Mosq Contr Assoc 1998; 14: 5-11.

Chadee DD, Rahaman A. Use of water drums by humans and Aedes aegypti in Trinidad. J Vector Ecol 2000; 25: 28-35.

Clark TM, Flis BJ, Remold SK. pH tolerances and regulatory abilities of freshwater and euryhaline Aedine mosquitoes larvae. J Exp Biol 2004a. 207:2297-304.

Clark TM, Flis BJ, Remold SK. Differences in the effects of salinity on larval growth and developmental programs of a freshwater and a euryhaline mosquito species (Insecta:Diptera, Culicidae). J Exp Biol 2004b. 207:2289-95.

Clements NA. The biology of mosquitoes. v.1. Chapman \& Hall. London. UK. CABI Publishing; 1992.

Connor ME, Monroe WM. Stegomyia indices and their value in yellow fever control. Am J Trop Med 1923; 3:9-19

Costanzo KS, Morman K, Juliano AS. Asymetrical competition and patterns of abundance of Aedes albopictus and Culex pipiens (Diptera: Culicidae). J Med Entomol 2005; 42(4): 559-70.

Cunha SP, Alves JRC, Lima MM, Duarte JR, Barros LCV, Silva JL, Gammaro AT, Filho OSM, Wanzeler AR. Presença de Aedes aegypti em Bromeliaceae e depósitos com plantas no Município do Rio de Janeiro, RJ. Rev Saúde Pública 2002; $36(2): 244-5$

Daugherty MP, Alto BW, Juliano SA. Invertebrate carcasses as a resource for competing Aedes albopictus and Aedes aegypti (Diptera: Culicidae). J Med Entomol 2000; 37(3): 364-72. 
Derek R. Mosquitoes (Diptera:Culicidae) breeding in brackish water: female ovipositional preferences or larval survival? J Med Entomol 1996; 33(4): 525-30

Estrada-Franco JG, Craig Jr GB. Biology, disease relationship, and control of Aedes albopictus. Washington (DC): Pan American Health Organization; 1995. (Technical Paper, 42).

Fajardo P, Monje CA, Lozano G, Realpe O, Hernández LE. Nociones populares sobre "dengue" y "rompehuesos", dos modelos de la enfermedad en Colombia. Rev Pan Amer Salud Publica 2001;10: 167-8.

Focks D A, Sackett S R, Bailey D L, Dame D A. Observations on container-breeding mosquitoes in New Orleans, Louisiana, with an estimate of the population density of Aedes aegypti (L.). Am J Trop Med Hyg 1981; 30: 1329-35.

Focks DA, Chadee DD. Pupal survey: an epidemiologically significant surveillance method for Aedes aegypti: an example using data from Trinidad. Am J Trop Med Hyg 1997; 56: 159-67.

Focks DA, Brenner RJ, Hayes J, Daniels E. Transmission thresholds for dengue in terms of Aedes aegypti pupae per person with discussion of their utility in source reduction efforts. Am J Trop Med Hyg 2000; 62:11-8.

Forattini OP. Aedes (Stegomyia) albopictus (Skuse) identification in Brazil. Rev Saúde Pública 1986; 20: 244-5.

Forattini OP, Kakitani I, Sallum MAM, Rezende L. Produtividade de criadouro de Aedes albopictus em ambiente urbano. Rev Saúde Pública 1997; 31: 545-55.

Forattini OP, Marques GRAM; Kakitani I; Brito M, Sallum MAM. Significado epidemiológico dos criadouros de Aedes albopictus em bromélias. Rev Saúde Pública 1998a; 32: 186-8. 
Forattini OP, Kakitani I, Marques GRAM, Brito M. Formas imaturas de anofelíneos em recipientes artificiais. Rev Saúde Pública 1998b; 32: 189-91.

Forattini OP. Mosquitos Culicidae como vetores emergentes de infecções. Rev Saúde Pública 1998c; 32: 497-502.

Forattini OP, Marques GRAM. Nota sobre o encontro de Aedes aegypti em bromélias. Rev Saúde Pública 2000; 34: 543-4.

Forattini OP. Culicidologia Médica: Identificação, Biologia, Epidemiologia. São Paulo: Edusp; 2002. v.2.

Forattini OP. Ecologia Epidemiologia e Sociedade. $2^{\mathrm{a}}$ ed. São Paulo: Artes Médicas: Edusp; 2004.

Forattini OP, Brito M. Reservatórios domiciliares de água e controle do Aedes aegypti. Rev Saúde Pública 2004; 37(5):676-7.

Getis A, Morrison AC, Gray K, Svott W. Characteristic of the spatial pattern of the dengue vector, Aedes aegypti, in Iquitos, Peru. Am J Trop Med Hyg 2003; 69(5):494-505.

Gilotra SK, Rozeboom LE, Bhattacharya NC. Observations on possible competitive displacement between populations of Aedes aegypti Linnaeus and Aedes albopictus Skuse in Calcutta. Bull WHO 1967; 37: 437-46.

Glasser CM, Gomes AC. Clima e sobreposição da distribuição de Aedes aegypti e Aedes albopictus na infestação do Estado de São Paulo. Rev Saúde Pública 2002; 36(2): 166-72.

Gomez FE, Suárez CMH, Cárdenas RC. Factores que modifican los indices larvários de Aedes aegypti en Colima, México. Rev Panam Salud Publica 2001; 10(1): 6-12. 
Grueber WB, Bradley TJ. The evolution of increased salinity tolerance in larvae of Aedes mosquitoes: a phylogenetic analysis. Phys Zool1994; 67(3):566-79.

Hawley WA. The biology of Aedes albopictus. J Am Mosq Control Assoc 1988; 4 Suppl.1: 1-39.

Honório NA, Lourenço-de-Oliveira R. Frequiência de larvas e pupas de Aedes aegypti e Aedes albopictus em armadilhas, Brasil. Rev Saúde Pública 2001; 35(4): 385-91.

Ibanez-Bernal S, Briseno B, Mutebi JP, Argot E, Rodriguez G, Martinez-Campos C, Paz R, La Fuente-San roman P, Tapia-Conyer R \& Flisser A. First Record in American of the Aedes albopictus naturally infected with dengue virus during the 1995 outbreak at Reynosa, México. Med Vet Entomol 1997; 11:305-9.

[IBGE] Instituto Brasileiro de Geografia e Estatística O Brasil município por município [consulta on line] 2003; Avaliable from: <URL:

http://www.ibge.gov.br/cidadesat/default.php>. [2003 Jan 06].

[INPE] Instituto de Pesquisas Espaciais Macrozoneamento da Região do Vale do Paraíba e Litoral Norte do Estado de São Paulo, São José dos Campos, SP, 1992.

Juliano SA. Species introduction and replacement among masquitoes: interespecific resource competition or apparent competition. Ecology 1998; 79(1): 255-68.

Juliano SA, O’Meara GI, Morrill JI, Cutwa MI. Desiccation and termal tolerance of eggs and the coexistence of competing mosquitoes. Oecologia 2002; 130: 458-69.

Juliano SA, Lounibos LP, O'Meara GF. A field test for competitive effects of Aedes albopictus on Aedes aegypti in South Florida: differences sites of coexistence and exclusion? Oecologia 2004; 139: 583-93. 
Juliano SA, Lounibos LP. Ecology of invasive mosquitoes: effects on resident species and on human health. Ecology Letters 2005; 8:558-574.

Jumali S, Gubler DJ, Nalim S, Eram S, Saroso JS. Epidemic dengue haemorrhagic fever in rural Indonesia. III. Entomological studies. Am J Trop Med Hyg 1979; 28(4): 717-24.

Kay B, Vu SN. New strategy against Aedes aegypti in Vietnam. Lancet 2005; 365(9459):613-7.

Kubota RL, Brito M, Voltolini JC. Método de varredura para exame de criadouros de vetores de dengue e febre amarela urbana. Rev Saúde Pública 2003; 37(2): 263-5.

Laird M. The natural history of larval mosquito habitats London: Academic Press; 1988.

Lefrève F, Lefrève AMC, Scandarc SAS, Yassumaro S. Representações sociais sobre relações entre vasos de plantas e o vetor da dengue. Rev Saúde Pública 2004; 38(3): 405-14.

Lopes J, Silva MAN, Borsato AM, Oliveira VDRB, Oliveira FJA. Aedes (Stegomyia) aegypti L. e a culicideofauna associada em área urbana da região sul, Brasil. Rev Saúde Pública 1993; 27(5): 326-33.

Lounibos LP, Suárez S, Menéndez Z, Nishimura N, Escher RL, O’Connell SM, Rey JR. Does temperature affect the outcome of larval competition between Aedes aegypti and Aedes albopictus? J Vector Ecology 2002; 27: 86-95.

Lounibos LP, O'Meara GF, Nishimura N, Escher RL. Interactions with native mosquito larvae regulate the production of Aedes albopictus from bromeliads in Florida. Ecol Entomol 2003; 28: 551-8. 
Lourenço-de-Oliveira R, Castro MG, Braks MAH, Lounibos LP. The invasion of urban Forest by dengue vectors in Rio de Janeiro. J Vector Ecology 2004; 29(1):94100.

Marques GRAM, Santos RLC, Forattini OP. Aedes albopictus em bromélias de ambiente antrópico no Estado de São Paulo, Brasil. Rev Saúde Pública 2001; 35(3): 243-8.

Marques GRAM e Forattini OP. Aedes albopictus em bromélias de solo em Ilhabela, litoral do Estado de São Paulo. Rev Saúde Pública 2005; 39(4): 548-52.

Macoris MLG, Mazine CAB, Andrieghetti MTM, Yasumaro S, Silva ME, Nelson MJ, Winch PJ. Factors favoring houseplant container infestation with Aedes aegypti larvae in Marília, São Paulo, Brasil. Rev Panam Salud Publica 1997; 1(4): 280-6.

Metselaar D, Grainger CR, Dei KG, Reynolds DG, Pudney M, Leake CJ, Tukei RM, D'Offay RM, Simpson DI. An outbreak of type 2 dengue fever in the Seychelles, probably transmitted by Aedes albopictus (Skuse). Bull WHO 1980; 58(6): 937-43.

[MS/FNS] Ministério da Saúde. Fundação Nacional da Saúde. Manual de dengue: vigilância epidemiológica e atenção ao doente. $2^{\text {a }}$ ed. Brasília: DEOPE; 1996.

[MS/FNS] Ministério da Saúde, Fundação Nacional de Saúde. Programa Nacional de Controle de Dengue. 2005. [on line]. Available from: <URL: http://portal.saude.gov.br/portal/svs/visualizar texto.cfm?idtxt=21389> [2005 nov 07].

Moore CG. Aedes albopictus in the United States: current status and prospects for further spread. J Am Mosq Control Assoc 1999; 15: 221-7.

Mori A. Effects of larval density and nutrition on some attributes of immature and adult Aedes albopictus. Trop Med1979; 21(2):85-103. 
Morrison AC, Astete H, Chapilliquen F, Ramirez-Prada G, Diaz G, Getis A, Gray K, Scott TW. Evaluation of sampling methodology for rapid assessment of Aedes aegypti infestation levels in Iquitos, Peru. J Med Entomol 2004a; 41(6):1123-42.

Morrison AC, Gray K, Getis A, Astete H, Sihuincha M, Focks D, Watts D, Stancil JD, Olson JG, Blair P, Scott TW. Temporal and geographic patterns of Aedes aegypti (Diptera:Culicidae) production in Iquitos, Peru. J Med Entomol 2004b; 41(3):50210 .

Natal D, Urbinatti PR, Taipe-Lagos C, Ceretti Jr W, Diederichsen A, Souza RG, Souza RP. Encontro de Aedes (Stegomyia) albopictus em Bromeliaceae na periferia de São Paulo, SP, Brasil. Rev Saúde Pública 1997; 31: 517-8.

O'Meara G, A Gettman, L. Evans, and G. Curtis. The spread of Aedes albopictus in Florida. Am Entomol 1993.; 39(3): 163-72.

O’Meara GF, Evans LF, Gettman AD, Patteson AW. Exotic tank bromeliads harboring immature Aedes albopictus and Aedes bahamensis (Diptera: Culicidae) in Florida. J Vector Ecol 1995; 20: 216-24.

[OPAS] Organização Pan-Americana de Saúde. Diretrizes relativas à prevenção e ao controle de dengue e do dengue hemorrágico nas Américas. Washington; 1991.

[PAHO] Pan American Health Organization. Disease Prevention and Control. 2005. [on line]. Available from <URL:

http://www.paho.org/english/ad/dpc/cd/dengue.htm> [2005 out 21].

Passos RA, Marques GRAM, Voltolini JC, Condino MLF. Dominância de Aedes aegypti sobre Aedes albopictus no litoral sudeste do Brasil. Rev Saúde Pública 2003; 37(6): 729-34. 
Pereira M Produtividade de criadouros de Aedes aegypti (Diptera:Culicidae) em Santos, São Paulo, Brasil. São Paulo; 2001. [Tese de Doutorado - Faculdade de Saúde Pública da USP].

Pope V, Wood RJ. Tolerance of Aedes aegypti larvae to synthetic sewage. Mosq News 1981; 41(4): 732-6.

Richardson BA. The bromeliad Microcosm and the assessment of faunal diversity in a Neotropical forest. Biotropica 1999; 31(2): 321-36.

Ricklefs RE. A Economia da natureza. 5a ed. Rio de Janeiro: Guanabara Koogan; 2001.

Romero-Vivas CME, Falconar AKL. Investigation of relationships between Aedes aegypti egg, larvae, pupae, and adult density indices where their main breeding sites were located indoors. J Am Mosq Control Assoc. 2005; 21(1):15-21.

Sanchez L, Pérez D, Pérez T, Sosa T, Cruz G, Kouri G, Boelaert M, Van der Stuyft P. Intersectoral cordination in Aedes aegypti control. A pilot project in Havana city, Cuba. Trop Med Public Health 2005; 10(1): 82-91.

Santos RLC. Atualização da distribuição de Aedes albopictus no Brasil (1997-2002). Rev Saúde Pública 2003; 37(5): 671-3.

Schreiber ET, Chamberlain S, Thomas R, Parsons R, Baker G. Surveys on artificial container inhabiting-mosquitoes in Sarasota and Tallahassee, Florida I: Characterizations of larval habitats. J Florida Mosq Control Assoc 1992; 63: 7-14.

[SEMASP/IF] Secretaria de Estado do Meio Ambiente de São Paulo, Instituto Florestal, Parque Estadual da Serra do Mar, Núcleo de São Sebastião, Plano de Gestão Ambiental 2005. 
[SESSP/SUCEN] Secretaria de Estado da Saúde, Superintendência de Controle de Endemias, Manual de Vigilância Entomológica de Aedes aegypti. São Paulo, 1997.

[SESSP/SUCEN] Secretaria de Estado da Saúde, Superintendência de Controle de Endemias. Normas e Recomendações Técnicas para Vigilância e Controle do Aedes aegypti no Estado de São Paulo. São Paulo, 2002.

[SESSP/CVE] Secretaria de Estado da Saúde de São Paulo, Centro de Vigilância Epidemiológica. Casos Autóctones de Dengue por Município de Infecção. 2005. [on line]. From: <URL:http://www.cve.saude.sp.gov.br/htm/zoo/Den dir05.htm>. [2005 out 20].

Serpa LLN. Competição intra e interespecífica de larvas de Aedes aegypti e Aedes albopictus (Diptera:Culicidae) em condições laboratoriais. São Paulo, 2001. [Dissertação de Mestrado - Faculdade de Saúde Pública da USP].

Serufo JC, Montes de Oca H, Tavares V, Souza AM, Rosa RV, Jamal MC. Isolation of dengue virus type 1 from larvae of Aedes albopictus in Campos Altos City, State of Minas Gerais, Brazil. Mem Inst Oswaldo Cruz 1993; 88(3): 503-4.

Service, MW. Importance of ecology in Aedes aegypti control. Southeast Asean J Trop Med Public Health 1992; 23(4): 681-90.

Sinha VP. Further observations on the physico-chemical factors of breeding places of Culex quinquefasciatus say = fatigans Wied. Mosq News 1976; 36(3): 358-60.

Souza-Santos R, Carvalho MS. Análise da distribuição espacial de larvas de Aedes aegypti na Ilha do Governador, Rio de Janeiro, Brasil. Cad Saúde Pública 2000; 16(1): 31-42. 
Sulaiman S, Pawanchee ZA, Arifin Z, Wahab A. Relationship between Breteau and house indices and cases of dengue/dengue hemorrhagic fever in Kuala Lumpur, Malaysia. J Am Mosq Control Assoc 1996; 12(3): 494-96.

Strickman D, Kittayapong P. Dengue and its vectors in Thailand: calculated transmission risk from total pupal counts of Aedes aegypti and association of winglength measurements with aspects of the larval habitat. Am J Trop Med Hyg 2003; 68(2):209-17.

Teixeira MG, Barreto ML, Costa MCN, Ferreira LDA, Vasconcelos PFC, Cairncross S. Dynamics of dengue virus circulation: a silent epidemic in a complex urban area. Trop Med Public Health 2002; 7(9): 757-62.

Thavara U, Tawatsin A, Chansang C, Kong-ngamsuk W, Paosriwong S, Boon-Long J, Rongsriyam Y, Komalamisra. Larval occurrence, oviposition behavior and biting activity of potential mosquito vectors of dengue on Samui Island, Thailand. J Vector Ecol 2001; 26(2): 172-80.

Tun-Lin W, Kay BH, Barnes A. Understanding productivity, a key to Aedes aegypti surveillance. Am J Trop Med Hyg 1995; 53(6): 595-601.

Urbinatti PR. Observações ecológicas de Aedes albopictus (Diptera:Culicidae) em áreas de proteção ambiental e urbana da periferia na Grande São Paulo. São Paulo; 2004. [Tese de Doutorado - Faculdade de Saúde Pública da USP].

Varejão JBM, Santos CB, Rezende HR, Bevilacqua LC, Falqueto A. Criadouros de Aedes (Stegomyia) aegypti (Linnaeus, 1762) em bromélias nativas na cidade de Vitória, ES. Rev Soc Bras Med Trop 2005. 38(3): 238-40.

Vezzani D, Schweigmann N. Suitability of containers from different sources as breeding sites of Aedes aegypti (L.) in a cemetery of Buenos Aires City, Argentina. Mem Inst Oswaldo Cruz 2002; 97(6): 789-92. 
Washburn JO. Regulatory factors affecting larval mosquito populations in container and pool habitats: implications for biological control. J Am Mosq Control Assoc $1995 ; 11: 279-83$.

Woodhill AR. The oviposition responses of three species of mosquitoes Aedes (Stegomyia) aegypti Linnaeus, Culex (Culex) fatigans Wiedemann, Aedes (Pseudoskusea) concolor Taylor, in relation to the salinity of the water. Proc Linnean Soc New South Wales 1941; Vol. LXVI.287-92.

[WHO] World Health Organization. DengueNet 2005. [on line]. Available from: <URL:http://www.who.int/globalatlas/default.asp >. [2005 out 21]. 


\section{ANEXOS}


Tabela 30 - Distribuição do $\mathrm{N}^{\circ}$ e \% de recipientes positivos para larvas e pupas de Ae. aegypti em São Sebastião, SP, Brasil, no período de 10/2002 a 04/2003 e 10/2003 e 04/2004.

\begin{tabular}{|c|c|c|c|c|c|c|c|}
\hline \multirow[b]{2}{*}{ Recipiente } & \multicolumn{2}{|c|}{ Recipiente } & \multicolumn{2}{|c|}{ Larvas } & \multicolumn{2}{|c|}{ Pupas } & \multirow{2}{*}{$\begin{array}{r}\text { Total } \\
\text { Imaturos }\end{array}$} \\
\hline & total & $\%$ & $\mathrm{~N}^{\circ}$ & $\%$ & $\mathrm{~N}^{\circ}$ & $\%$ & \\
\hline Bromélia & 95 & 11,9 & 512 & 5,3 & 74 & 3,2 & 586 \\
\hline Vaso/Prato Planta & 88 & 11,0 & 1108 & 11,5 & 148 & 6,4 & 1256 \\
\hline Barco/casco/bote/caiac & 59 & 7,4 & 930 & 9,7 & 150 & 6,5 & 1054 \\
\hline Cx. d'água & 52 & 6,5 & 527 & 5,5 & 62 & 2,7 & 589 \\
\hline Latas & 52 & 6,5 & 950 & 9,9 & 210 & 9,0 & 1160 \\
\hline Ralo & 51 & 6,4 & 547 & 5,7 & 148 & 6,4 & 695 \\
\hline Vaso sanitário & 41 & 5,1 & 329 & 3,4 & 39 & 1,7 & 368 \\
\hline Pote plástico & 39 & 4,9 & 612 & 6,4 & 32 & 1,4 & 644 \\
\hline Peças plástico & 37 & 4,6 & 431 & 4,5 & 131 & 5,6 & 554 \\
\hline Balde plástico & 30 & 3,8 & 584 & 6,1 & 146 & 6,3 & 737 \\
\hline Lona plástica & 27 & 3,4 & 227 & 2,4 & 21 & 0,9 & 248 \\
\hline Pneu & 25 & 3,1 & 272 & 2,8 & 45 & 1,9 & 317 \\
\hline Tambor metal & 24 & 3,0 & 478 & 5,0 & 81 & 3,5 & 559 \\
\hline Planta aquática & 20 & 2,5 & 228 & 2,4 & 23 & 1,0 & 251 \\
\hline Cx. plástica & 17 & 2,1 & 179 & 1,9 & 60 & 2,6 & 239 \\
\hline Peças metal & 12 & 1,5 & 157 & 1,6 & 44 & 1,9 & 201 \\
\hline Cx. Areia/contenção/canaleta & 11 & 1,4 & 61 & 0,6 & 24 & 1,0 & 85 \\
\hline Garrafa vidro & 11 & 1,4 & 148 & 1,5 & 16 & 0,7 & 164 \\
\hline Bambú & 10 & 1,3 & 157 & 1,6 & 17 & 0,7 & 174 \\
\hline Peças carro & 8 & 1,0 & 64 & 0,7 & 4 & 0,2 & 68 \\
\hline Bandeja de geladeira & 8 & 1,0 & 124 & 1,3 & 17 & 0,7 & 141 \\
\hline Galão plástico & 8 & 1,0 & 120 & 1,2 & 2 & 0,1 & 122 \\
\hline Calha de plástico & 8 & 1,0 & 124 & 1,3 & 7 & 0,3 & 131 \\
\hline Calçamentos Cimento & 7 & 0,9 & 72 & 0,7 & 1 & 0,0 & 73 \\
\hline Panela/chaleira & 6 & 0,8 & 63 & 0,7 & 12 & 0,5 & 75 \\
\hline Cx. de descarga plástico & 6 & 0,8 & 55 & 0,6 & 0 & 0,0 & 55 \\
\hline Cascata/Fonte/Espelho & 6 & 0,8 & 117 & 1,2 & 84 & 3,6 & 201 \\
\hline Oco de árvore & 5 & 0,6 & 22 & 0,2 & 1 & 0,0 & 23 \\
\hline Peças fibra & 5 & 0,6 & 159 & 1,7 & 142 & 6,1 & 301 \\
\hline Bebedouro plástico & 5 & 0,6 & 30 & 0,3 & 4 & 0,2 & 34 \\
\hline Embalagem plástica & 5 & 0,6 & 43 & 0,4 & 79 & 3,4 & 122 \\
\hline Casa máquina cimento & 5 & 0,6 & 55 & 0,6 & 57 & 2,5 & 112 \\
\hline Peças Vidro & 5 & 0,6 & 46 & 0,5 & 4 & 0,2 & 50 \\
\hline Pia louça & 4 & 0,5 & 15 & 0,2 & 0 & 0,0 & 15 \\
\hline Peças louça/cerâmica & 3 & 0,4 & 9 & 0,1 & 2 & 0,1 & 11 \\
\hline Luminária metal & 1 & 0,1 & 30 & 0,3 & 413 & 17,8 & 443 \\
\hline Canoa madeira & 1 & 0,1 & 44 & 0,5 & 22 & 0,9 & 66 \\
\hline Cx. leite longa vida & 1 & 0,1 & 3 & 0,0 & 1 & 0,0 & 4 \\
\hline Total & 798 & 100 & 9632 & 100 & 2323 & 100 & 11955 \\
\hline
\end{tabular}


Tabela 31 - Distribuição do $\mathrm{N}^{\circ} \mathrm{e} \%$ de recipientes positivos para larvas e pupas de Ae. albopictus no período de 10/2002 a 04/2003 e 10/2003 e 04/2004, em São Sebastião, SP, Brasil.

\begin{tabular}{|c|c|c|c|c|c|c|c|}
\hline \multirow[b]{2}{*}{ Recipiente } & \multicolumn{2}{|c|}{ Recipiente } & \multicolumn{2}{|c|}{ Larvas } & \multicolumn{2}{|r|}{ Pupas } & \multirow{2}{*}{$\begin{array}{r}\text { Total } \\
\text { Imaturos }\end{array}$} \\
\hline & total & $\%$ & $\mathrm{~N}^{\circ}$ & $\%$ & $\mathrm{~N}^{\mathrm{o}}$ & $\%$ & \\
\hline Bromélia & 123 & 23,3 & 439 & 11,1 & 77 & 9,9 & 516 \\
\hline Vaso/Prato Planta & 54 & 10,2 & 383 & 9,7 & 87 & 11,2 & 470 \\
\hline Lata metal & 43 & 8,2 & 421 & 10,6 & 36 & 4,6 & 457 \\
\hline Peças de Plástico & 37 & 7,0 & 351 & 8,9 & 114 & 14,7 & 465 \\
\hline Lona & 30 & 5,7 & 223 & 5,6 & 48 & 6,2 & 271 \\
\hline Pote & 23 & 4,4 & 262 & 6,6 & 51 & 6,6 & 313 \\
\hline Cx. d'água & 22 & 4,2 & 202 & 5,1 & 12 & 1,5 & 214 \\
\hline Bambú & 19 & 3,6 & 237 & 6,0 & 23 & 3,0 & 260 \\
\hline Pneu & 16 & 3,0 & 170 & 4,3 & 57 & 7,3 & 227 \\
\hline Vaso sanitário & 14 & 2,7 & 85 & 2,1 & 11 & 1,4 & 96 \\
\hline Balde & 13 & 2,5 & 109 & 2,7 & 27 & 3,5 & 136 \\
\hline Cx. Plástica & 12 & 2,3 & 146 & 3,7 & 15 & 1,9 & 161 \\
\hline $\begin{array}{l}\text { Garrafa/tigela/copo } \\
\text { vidro }\end{array}$ & 12 & 2,3 & 89 & 2,2 & 15 & 1,9 & 104 \\
\hline Tambor metal & 10 & 1,9 & 134 & 3,4 & 39 & 5,0 & 173 \\
\hline Oco de árvore & 9 & 1,7 & 65 & 1,6 & 44 & 5,7 & 109 \\
\hline Caule/casca/folha & 9 & 1,7 & 103 & 2,6 & 8 & 1,0 & 111 \\
\hline Planta aquática & 9 & 1,7 & 29 & 0,7 & 7 & 0,9 & 36 \\
\hline Ralo & 8 & 1,5 & 25 & 0,6 & 12 & 1,5 & 37 \\
\hline Outros & 8 & 1,5 & 73 & 1,8 & 6 & 0,8 & 79 \\
\hline Peças de louça & 7 & 1,3 & 74 & 1,9 & 11 & 1,4 & 85 \\
\hline Embalagens & 7 & 1,3 & 32 & 0,8 & 2 & 0,3 & 34 \\
\hline Bandeja/bacia/copos & 7 & 1,3 & 54 & 1,4 & 4 & 0,5 & 58 \\
\hline Peças de metal & 6 & 1,1 & 82 & 2,1 & 8 & 1,0 & 90 \\
\hline Calçamentos/lajes & 5 & 0,9 & 45 & 1,1 & 7 & 0,9 & 52 \\
\hline Panela/chaleira & 5 & 0,9 & 47 & 1,2 & 1 & 0,1 & 48 \\
\hline Barco/caiaque & 4 & 0,8 & 31 & 0,8 & 6 & 0,8 & 37 \\
\hline Bebedouro & 4 & 0,8 & 10 & 0,3 & 0 & 0,0 & 10 \\
\hline Peças de fibra & 3 & 0,6 & 13 & 0,3 & 33 & 4,3 & 46 \\
\hline Casa máquina cimento & 2 & 0,4 & 6 & 0,2 & 4 & 0,5 & 10 \\
\hline Cx. cimento & 2 & 0,4 & 14 & 0,4 & 5 & 0,6 & 19 \\
\hline Concha & 2 & 0,4 & 2 & 0,1 & 0 & 0,0 & 2 \\
\hline Cx. de descarga plástico & 2 & 0,4 & 8 & 0,2 & 6 & 0,8 & 14 \\
\hline Total & 527 & 100 & 3964 & 100 & 776 & 100 & 4735 \\
\hline
\end{tabular}


Tabela 32 - Distribuição do $\mathrm{N}^{\circ}$ e \% de recipientes, larvas e pupas de Aedes aegypti e Ae. albopictus em recipientes com ambas as espécies, no período de 10/2002 a 04/2003 e 10/2003 e 04/2004, em São Sebastião, SP, Brasil.

\begin{tabular}{|c|c|c|c|c|c|c|c|c|c|c|}
\hline \multirow[b]{3}{*}{ Recipiente } & \multirow{2}{*}{\multicolumn{2}{|c|}{$\begin{array}{c}\text { Total de } \\
\text { Recipientes }\end{array}$}} & \multicolumn{4}{|c|}{ Ae. aegypti } & \multicolumn{4}{|c|}{ Ae. albopictus } \\
\hline & & & \multicolumn{2}{|c|}{ Larva } & \multicolumn{2}{|c|}{ Pupa } & \multicolumn{2}{|c|}{ Larva } & \multicolumn{2}{|c|}{ Pupa } \\
\hline & $\mathrm{N}^{\circ}$ & $\%$ & $\mathrm{~N}^{\circ}$ & $\%$ & $\mathrm{~N}^{\circ}$ & $\%$ & $\mathrm{~N}^{\circ}$ & $\%$ & $\mathrm{~N}^{\circ}$ & $\%$ \\
\hline Bromélia & 27 & 15,0 & 165 & 7,5 & 16 & 4,0 & 137 & 11,3 & 19 & 6,1 \\
\hline Vaso/prato & 22 & 12,2 & 254 & 11,6 & 28 & 6,9 & 85 & 7,0 & 15 & 4,8 \\
\hline Lata & 19 & 10,6 & 360 & 16,4 & 69 & 17,0 & 143 & 11,8 & 16 & 5,2 \\
\hline Pote plástico & 12 & 6,7 & 248 & 11,3 & 13 & 3,2 & 117 & 9,7 & 22 & 7,1 \\
\hline Peças de plástico & 12 & 6,7 & 169 & 7,7 & 15 & 3,7 & 68 & 5,6 & 10 & 3,2 \\
\hline Lona & 11 & 6,1 & 77 & 3,5 & 6 & 1,5 & 107 & 8,8 & 25 & 8,1 \\
\hline Vaso sanitário louça & 11 & 6,1 & 87 & 4,0 & 17 & 4,2 & 65 & 5,4 & 5 & 1,6 \\
\hline Caixa d'água & 10 & 5,6 & 115 & 5,3 & 10 & 2,5 & 31 & 2,6 & 2 & 0,6 \\
\hline Balde plástico & 9 & 5,0 & 110 & 5,0 & 4 & 1,0 & 56 & 4,6 & 20 & 6,5 \\
\hline Pneu & 6 & 3,3 & 54 & 2,5 & 27 & 6,7 & 66 & 5,5 & 50 & 16,1 \\
\hline Tambor metal & 6 & 3,3 & 99 & 4,5 & 9 & 2,2 & 27 & 2,2 & 22 & 7,1 \\
\hline Caixa plástica & 5 & 2,8 & 41 & 1,9 & 1 & 0,2 & 54 & 4,5 & 3 & 1,0 \\
\hline Bambú & 4 & 2,2 & 73 & 3,3 & 4 & 1,0 & 40 & 3,3 & 7 & 2,3 \\
\hline Barco/caiac & 3 & 1,7 & 34 & 1,6 & 3 & 0,7 & 30 & 2,5 & 3 & 1,0 \\
\hline Calha plástica & 3 & 1,7 & 27 & 1,2 & 5 & 1,2 & 29 & 2,4 & 46 & 14,8 \\
\hline Ralo & 3 & 1,7 & 11 & 0,5 & 24 & 5,9 & 3 & 0,2 & 1 & 0,3 \\
\hline Planta aquática & 2 & 1,1 & 38 & 1,7 & 0 & 0,0 & 3 & 0,2 & 0 & 0,0 \\
\hline Bebedouro cimento & 1 & 0,6 & 25 & 1,1 & 0 & 0,0 & 1 & 0,1 & 0 & 0,0 \\
\hline Bloco cimento & 1 & 0,6 & 6 & 0,3 & 0 & 0,0 & 16 & 1,3 & 0 & 0,0 \\
\hline Canaleta de cimento & 1 & 0,6 & 4 & 0,2 & 2 & 0,5 & 1 & 0,1 & 0 & 0,0 \\
\hline Carrinho gás metal & 1 & 0,6 & 6 & 0,3 & 14 & 3,5 & 0 & 0,0 & 1 & 0,3 \\
\hline Cascata cimento & 1 & 0,6 & 21 & 1,0 & 1 & 0,2 & 16 & 1,3 & 0 & 0,0 \\
\hline Chaleira metal & 1 & 0,6 & 15 & 0,7 & 1 & 0,2 & 2 & 0,2 & 0 & 0,0 \\
\hline Copo vidro & 1 & 0,6 & 19 & 0,9 & 2 & 0,5 & 12 & 1,0 & 7 & 2,3 \\
\hline Caixa de descarga & 1 & 0,6 & 2 & 0,1 & 0 & 0,0 & 5 & 0,4 & 6 & 1,9 \\
\hline Caixa fibra & 1 & 0,6 & 53 & 2,4 & 0 & 0,0 & 3 & 0,2 & 0 & 0,0 \\
\hline Caixa de leite & 1 & 0,6 & 3 & 0,1 & 1 & 0,2 & 22 & 1,8 & 1 & 0,3 \\
\hline Ôco de árvore & 1 & 0,6 & 1 & 0,0 & 0 & 0,0 & 4 & 0,3 & 0 & 0,0 \\
\hline Panela & 1 & 0,6 & 12 & 0,5 & 0 & 0,0 & 10 & 0,8 & 0 & 0,0 \\
\hline Peça fibra & 1 & 0,6 & 52 & 2,4 & 133 & 32,8 & 8 & 0,7 & 29 & 9,4 \\
\hline Pia louça & 1 & 0,6 & 1 & 0,0 & 0 & 0,0 & 12 & 1,0 & 0 & 0,0 \\
\hline Vaso cerâmica & 1 & 0,6 & 7 & 0,3 & 0 & 0,0 & 37 & 3,1 & 0 & 0,0 \\
\hline Total & 180 & 100 & 2189 & 100 & 405 & 100 & 1210 & 100 & 310 & 100 \\
\hline
\end{tabular}


Tabela 33 - Relação entre os sexos de pupas Ae. aegypti e Ae. albopictus oriundas de criadouros onde as espécies estavam separadas ou em situação de coexistência, coletadas no período de 10/2002 a 04/2003 e 10/2003 e 04/2004, em São Sebastião, SP, Brasil.

\begin{tabular}{llll}
\hline & Separados & & Em coexistência \\
$\begin{array}{l}\text { Ae. aegypti } \\
(\mathrm{n}=2326)\end{array}$ & $\begin{array}{l}\text { Ae. albopictus } \\
(\mathrm{n}=776)\end{array}$ & $\begin{array}{l}\text { Ae. aegypti } \\
(\mathrm{n}=405)\end{array}$ & $\begin{array}{l}\text { Ae. albopictus } \\
(\mathrm{n}=310)\end{array}$ \\
\hline $\mathrm{U}=98$ & $\mathrm{U}=125$ & $\mathrm{U}=120$ & $\mathrm{U}=122$ \\
$\mathrm{p}=0,99$ & $\mathrm{p}=0,22$ & $\mathrm{p}=0,32$ & $\mathrm{p}=0,28$ \\
\hline
\end{tabular}

Teste de Mann-Whitney $(\alpha<0,05)$ 
Produção média de imaturos de Ae. aegypti e Ae. albopictus por categoria de recipiente no período de 10/2002 a 04/2003 e 10/2003 e 04/2004, em São Sebastião, SP, Brasil.

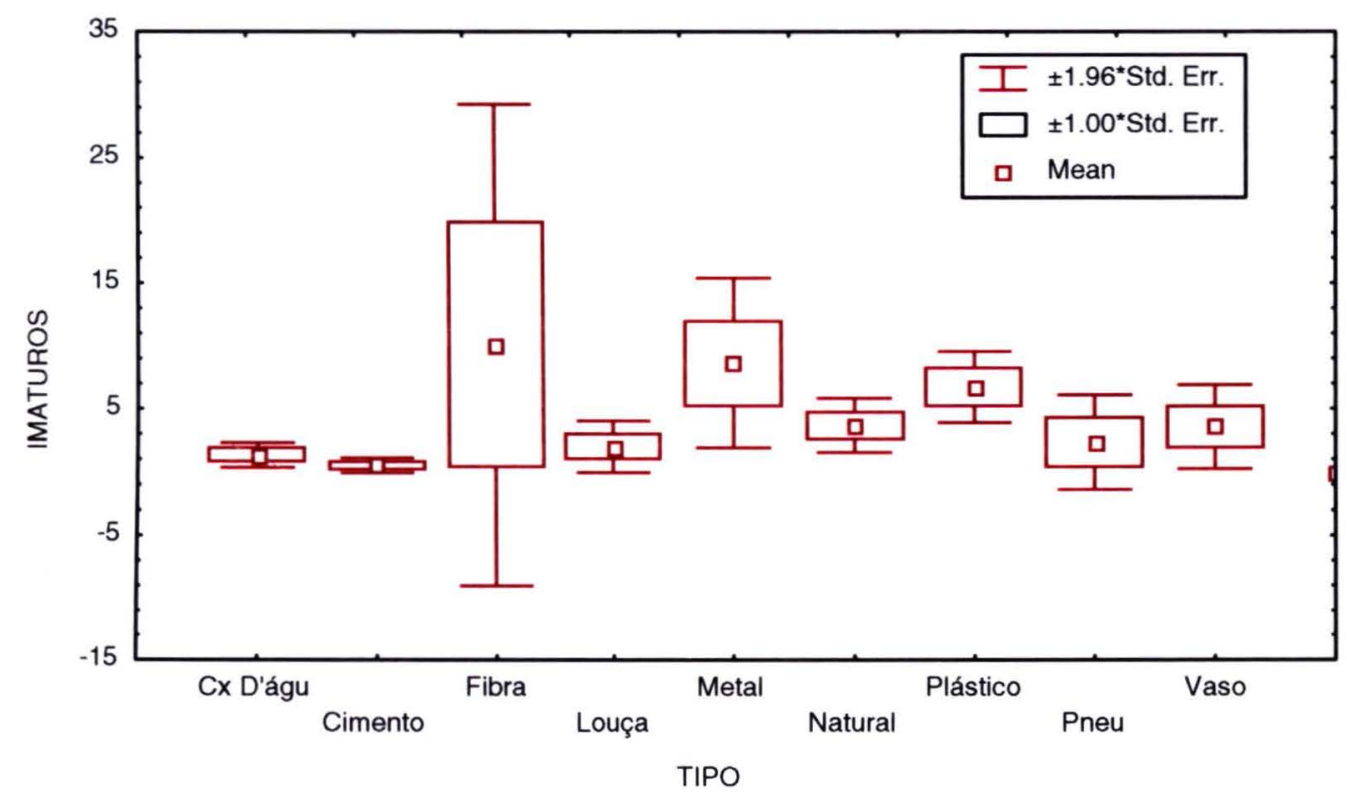

Figura 17- Produção média de imaturos de Ae. aegypti segundo categoria de recipiente.

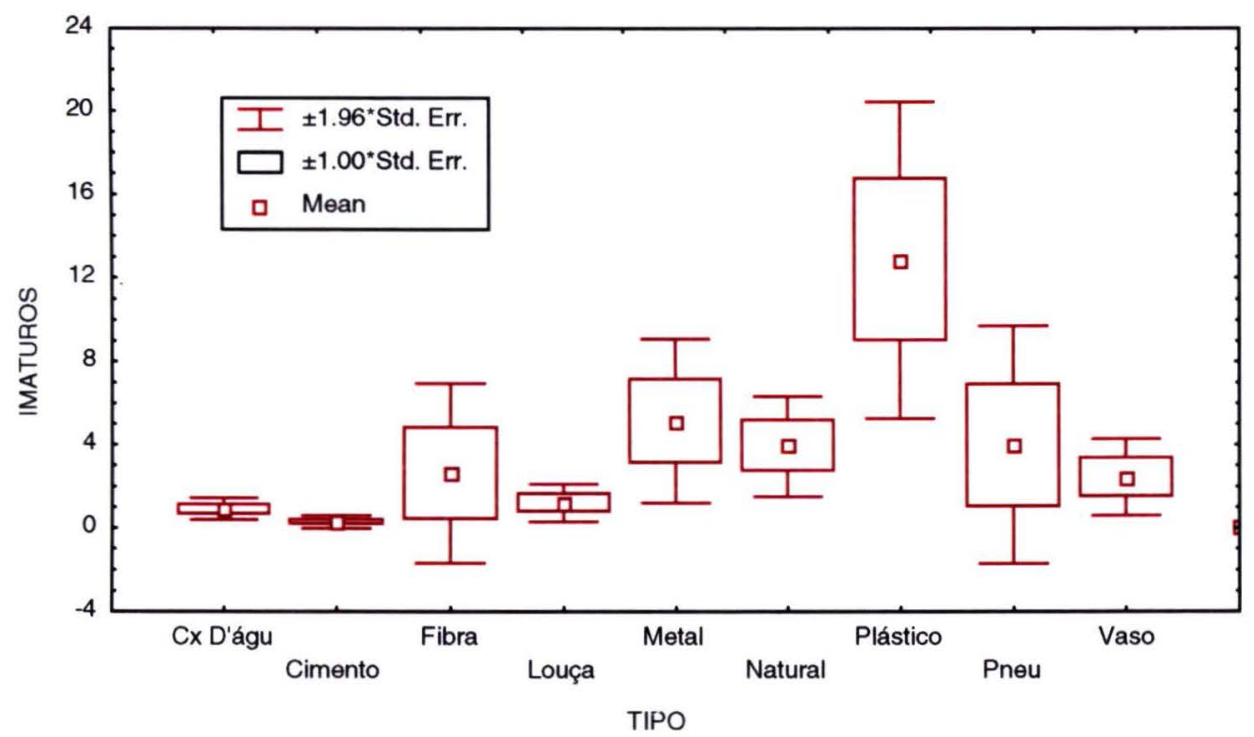

Figura 18 - Produção média de imaturos de Ae. albopictus segundo categoria de recipiente. 
Tabela 34 - Distribuição mensal dos valores de Índice de Recipiente, Predial e de Breteau, de Ae. aegypti, Ae. albopictus e as duas espécies em coexistência, no período de 10/2002 a 04/2003 e 10/2003 e 04/2004, em São Sebastião, SP, Brasil.

\begin{tabular}{lccccccccc}
\hline & \multicolumn{3}{c}{ Ae. aegypti } & \multicolumn{4}{c}{ Ae. albopictus } & \multicolumn{3}{c}{ Em coexistência } \\
\hline Mês & IR & IP & IB & IR & IP & IB & IR & IP & IB \\
\hline Outubro & 1,2 & 4,2 & 5 & 0,5 & 1,5 & 2,4 & 0,3 & 0,6 & 1,5 \\
Novembro & 3,5 & 8,6 & 13 & 3,8 & 6,6 & 14,0 & 0,9 & 3,7 & 3,3 \\
Dezembro & 4,4 & 7,5 & 14 & 4,5 & 7,2 & 14,2 & 1,9 & 3,1 & 5,8 \\
Janeiro & 7,9 & 7,6 & 13 & 15,6 & 12,7 & 25,0 & 3,8 & 4,3 & 6,2 \\
Fevereiro & 7,0 & 13,6 & 24 & 4,7 & 6,1 & 16,3 & 1,6 & 2,7 & 5,4 \\
Março & 3,2 & 7,9 & 14 & 3,0 & 10,2 & 13,3 & 0,6 & 4,1 & 2,9 \\
Abril & 7,2 & 10,1 & 19 & 5,8 & 10,9 & 15,3 & 2,0 & 5,2 & 5,2 \\
Outubro & 3,4 & 6,1 & 9 & 1,6 & 2,1 & 4,0 & 0,4 & 0,6 & 0,9 \\
Novembro & 4,3 & 7,4 & 12 & 2,2 & 3,6 & 6,3 & 1,1 & 2,3 & 3,2 \\
Dezembro & 4,4 & 9,0 & 15 & 3,1 & 5,1 & 10,5 & 0,9 & 2,7 & 2,9 \\
Janeiro & 6,2 & 10,9 & 16 & 3,5 & 3,9 & 8,8 & 1,3 & 2,1 & 3,2 \\
Fevereiro & 4,3 & 9,9 & 14 & 2,0 & 4,3 & 6,5 & 0,8 & 2,2 & 2,5 \\
Março & 9,5 & 11,8 & 25 & 2,9 & 5,0 & 7,7 & 1,3 & 3,0 & 3,4 \\
Abril & 7,3 & 13,6 & 20 & 2,3 & 3,6 & 6,2 & 1,2 & 2,9 & 3,3 \\
\hline
\end{tabular}


Tabela 35 - Distribuição mensal dos valore de Indicadores de Densidade de larvas e pupas por recipientes e imóveis, de Ae. aegypti, Ae. albopictus e das duas espécies em coexistência, no período de 10/2002 a 04/2003 e 10/2003 e 04/2004, em São Sebastião, SP, Brasil.

\begin{tabular}{|c|c|c|c|c|c|c|c|c|c|c|c|c|}
\hline \multirow[b]{3}{*}{ Mês } & \multicolumn{4}{|c|}{ Ae. aegypti } & \multicolumn{4}{|c|}{ Ae. albopictus } & \multicolumn{4}{|c|}{ Em coexistência } \\
\hline & \multicolumn{2}{|c|}{ Dens. em Rec } & \multicolumn{2}{|c|}{ Dens.em Imóv } & \multicolumn{2}{|c|}{ Dens. em Rec } & \multicolumn{2}{|c|}{ Dens.em Imóv } & \multicolumn{2}{|c|}{ Dens. em Rec } & \multicolumn{2}{|c|}{ Dens.em Imóv } \\
\hline & Lv & $\mathrm{Pp}$ & Lv & $\mathrm{Pp}$ & Lv & $\mathrm{Pp}$ & Lv & $\mathrm{Pp}$ & Lv & $\mathrm{Pp}$ & Lv & $\mathrm{Pp}$ \\
\hline Outubro & 16,7 & 2,5 & 72,4 & 11,0 & 2,7 & 0,5 & 11,6 & 2,4 & 7,6 & 1,2 & 32,9 & 5,3 \\
\hline Novembro & 35,1 & 5,1 & 129,6 & 18,9 & 30,0 & 9,6 & 110,6 & 35,5 & 10,7 & 2,9 & 39,5 & 10,6 \\
\hline Dezembro & 49,9 & 8,7 & 155,8 & 27,2 & 33,5 & 2,0 & 104,4 & 6,4 & 25,8 & 3,6 & 80,6 & 11,1 \\
\hline Janeiro & 146,4 & 4,8 & 234,4 & 7,6 & 129,9 & 24,7 & 208,0 & 39,5 & 119,5 & 6,3 & 191,3 & 10,1 \\
\hline Fevereiro & 79,1 & 8,1 & 274,6 & 28,1 & 43,2 & 9,6 & 149,8 & 33,2 & 33,3 & 4,3 & 115,6 & 14,9 \\
\hline Março & 48,9 & 7,1 & 215,9 & 31,4 & 20,3 & 1,7 & 89,8 & 7,6 & 11,6 & 1,3 & 51,1 & 5,7 \\
\hline Abril & 103,2 & 27,3 & 274,0 & 72,4 & 52,4 & 12,9 & 139,1 & 34,2 & 42,7 & 27,6 & 113,4 & 73,2 \\
\hline Outubro & 34,7 & 16,5 & 85,7 & 40,7 & 16,5 & 4,2 & 40,7 & 10,3 & 11,2 & 0,2 & 27,7 & 0,6 \\
\hline Novembro & 57,3 & 11,1 & 163,0 & 31,6 & 18,3 & 6,4 & 51,9 & 18,1 & 26,1 & 5,9 & 74,0 & 16,7 \\
\hline Dezembro & 46,8 & 4,6 & 159,6 & 15,6 & 17,9 & 1,1 & 61,1 & 3,6 & 13,2 & 0,9 & 45,0 & 2,9 \\
\hline Janeiro & 63,2 & 23,0 & 160,9 & 58,6 & 19,0 & 3,5 & 48,4 & 9,0 & 14,7 & 1,1 & 37,5 & 2,8 \\
\hline Fevereiro & 46,9 & 14,5 & 150,9 & 46,6 & 10,9 & 1,3 & 35,0 & 4,3 & 10,0 & 2,4 & 32,3 & 7,8 \\
\hline Março & 105,8 & 48,5 & 284,1 & 130,2 & 24,2 & 5,5 & 65,0 & 14,8 & 24,0 & 7,4 & 64,3 & 19,8 \\
\hline Abril & 88,5 & 25,3 & 243,8 & 69,6 & 12,9 & 1,6 & 35,6 & 4,3 & 20,9 & 3,9 & 57,7 & 10,8 \\
\hline
\end{tabular}


Tabela 36 - Distribuição do \% de recipientes, Média de larvas e pupas por categoria segundo o tamanho do recipiente positivo para Ae. aegypti, no período de 10/2002 a 04/2003 e 10/2003 e 04/2004, em São Sebastião, SP, Brasil.

\begin{tabular}{|c|c|c|c|c|c|c|c|c|c|c|}
\hline \multirow[b]{2}{*}{ Categoria } & \multicolumn{4}{|c|}{$\begin{array}{c}\% \text { de } \\
\text { recipientes }\end{array}$} & \multicolumn{3}{|c|}{$\begin{array}{c}\text { Média } \\
\text { Larva/recipiente }\end{array}$} & \multicolumn{3}{|c|}{$\begin{array}{c}\text { Média } \\
\text { Pupa/recipiente }\end{array}$} \\
\hline & & $P$ & $M$ & $\mathrm{G}$ & $P$ & $M$ & $\mathrm{G}$ & $P$ & $M$ & G \\
\hline Cx. D'água & & 0 & 0 & 100 & 0,0 & 0,0 & 10,1 & 0,0 & 0,0 & 1,2 \\
\hline Louça & & 33 & 67 & 0 & 11,0 & 5,4 & 0,0 & 0,0 & 1,3 & 0,0 \\
\hline Cimento & & 22 & 33 & 44 & 1,0 & 5,9 & 19,0 & 0,0 & 3,3 & 10,5 \\
\hline Fibra & & 41 & 39 & 20 & 10,2 & 16,9 & 26,5 & 1,5 & 6,4 & 6,1 \\
\hline Metal & & 50 & 44 & 6 & 14,6 & 20,0 & 8,3 & 0,4 & 16,1 & 0,0 \\
\hline Natural & & 97 & 3 & 0 & 6,2 & 2,0 & 0,0 & 0,9 & 0,0 & 0,0 \\
\hline Planta & & 67 & 33 & 0 & 8,0 & 18,3 & 0,0 & 0,6 & 2,3 & 0,0 \\
\hline Plástico & & 57 & 27 & 16 & 12,1 & 13,2 & 14,3 & 2,0 & 4,9 & 1,0 \\
\hline Pneu & & 82 & 9 & 9 & 10,3 & 21,8 & 4,8 & 2,2 & 0,0 & 0,0 \\
\hline Ralo & & 60 & 40 & 0 & 10,4 & 11,3 & 0,0 & 2,1 & 4,1 & 0,0 \\
\hline Vaso/prato & & 83 & 17 & 0 & 13,5 & 8,1 & 0,0 & 2,0 & 0,0 & 0,0 \\
\hline Vidro & & 50 & 0 & 50 & 18,7 & 0,0 & 0,0 & 2,5 & 0,0 & 0,0 \\
\hline Total & & 462 & 211 & 125 & 4947 & 2810 & 1606 & 652 & 1312 & 304 \\
\hline$\%$ & & 58 & 26 & 16 & 53 & 30 & 17 & 29 & 58 & 13 \\
\hline \multirow[t]{5}{*}{$\begin{array}{l}\text { Kruskall } \\
\text { Wallis } \\
\end{array}$} & \multicolumn{4}{|c|}{ Recipientes } & \multicolumn{3}{|c|}{ Larvas } & \multicolumn{3}{|c|}{ Pupas } \\
\hline & \multirow{2}{*}{\multicolumn{4}{|c|}{$\begin{array}{l}H=9,06 \\
p=0,010\end{array}$}} & \multicolumn{3}{|c|}{$H=2,38$} & \multicolumn{3}{|c|}{$H=2,46$} \\
\hline & & & & & \multicolumn{3}{|c|}{$p=0,30$} & \multicolumn{3}{|c|}{$p=0,29$} \\
\hline & $\mathrm{P}>\mathrm{M}$ & \multicolumn{3}{|c|}{$p=0,037$} & & & & & & \\
\hline & $P>G$ & \multicolumn{3}{|c|}{$p=0,025$} & & & & & & \\
\hline
\end{tabular}


Tabela 37 - Distribuição do \% de recipientes, Média de larvas e pupas por categoria segundo o tamanho do recipiente positivo para Ae. albopictus, no período de 10/2002 a 04/2003 e 10/2003 e 04/2004, em São Sebastião, SP, Brasil.

\begin{tabular}{|c|c|c|c|c|c|c|c|c|c|}
\hline \multirow[b]{2}{*}{ Categoria } & \multicolumn{3}{|c|}{$\begin{array}{c}\% \text { de } \\
\text { recipientes }\end{array}$} & \multicolumn{3}{|c|}{$\begin{array}{c}\text { Média } \\
\text { Larva/recipiente }\end{array}$} & \multicolumn{3}{|c|}{$\begin{array}{c}\text { Média de } \\
\text { Pupa/recipiente }\end{array}$} \\
\hline & $\mathrm{P}$ & M & G & $P$ & $M$ & G & $P$ & $M$ & G \\
\hline Cx. D'água & 0 & 0 & 100 & 0,0 & 0,0 & 9,2 & 0,0 & 0,0 & 0,5 \\
\hline Louça & 33 & 67 & 0 & 4,6 & 9,1 & 0,0 & 3,2 & 0,0 & 0,0 \\
\hline Cimento & 0 & 100 & 0 & 0,0 & 7,2 & 0,0 & 0,0 & 1,8 & 0,0 \\
\hline Fibra & 0 & 60 & 40 & 0,0 & 1,8 & 13,0 & 0,0 & 4,3 & 7,6 \\
\hline Metal & 0 & 71 & 29 & 0,0 & 13,0 & 5,2 & 0,0 & 1,4 & 1,1 \\
\hline Natural & 86 & 14 & 0 & 4,5 & 9,7 & 0,0 & 1,0 & 0,8 & 0,0 \\
\hline Plástico & 56 & 38 & 6 & 11,8 & 8,0 & 3,0 & 1,0 & 2,9 & 5,2 \\
\hline Pneu & 75 & 25 & 0 & 11,9 & 6,8 & 0,0 & 4,1 & 1,9 & 0,0 \\
\hline Ralo & 0 & 50 & 50 & 0,0 & 4,7 & 1,6 & 0,0 & 0,0 & 3,0 \\
\hline Vaso/prato & 44 & 56 & 0 & 6,6 & 7,5 & 0,0 & 0,0 & 2,8 & 0,0 \\
\hline Outros & 50 & 50 & 0 & 10,2 & 2,9 & 0,0 & 1,1 & 0,0 & 0,0 \\
\hline Total & 272 & 200 & 55 & 1875 & 1731 & 365 & 301 & 355 & 108 \\
\hline$\%$ & 52 & 38 & 11 & 47 & 44 & 9 & 39 & 46 & 14 \\
\hline Kruskall Wallis & $\begin{array}{l}\text { Recipientes } \\
H=4,8 \\
p=0,08\end{array}$ & & & & & & & & \\
\hline
\end{tabular}


Tabela 38 - Coeficiente de Incidência de casos autóctones na região do litoral norte do Estado de São Paulo por município - Período de 2001 a 2004.

\begin{tabular}{lrrrrr}
\hline Município & & $\mathbf{2 0 0 1}$ & $\mathbf{2 0 0 2}$ & $\mathbf{2 0 0 3}$ & $\mathbf{2 0 0 4 *}$ \\
\hline & São Sebastião & 864,08 & 2135,78 & 10,69 & 48,65 \\
& Ilhabela & 20,02 & 31,28 & 47,64 & 281,58 \\
& Caraguatatuba & 0,00 & 459,85 & 43,70 & 469,36 \\
\hline *2004 até agosto & & & & &
\end{tabular}

Fonte: Núcleo de Caraguatatuba - CVE - Secretaria de Estado da Saúde de São Paulo 


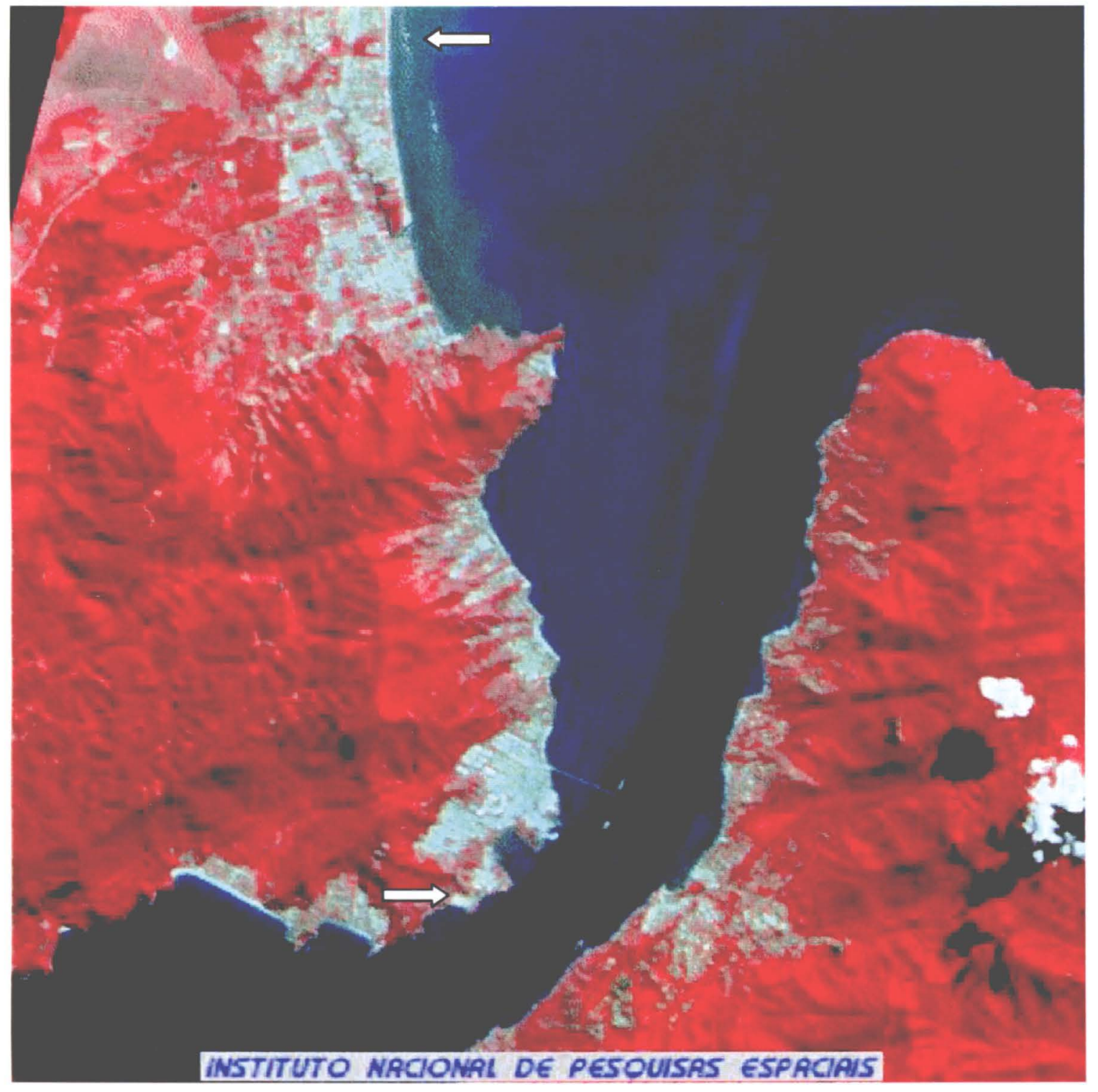

Figura 19 - Imagem obtida do satélite LANDSAT 7. A área trabalhada está delimitada entre as setas. Município de São Sebastião, São Paulo, Brasil.

Fonte: Imagem de satélite INPE São José dos Campos. 

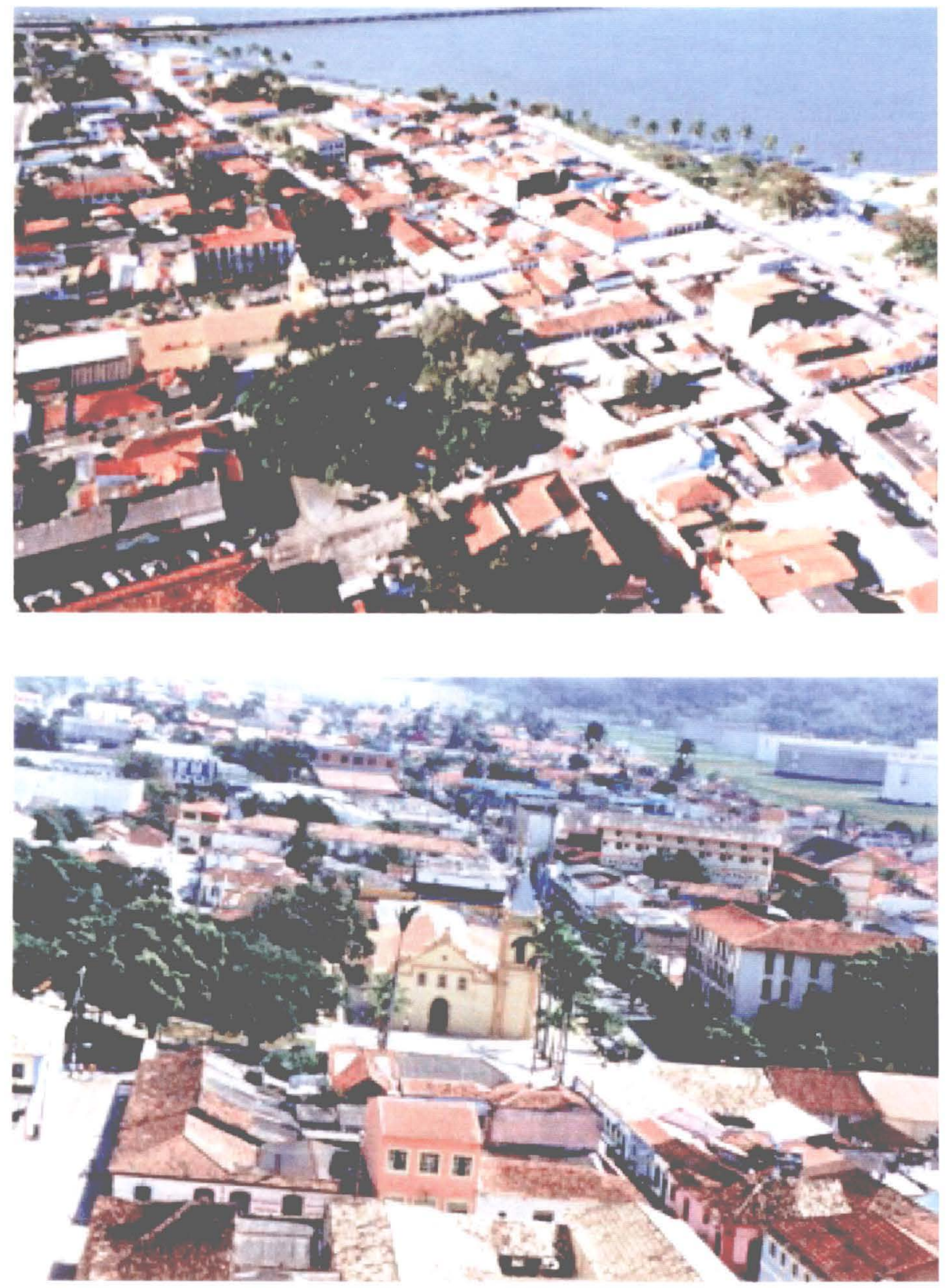

Figuras 20 e 21 - Aspectos da área central do município de São Sebastião, São Paulo, Brasil.

fonte: www.prefeiturasaosebastiao.sp.gov.br 


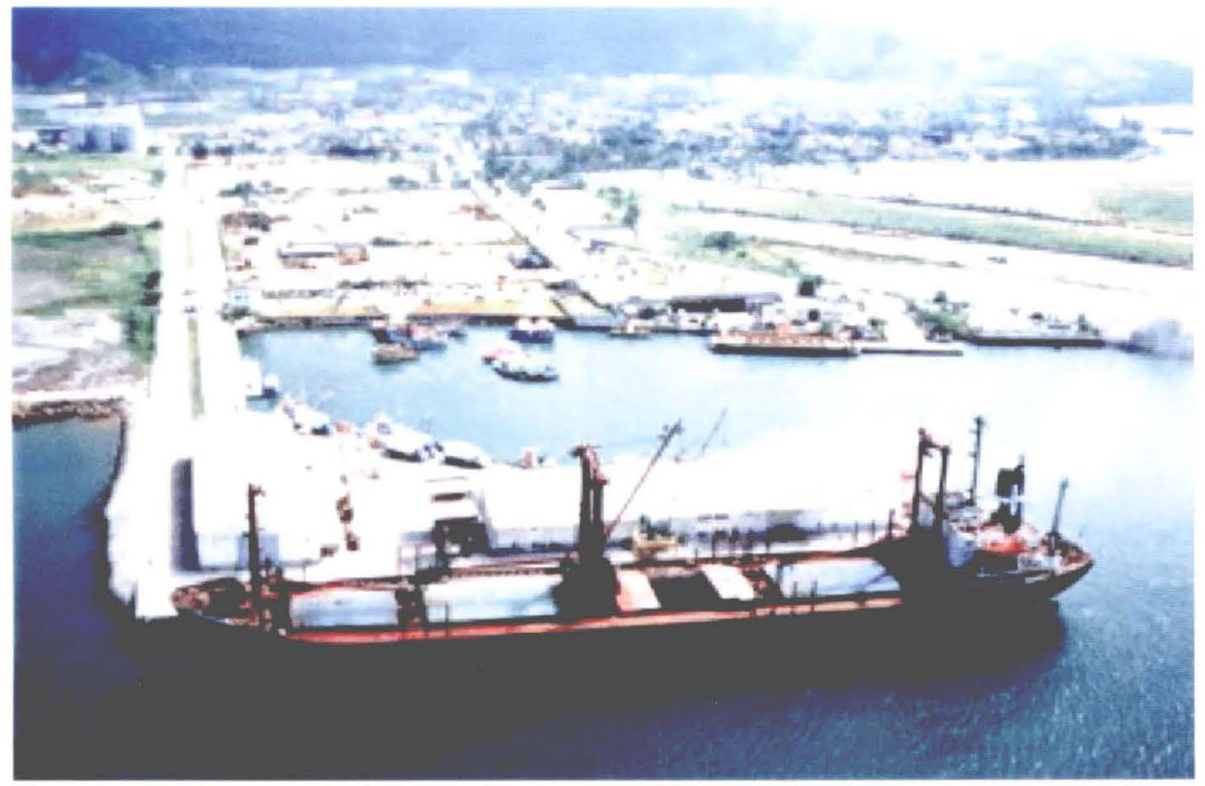

Figura 22 - Foto aérea do porto e área urbana do município de São Sebastião, São Paulo, Brasil.

fonte: www.prefeiturasaosebastiao.sp.gov.br

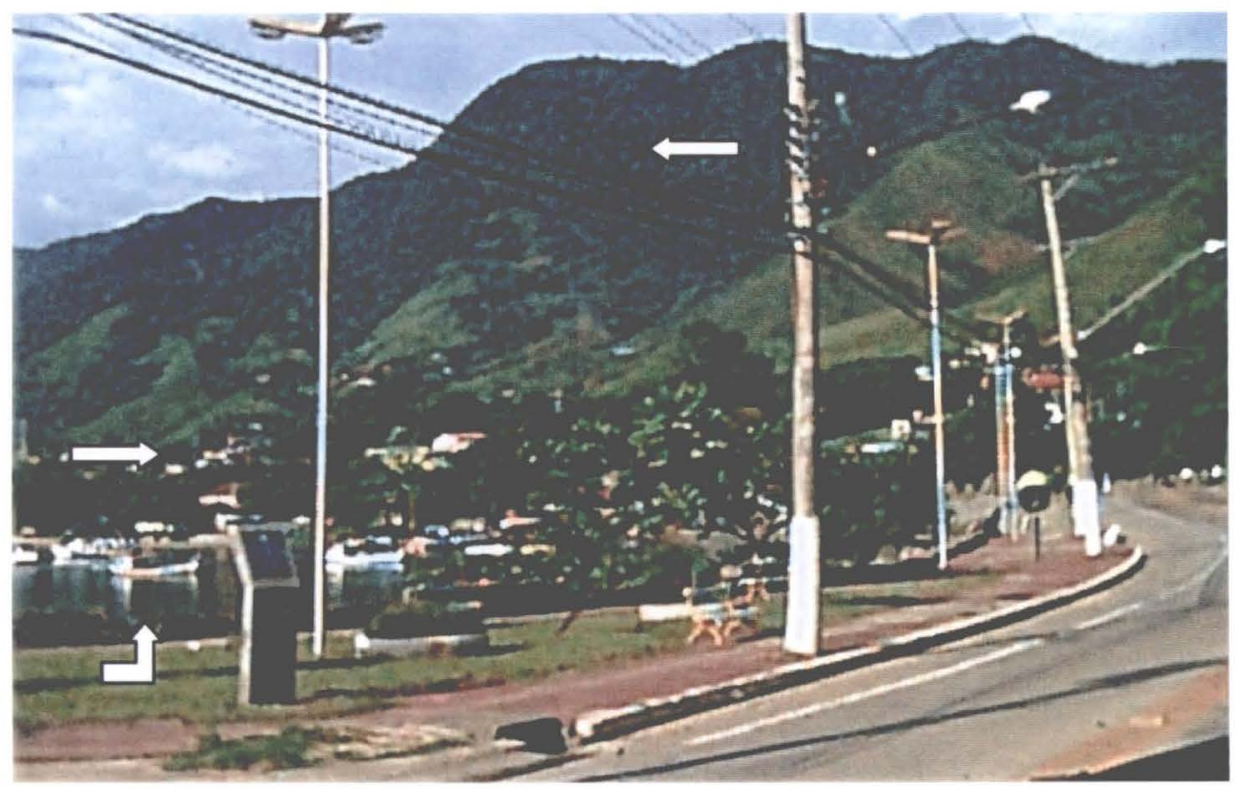

Figura 23 - As setas indicam o mar, a área urbana e a mata próxima. Município de São Sebastião, São Paulo, Brasil. 


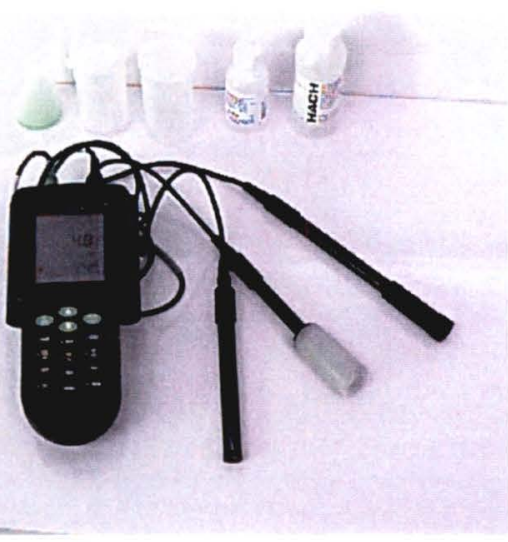

Figura 24 - Aparelho multiparâmetro

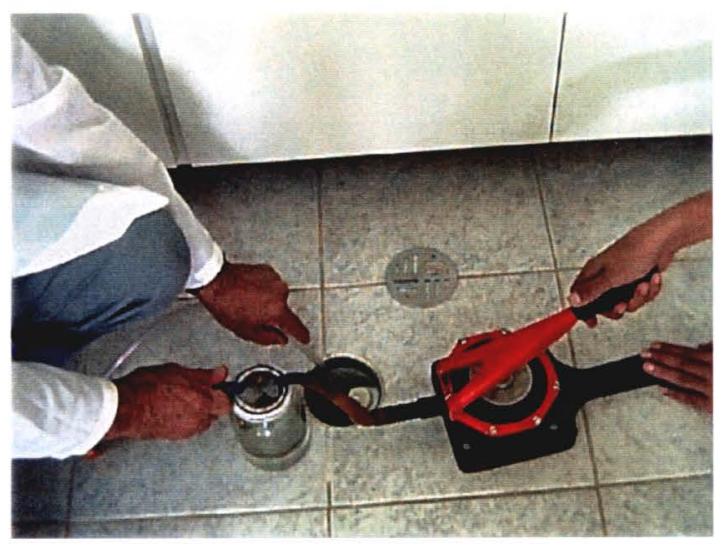

Figura 25 - Bomba de sucção

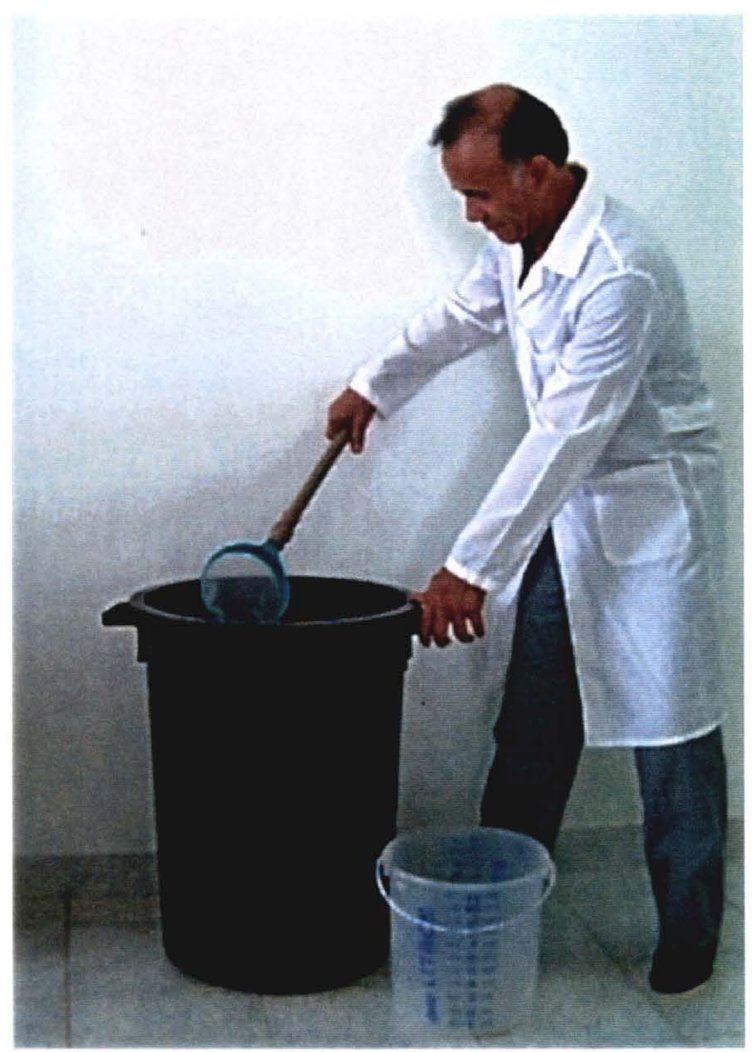

Figura 26 - Simulação da Técnica de varredura para inspeção d grandes recipientes - São executados movimento circulares da superfície até o fundo. Posteriormente a peneira é passada, no centro do redemoinho que se forma, do fundo até a superfície. São realizadas 10 varreduras para cada recipiente. 